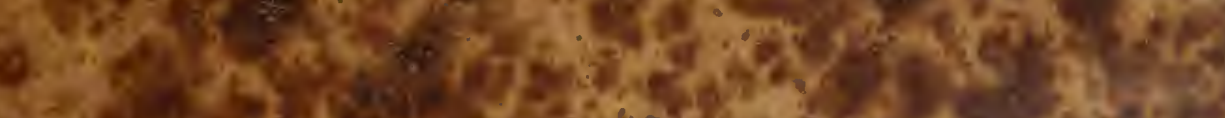

$$
\begin{aligned}
& \text { - } 4003 \\
& \text { on: } 0.2 \times
\end{aligned}
$$

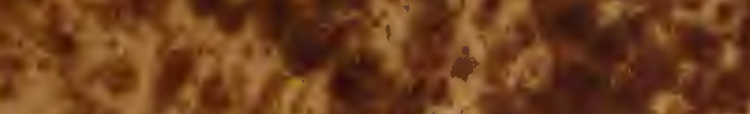

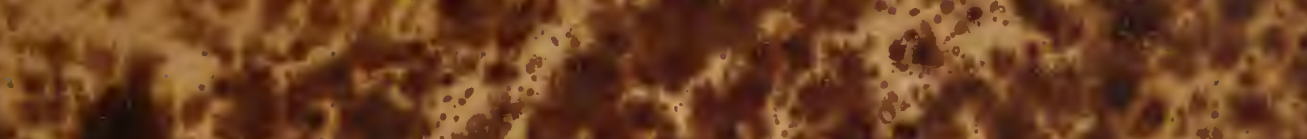
H. ar.

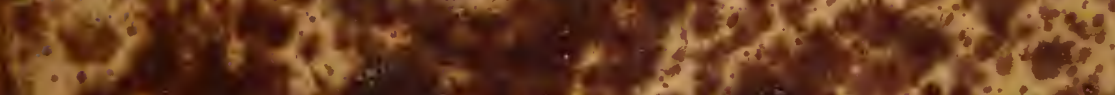

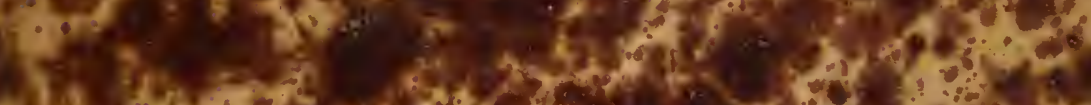

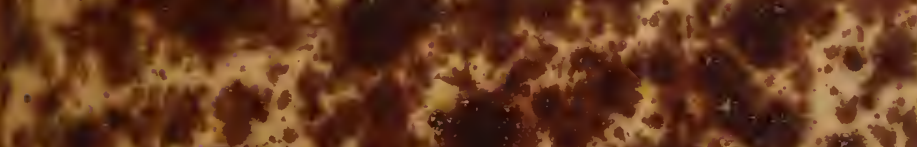

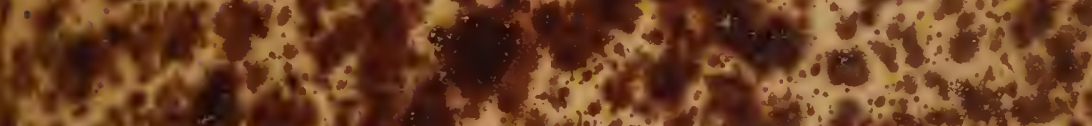

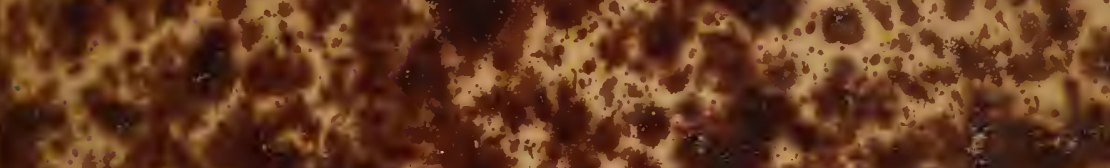

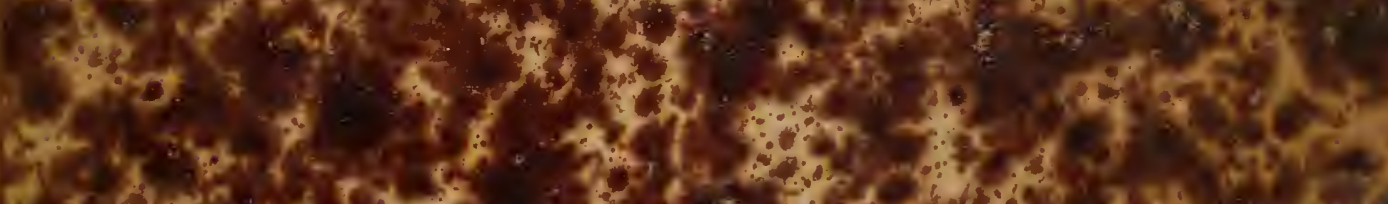

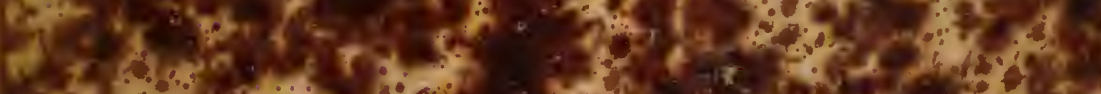

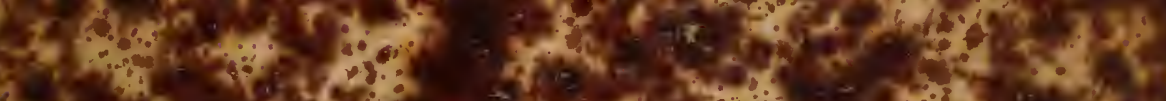

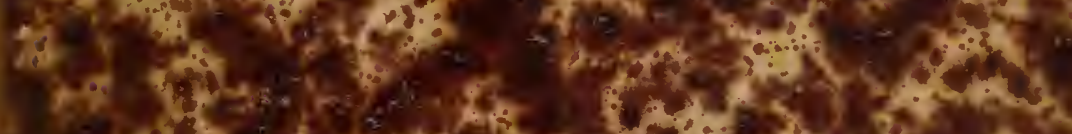

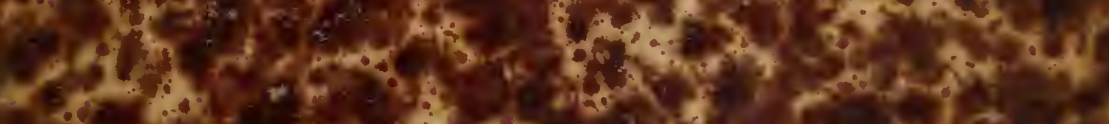

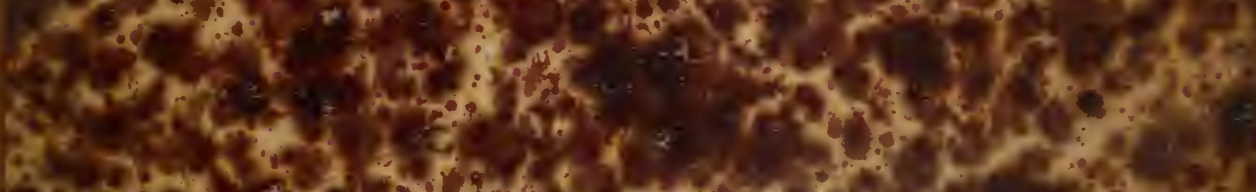

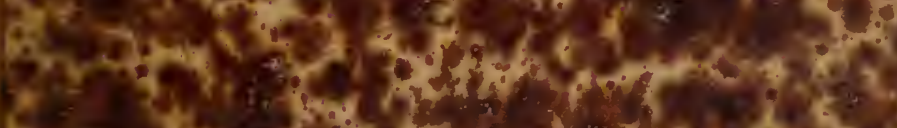

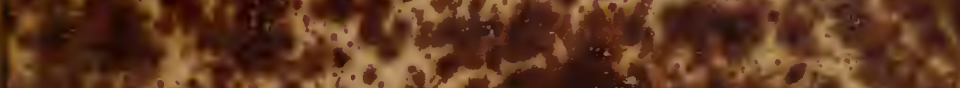

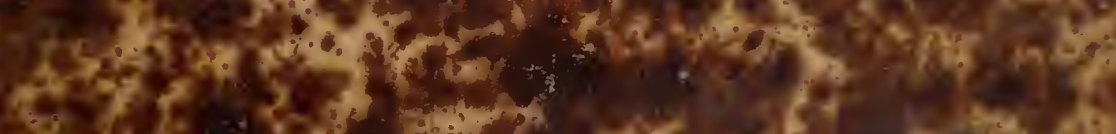
13.

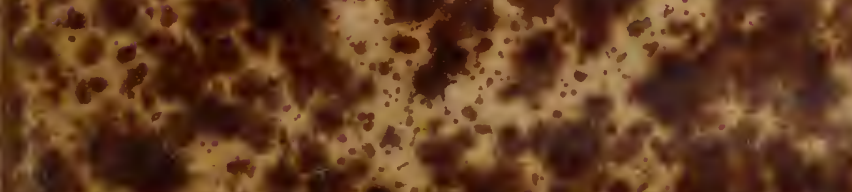

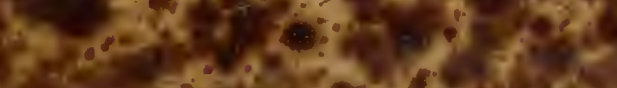

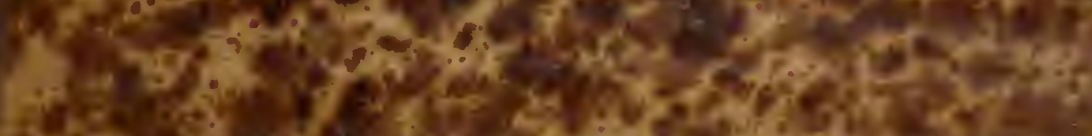

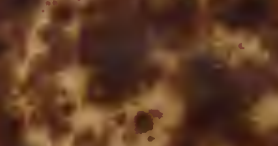
$c_{i=1}=\frac{2}{2}$ 
Bibliothèque botanique

E M ILE BURNAT

Calalogue N"//23.

Trovienl de

roiz $n 0732$.

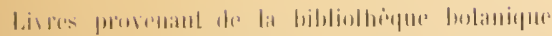

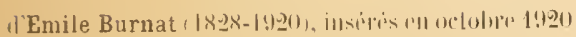

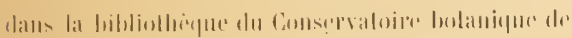

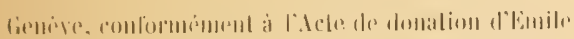

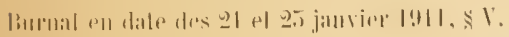

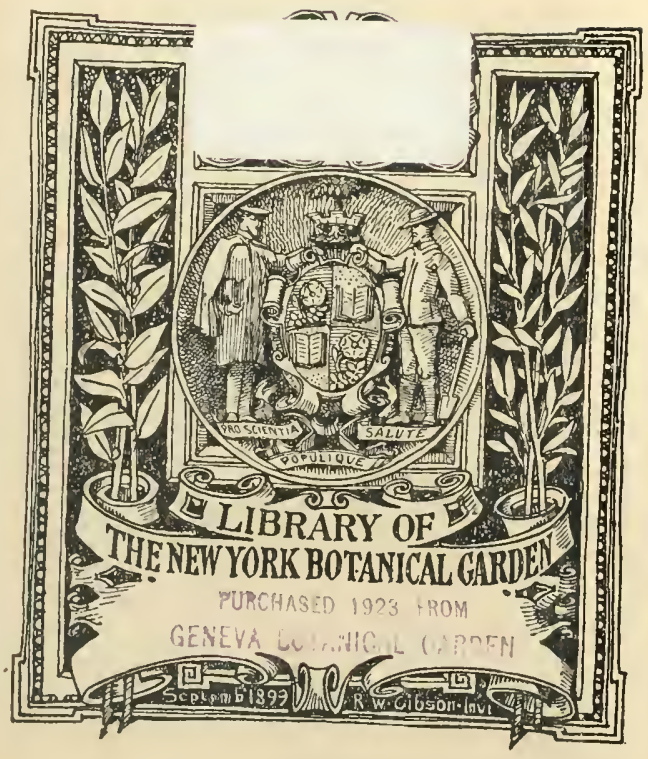


DUPLICATA DE LA BIBLIOTHEQQUE

DU CONSFRVATOIRE BOTANIQUE DE GENEVE VENDU EN 1922 



\section{PLANTAE RARIORES}

QUAS IN ITINERE PER ORAS

JONII AC ADRIATICI MARIS

E T

\section{PER REGIONES SAMNII AC APRUTII}

COLLEGIT

\section{JOANNES GUSSONE}

II E D. D O C T.

ET PRAEFECTVS H. R, BOTANICI IN BOCCADIFALCO.

$$
\begin{aligned}
& \text { LPOARW } \\
& \text { 구 त Y Y } \\
& \text { FITARRCAK } \\
& \text { पARUEN } \\
& \text { I C O NES. }
\end{aligned}
$$

\section{N E A P O L I,}

EX REGIA TYPOGRA P II IA.

$$
\begin{gathered}
\text { MDCcexivi. } \\
18 ? !
\end{gathered}
$$




$$
\begin{gathered}
+Q K 332 \\
\text {. G85 } \\
\text { v.2 }
\end{gathered}
$$




\section{EXPLICATIO TABULARUM.}

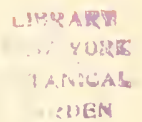

TAB. I, et II.

ubi umbilicatus. 4 Idem ex dorso visus, ubi bicostatus.

1 - 1 ructus integer, et auclus cum pistillis. 2 Idem horizontaliter sectus.

TAB. 111.

I Calyx cum peduneulo auctus. 2. Corolla aucta cum genitalibus. 5 Capsula oblonga, emarginata, aucta.

\section{TAB IV. $f$. .}

1 1 Ramulus cum floribus fructibus$Ð$ que auctus. 2. Corolla cum fructu, et bractea aucta. 5 Fructus auctus, ex facic interiorc visus,
TAB. IV. f. 2.

1 I Ramus horizontaliter sectus, et una cum foliis ac floribus auctus. 2 Flos cum bracteis, it folio subjecto auctus. 3 Calyx cum bracteis auctus.

TAB. V. $f .$, , et 2.

1 Basis folii cum liguli. 2 Spicula aucta. 5 Gluma corollina exterior apice bifido-aristata, cum arista dorsali geniculata. Fig. 2. 1 Basis folii cum ligula. 2 Spicula aucta. 3 Glumac corollinae cum staminibus et pistillis auctae. 
TAP. VI.

1 Spicula ancta. 2 Glumae corollinae floseulorum inferiorum cujusque spiculae auctae. 3 Eacdem flosculorum superiorum anctac.

TAB. VII.

1 Spicula ancta. 2 Calycis glumae auctac. 3 Glumae corollinac cum staminilus, et pistillis auctae.

TAB. VIII. $f .1$, et 2.

1 Spicula magnitudine naturali. 2 Calycis glumac auctac. 3 Glumac corollinae cum staminibus, et pistillis auctae. In fig. 2. numeri easdem partes indicant, sed spicula duplo aucta est.

\section{TAB. IX.}

1 Spicula aucta. 2 Glumae corollinae auctac, cum arista dorsali contorta, et pilorum fasciculo ad basim. 5 Germen auctum, cum staminibus pistillis, et duabus squanis ( Nectaria Lill. ).

TAB. A. f. I, et 2.

I Folinm anctum, cum ligula ad cjusdem basim. 2 Spicula ancta. 5 Gluma calycina cxterior aucta. 4. Glunac corollinae auctar. In fig. 2. ․ 1. spiculam auctan indicat.

\section{TAB. XI.}

1 Folium auctum, cum ligula. 2 1 lores tcrni, cum involucris aucti. 5 Glumae corollinae floris hermaphroditi cum staminibus et pistillis auctac.

\section{TAB. XII.}

I Pedunculus cum receptaculi pateis, et foliolis calycinis reflexis. 2 Scmen auctum, striatum, basi setosum, cum calyculo denticulato ac pappo 5-scto. 3 Calyculus, ac pappus aucti ex facie inspecti. 4 Semen auctum, calyculo orbatum, et solo pappo coronatum.

TAB. XIII. $f . t, t t 2$.

1 Corolla cum staminibus ancta. 2 Fructus aucti.

TAB. XIII. f. 3.

I Bractea aucta, ad carinam albida, margine fusco-scariosa. 2 
Calycis foliola quatuor basi $p^{\mathrm{i}-}$ losa, cum stylo villoso aucta. 5 Corolla aucta cum staminilusus. 4 Capsula aucta, disperma, circumscissa.

TAB. XIV.

I Calyeis foliolum anctum, apice denticulatum. 2 Petalum exterius majus, anctum, trilobum. 5 Petalum interius auctum, tripartitum; lacinia media apice denticulata, in icone aperta, sed in statu naturali conduplicata. 4 Stamina, et pistillun aucta.

TAB. XV.

1 Calycis foliolum auctum, intcgrum. 2 Petalum exterius auctum, obsolete trilobum, quod in icone vix conspicitar ob margines revoiutos. 5 Petalum intcrius auctum, tripartitunı, lacinia media fere plana. 4 Stamina ct pistillum aucta.

\section{TAB. XVI.}

1 Calyx auctus, cum pistillo exserto. 2 Corolla aucta, longitudinaliter fissa, cum antheris et fornicibus penicillifornibus.

\section{TAB. XVII.}

1 Calyx cum pistillo magnitudine naturali. 2 Idem auctus. $3 \mathrm{Co}-$ rolla clausa, aueta. 4 Eadenı longitudinaliter fissa cum staminibus. 5 Semina giblosa, uberculata, ancta.

\section{TAB. I VIII.}

I Calyx quinquedentatus, auctus. 2. Corolla quinquefida, aucta, longitudinaliter fissa. 5 Capsula aucta, trilocularis, transiersin scissa.

TAB. XIX.

1 Callyx cum bractea auctus. 2 Corolla quinquefida, aucla, longiudinaliter fissa alssque staminibus. 5 Corollae basis aperta aucta, cum staminibus basi dilatatis. 4 Germen anctum cum stylo ac stigmate, clavato trifido pubescente. 5 Capsula sulcata, ancta, foris sub apice dehiscens. 6 Eadem trilocularis, horizontaliter secta.

TAB. XX. $f .1$, et 2.

1 Fructus auctus cum calyee apcrto, obtuso, quinquedentato. 2 Idem 
jam perfectus, auctus, calyce exsiccato coronatus, longitudinaliter lincatus. In fig. 2. num. 1. calycem quinquefidum cxlibet, et uum. 2 fructrom calyec coronatım ac reticulato-angulatum.

TAB. XXI.

1 Bractea, calycis foliola, et capsula. 2 Corolla patcos. 5 Stamina basi corollae inserta. $4 \mathrm{Ger}-$ men cum stylo et stigmate; omnia magnitudine naturali. 5 Semen auctum, tetragonum, excarato-rugosum. (6) Capsulae 2-locularis sectio transversalis.

\section{T.AB. XXII.}

1 Umbellula vix aucta cum involucellis et radiis inacqualibus. 2 Involucelli foliolım auctun, nervis anastomosantibus exquisitc reticulatum. 5 Flos auctus cum petalis involutis. 4 Fructus auctus, ecostatus, $\mathrm{er}$ dorso visus. 5 Idem ex facic commissurali, ubi sulco lato notatus.

$$
\text { TAB. XXIII. f: } 1 \text {, et } 2 .
$$

1 Umbellula aucta cum involucellis patentibus, et radiis aequali- bus. 2 Involueclli foliolum nervis non anastomosantibus obsolcte notatum. 3 Flos auctus. \& Fruetus subtctragons, obsoletc costatus, utrinque subtruncatus, ex dorso visus. 5 Iden ex facie commissurali, ubi sulco lato notatus. In fig. 2. n.. 6 . Umbellula ancta cum radiis inacqualibus. 7 Involucelli foliolum auctum, margine denticulatum. 8 Flos auctus. 9 Fructus auctus, ex facie commissurali visus. 10 Idem latcraliter visus.

\section{TAB. XXIV.}

1 Flos auctus. 2 Fructus striatus, apice stylis persistentibus et dentibus calycinis coronatus.

TAB. XXV.

1 Involucri foliolum magnitudine naturali. 2 Fructus striatus, auctus.

\section{TAB. XYVI.}

1 Flos auctus. 2 Fructus anctus, costato-alatus. $5 \mathrm{Idcm}$ transverse sectus, ut costac subalatac conspiciantur. 
1 Flos anctus. 2 Fructus parum auctus ex dorso visus. 5 Idem cx facie commissurali.

\section{TAB. XITII.}

1 Valvula calycina granifera, aucta, nervis reliculata. 2 Eadem granulo destituta.

\section{TIB. ХXIS.}

1 Valvula calycina, setaceo-dentata, granifera, valde ancta.

TAE. XXX.

1 Calyx campanulatus anctus, dentibus margine scariosis alididis. 2 Flos auctus. 5 Semen auctum, tuberculatum, globoso-cordatum.

\section{TAB. XXXI.}

] Stamina decem vix aucta, quorum quinque alterna Iongiora. 2 Petalım auctum. 3 Germen auctum, cum stylis et glandulis nncinatis ad basim. 4 Scmen auctum, tubcrculatum, sulgglobosum.
1 Bracteae quatuor exteriores flores cilcumdantes auctae. 2 los pedunculatus, capsula et bracteae interiores anctae, absrque bractcis esterioribus. 5 Stamina, germen el styli aucti. 4 Capsnla jam matura ct apice hians, cum calyce linc disrupto ex latere dicjecto. 5 Semen anctum, ex dorso visum, tubercnlatum. (i Idem ex facic interiore, ubj in medio excavatum. 7 Caulis articulns inferior auctus, ut pubescentia magis conspiciatur.

\section{TAB. XXXIII.}

1 Calyx striatus, auctus, cum bracteis imbricatis ciliatis. $2 \mathrm{P}_{\mathrm{C}}$ tala, stamina, germen et styli magnitudine naturali. 5 Capsula apice 5-dentata. \& Semen subcompressum, oratum, facie interiore visum, ubi vix in mcdio foveola notatum.

TAB. XXXIV.

1 Calyx auctus, 10-striatus, dentilus membrana albida scariosa appendiculatis. 2 Capsula aucta, 
pedicello striato pubescente suffulta intra calycem.

\section{TAB. XXXV.}

1 Petalum anctum cum lamina bipartita, et coronae foliolo bicuspidato. 2 Capsula cum staminibus et stylis pcdicello striato glabro suffulta intra calyccnı. A. Ramus, in quo pubescentia magis capressa, it in nomuullis individuis observatur.

\section{TAB. XXXVI.}

1 Calyx fructiferus auctus, 10nervosus, dentibus margine vix membrana allida scariosa auctis. 2 Capsula, cunı staminibus et stylis, brevi pedicello suffulta intra calycem.

\section{TAB. XXXVII. $f \cdot 1$, et 2.}

1 Capsula aucta, et clausa, cum stylis. 2 Eadem apice aperta. 3 Scmen auctum, tubcrculatum, cordato-globosum. -- Fig. 2. 11." 1. Flos auctus, et apertus. 2 Capsulae quinque vix auctae.

TAB. XXXVIII.

1 Flos cum capsula setosa anctus.
TAB. XXXIX.

1 Fructus jam maturus longitudinaliter sectus, vix auctus.

\section{TAB. XL.}

1 Flos anctus. 2 Calyx auctus post anthesim. 5 Capsulac nondum perfectae, auctae.

\section{TAB. XLI.}

1 Capsulac tres, rostratac, jam perfectae et apertae, ncrvis prominulis notatae.

\section{TAB. XLII.}

1 Florum corymbus cum bracteis, calycibus et corolla auctus.

TAB. XLIII, XLIV, et XLV.

1 Calyx anctus, cum dentibus membrana albida appendiculatis. 2 Corolla clausa cum staninibus. 5 Eadem longitudinaliter fissa cum staminibus. 4 Corollao appendis.

TAB. SLVI. $f: 1,2$, el 3 .

1 Petala aequalia, ac stamina quatuor didynamica, aucta. $2 \mathrm{Si}$ - 
licula integra, aucta. 5 Siliculac dissepimentum auctum -Fig. 2 -- I. Siliculae valvula ancta. 2 Siliculae dissepimentum semina gerens et auctum, in cujus apice stylus oblique insertus. 3 Semen compressum, rotundum -- Fig. 3. -- 1. Siliculae valvula aucta. 2 Silieulae dissepimentum semina gerens, et auctum, in cujus apice stylus in medio insertus. 5 Semen oblongum, auctum.

TAB. XLVII.

1 Calys anctus. 2 Petalum unicum, semibifidum, cum staminibus tetradynamicis, germine et stylo. 5 Siliculae dissepimentunı magnitudine naturali cum staminibus. 4 Semen compressum, marginatum, vix auctum.

\section{TAB. XLVIII.}

1 Calyx cum legumine magnitudine naturali. 2 Legumon vix auctum, apertum, cum seminibns.

TAB. XLIX.

Legumen apertum cum scmini- bus magnitudine naturali. 2 Semen globosum, auctum.

'T AB. L.

1. Calyx anctus, dentibus inacqualibus. 2 Legume'n auctum, foveolatum, et $\tan$ in dorso quam ad suturam aculeatum.

TAB. LI.

1 Calyx auctus. 2 Legumen rostratum, auctum. 5 Semen reniforme, auctum.

TAlj. LII.

1 Legumen auctum, anfractibus reticulatis.

TAB. LIII.

1 Semen vix auctum, striatum, et laminibus transversalibus scabrum.

TAB. LIV.

1 Semen vix auctum, striatum, ad angulos muricatum, cum $\mathrm{l}^{\mathrm{a}} \mathrm{p}-$ po plumoso. 
TAB. LV. f. , et 2.

TAB. LX.

1 Senten vix auctum, striatım, leve.

TAB. LVI.

1 Corollula raclii vix aucta, apice denticulata. 2 Foliolum calycis intcrius, semcn cum pappo sessili includens. 5 Scmen disei scabrum, cum pappo stipitato.

\section{TAB. LVII.}

1 Semen pappo et corollula tubulosa vix auctum.

TAB. LVIII.

1 Scmen auctum, glabrum, cum corollula. 2 Idem striatum, magis auctum, cum corolla exsiccata in apice. 5 Receptaculi palea concava, apice tridentata, dente intermedio elongato mucronato.

\section{TAB. LIX.}

1. Florum capitulus integer, lana involutus. 2 Calyx et corollulae auctae. 5 Folium calycis extcrius ad margines scariosum ac serrulatum. 4 Corollula aucta cum semina pappo coronata.
1 Rieceptaculi palea. 2 Corollula radii tridentata, parun aucta, cum semine coronato pappo dimidiato, 5 Semen disci, cum corollula auctum. 4 Semen radii auctum; et pappo integro, dimidiato, antice viso coronatum. 5 Idem cum pappo obsolete tridentato, postice visum. 6 Semen disci corona brevissima integra instructum.

TAB. LXI,

1 Foliolum calycis exterius auctum. 2 Idem interius in margine obsolete denticulatum. 5 Semen cum pappo et corollula auctum.

\section{TAB. LXII.}

Ranulus cum foliis parvis imbricatis auctus. 2 Idem cum foliis longioribus, scmipatentibus. 5 Bacca magnitudine naturali.

\section{TAB. LXIII}

1 Samarae tres pedunculatac, utrinque attenuatae, magnitudine na- 


\section{(11)}

turali. 2 Folium magnitudine TAB. LXVI.

propria.

TAB. LXIV, et LXV.

1 Bractca verticillis vel raccmulis florum subjecta. 2 Calyx, el corolla accualiter quadrifida, aucti.

1 Frondis pinnula cum soris aucta.

N. B. In tabula XLV. lege tab. XLIV, ac viceversa; et ScroPHULARIA MULTIFIDA pro S. CHRYSANTHEMIforid. 


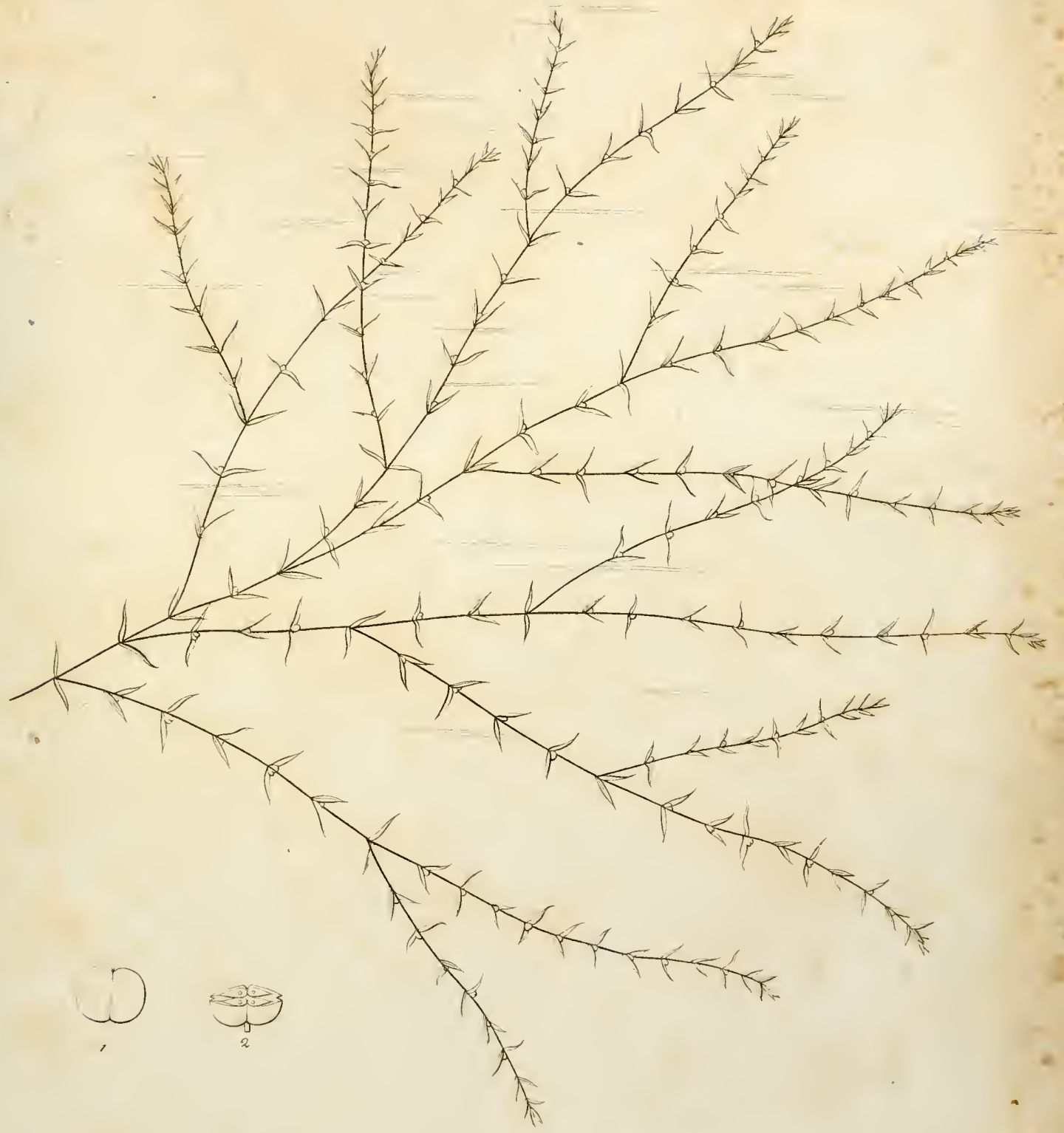

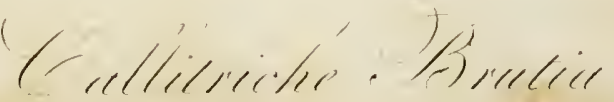



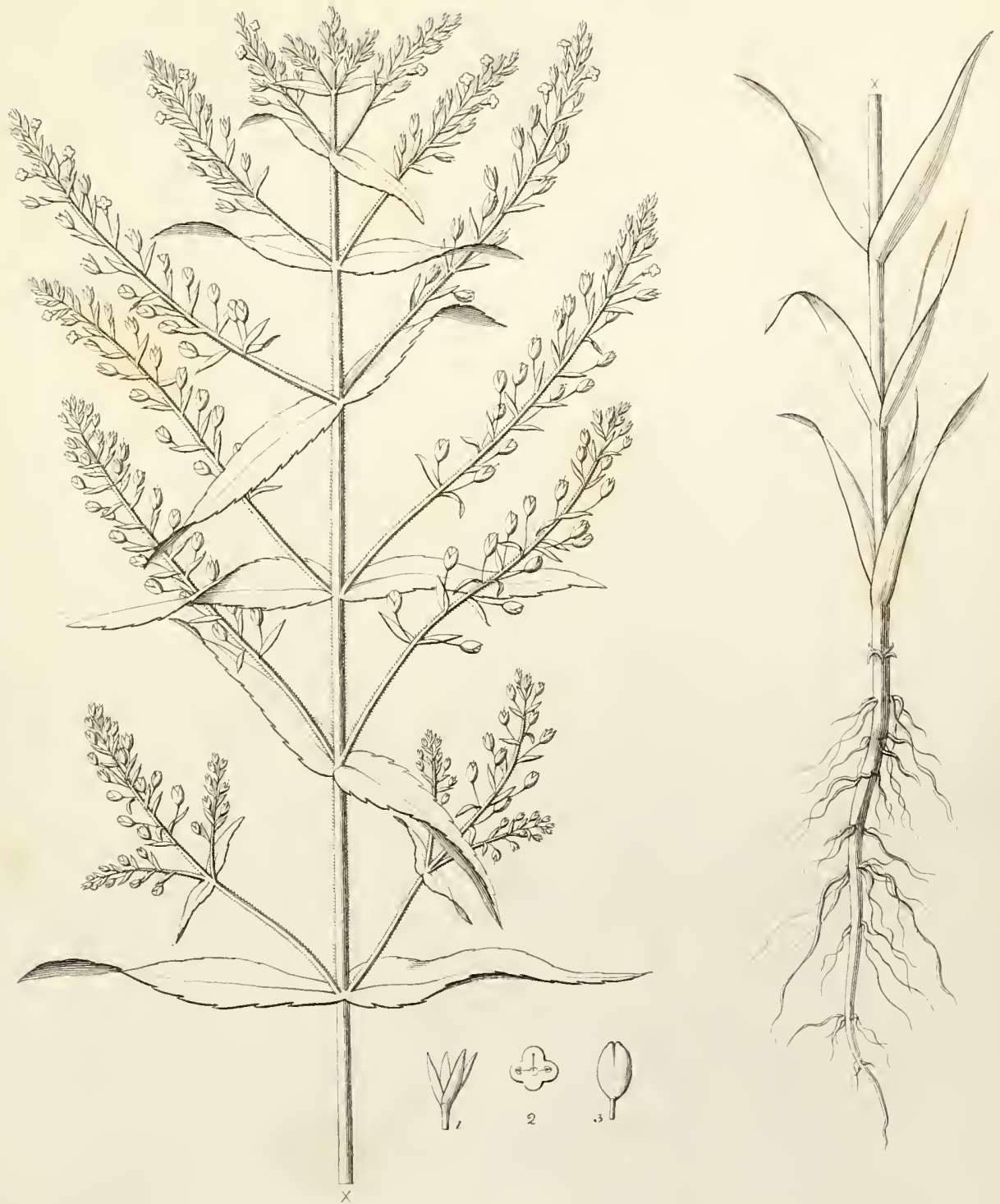


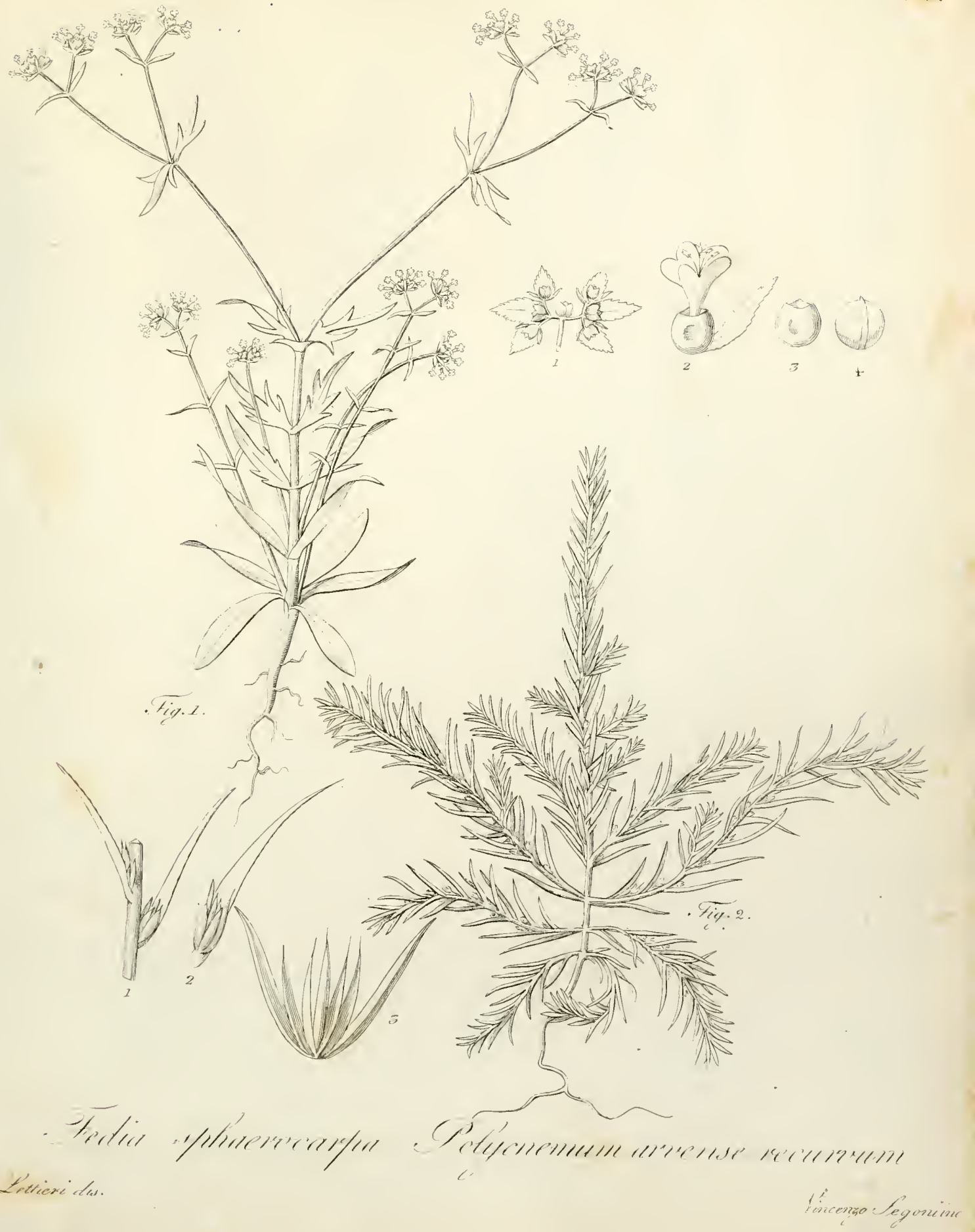




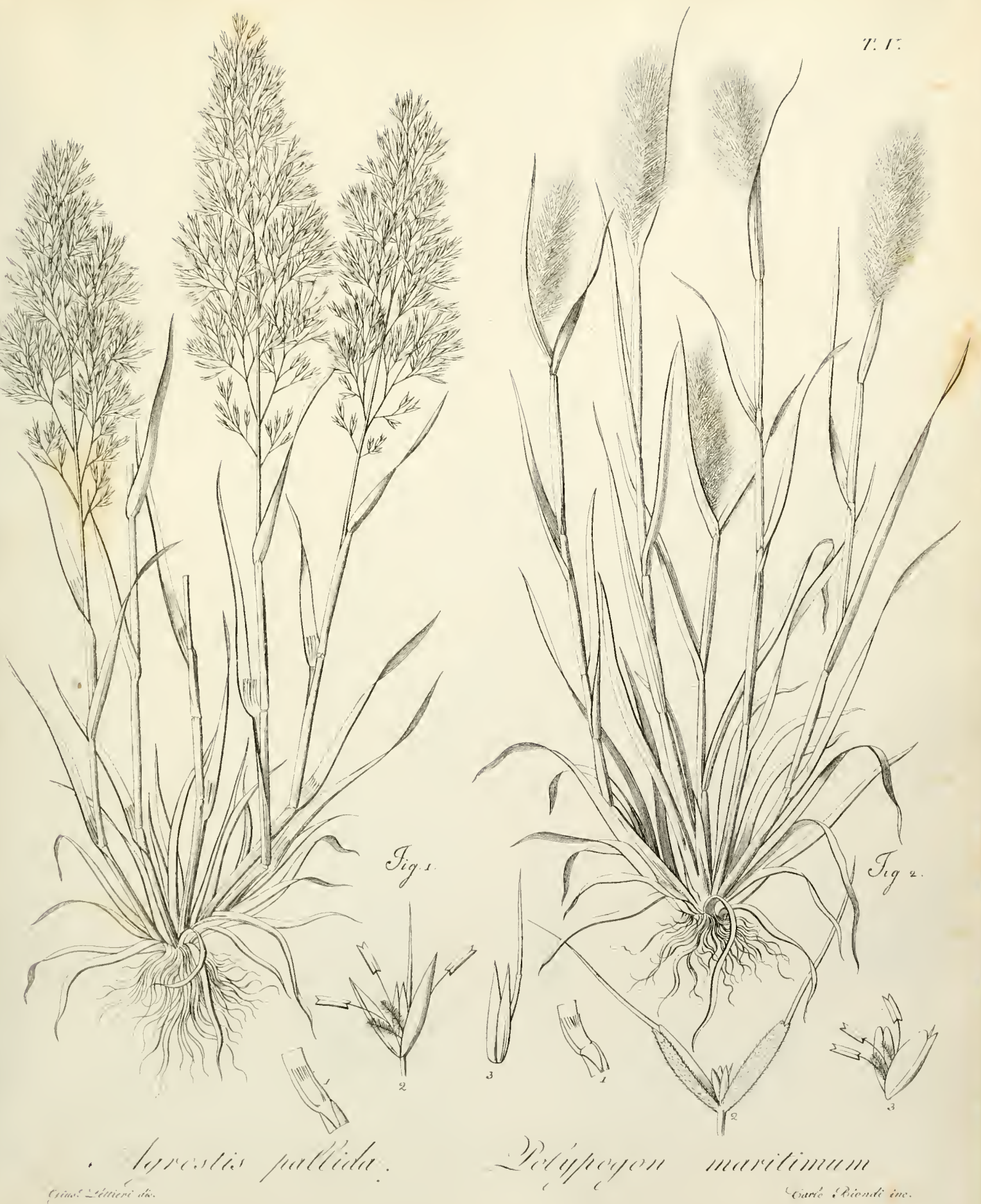




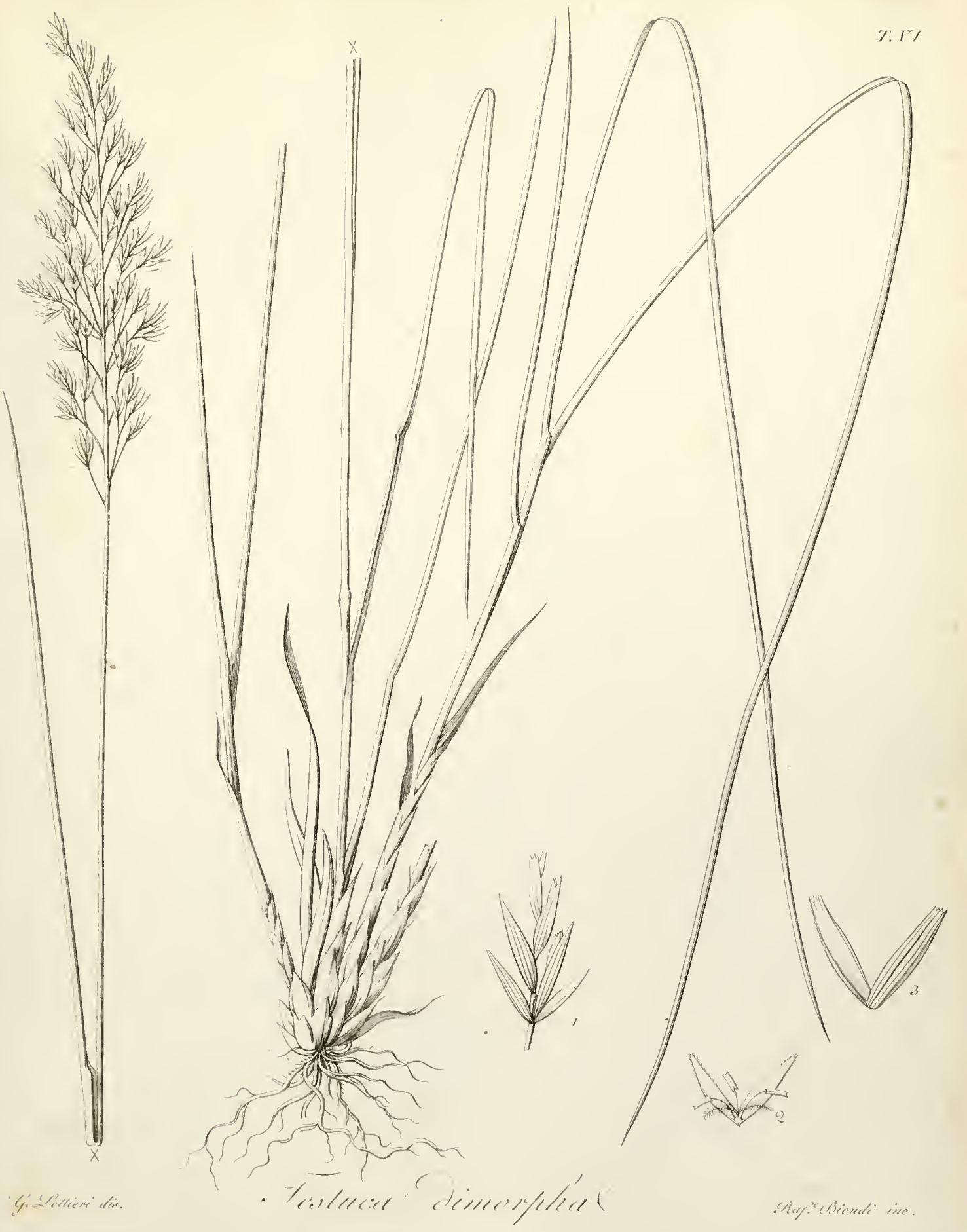


- 
T. TII.

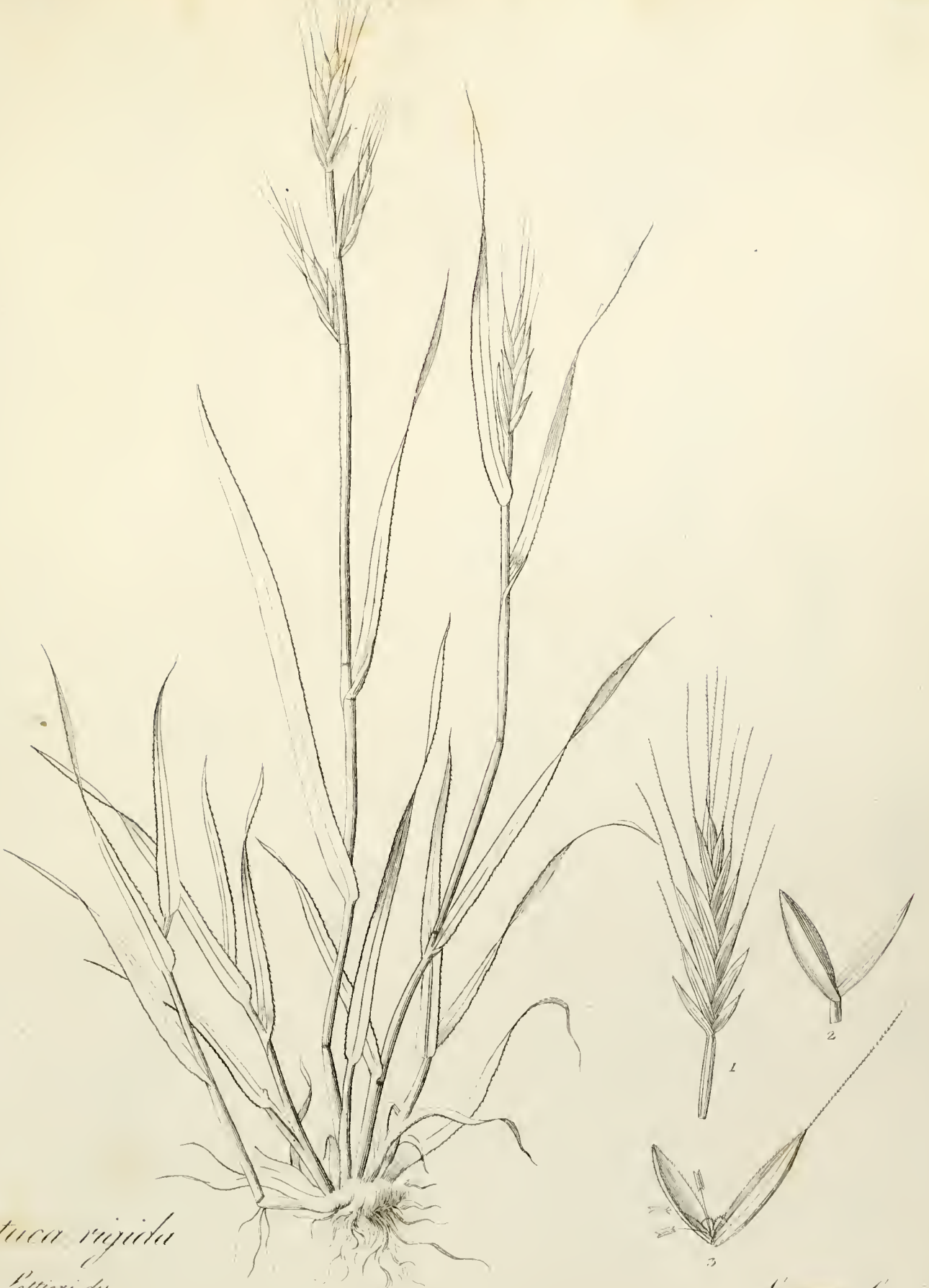
tiere. éefriese das.

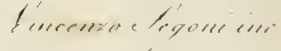




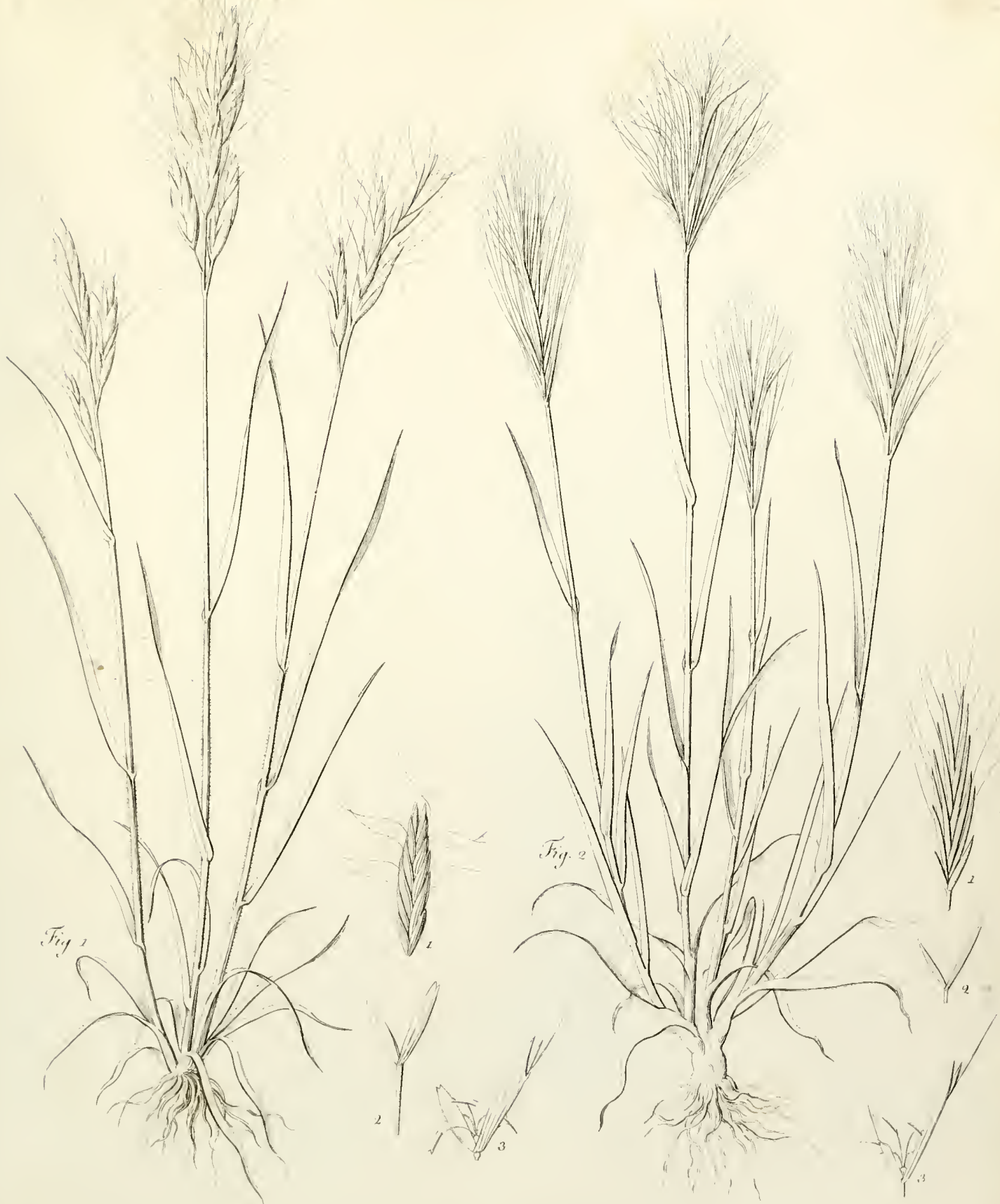

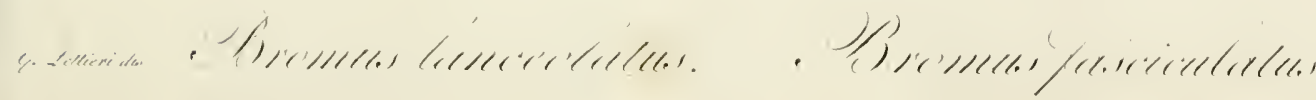




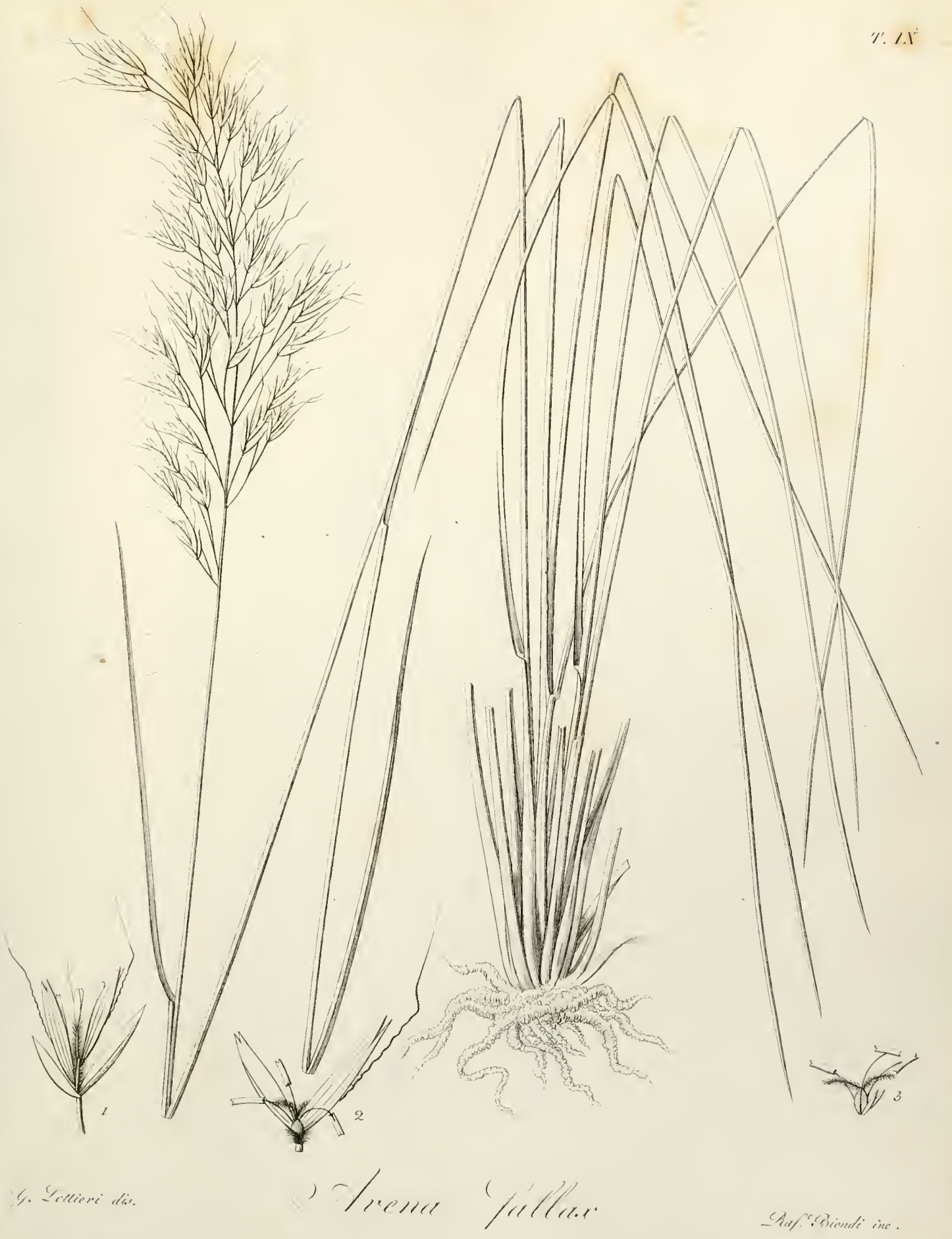




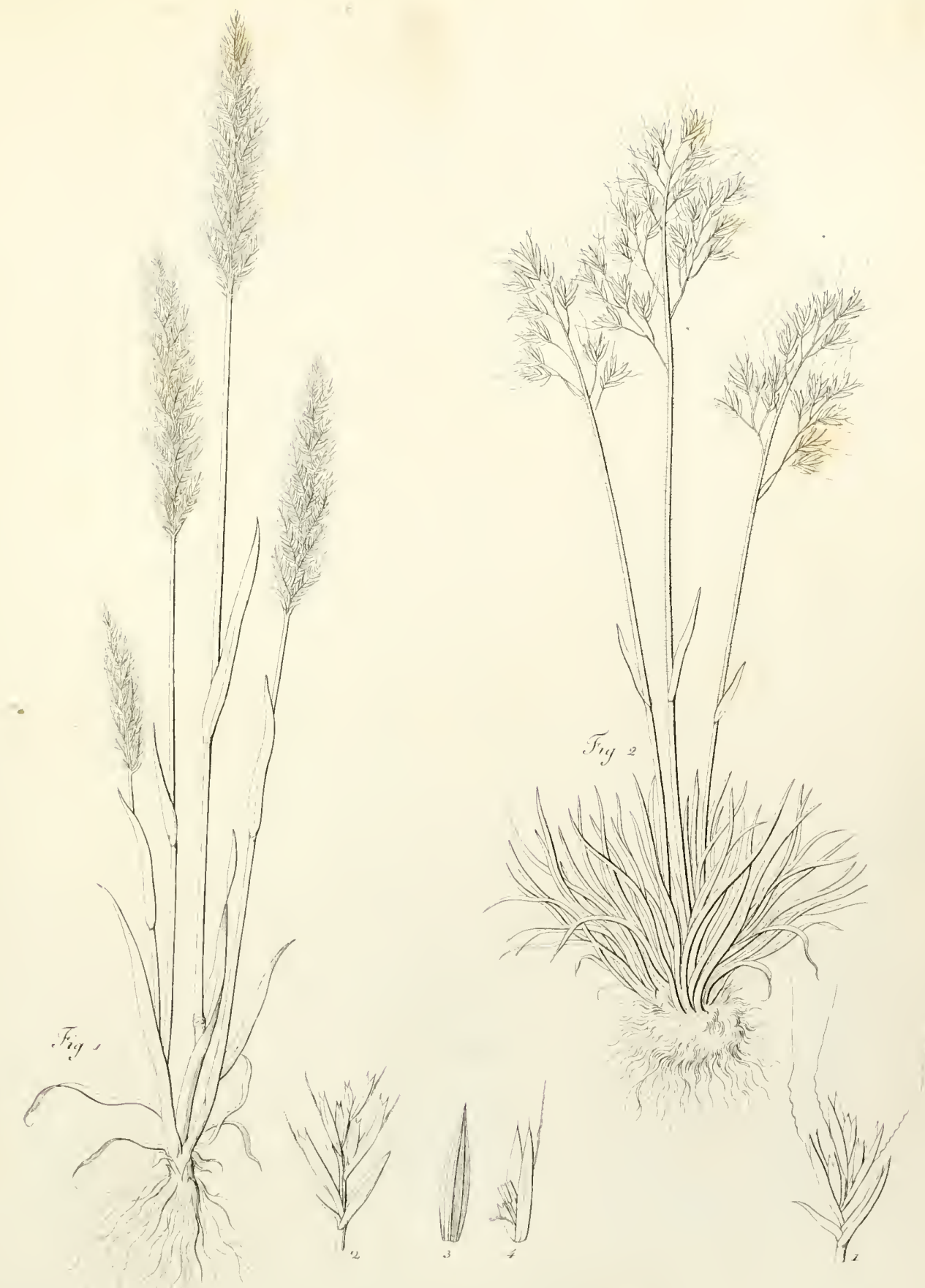

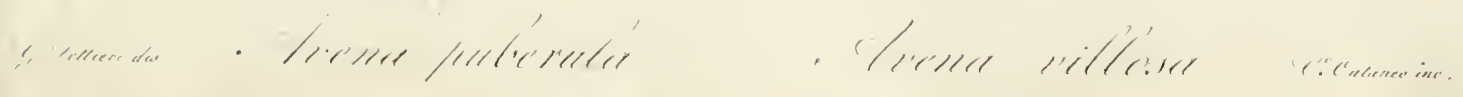



7. 1\%. 



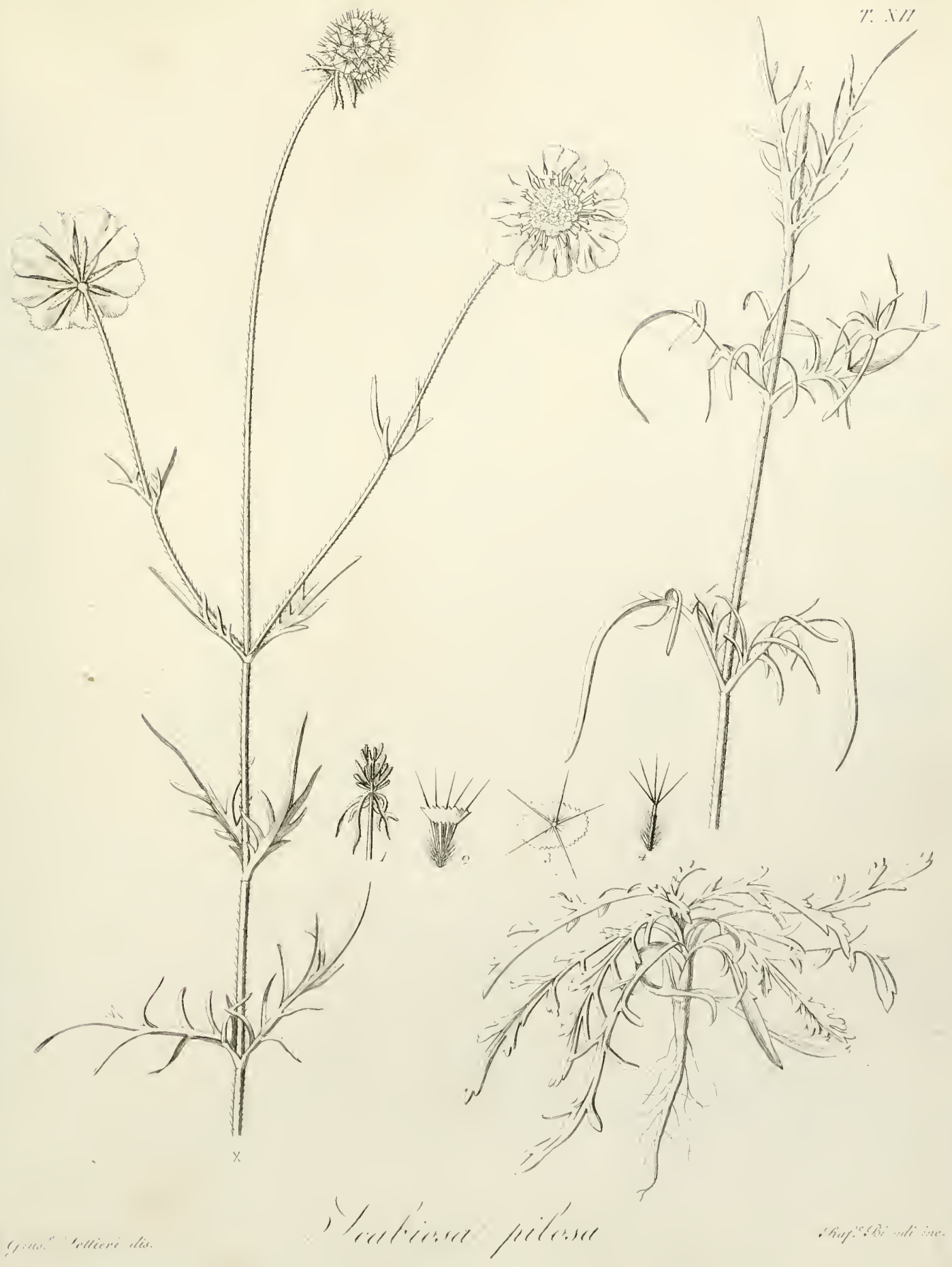


$\sqrt[3]{3}$

WV

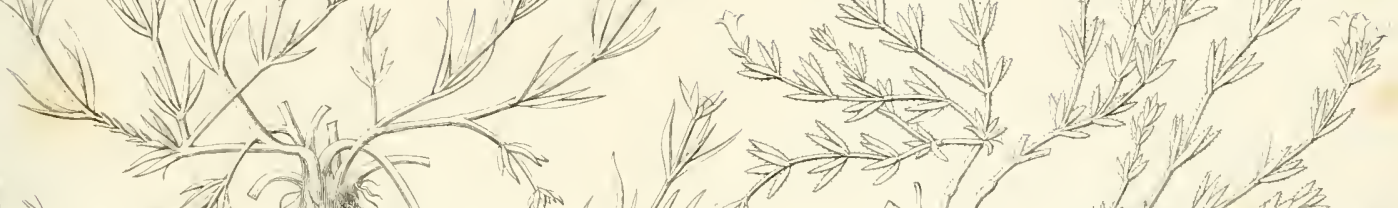

$3+2$

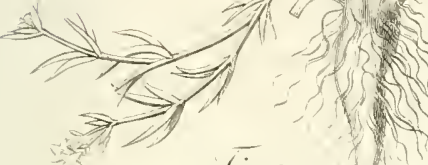

$\rightarrow$
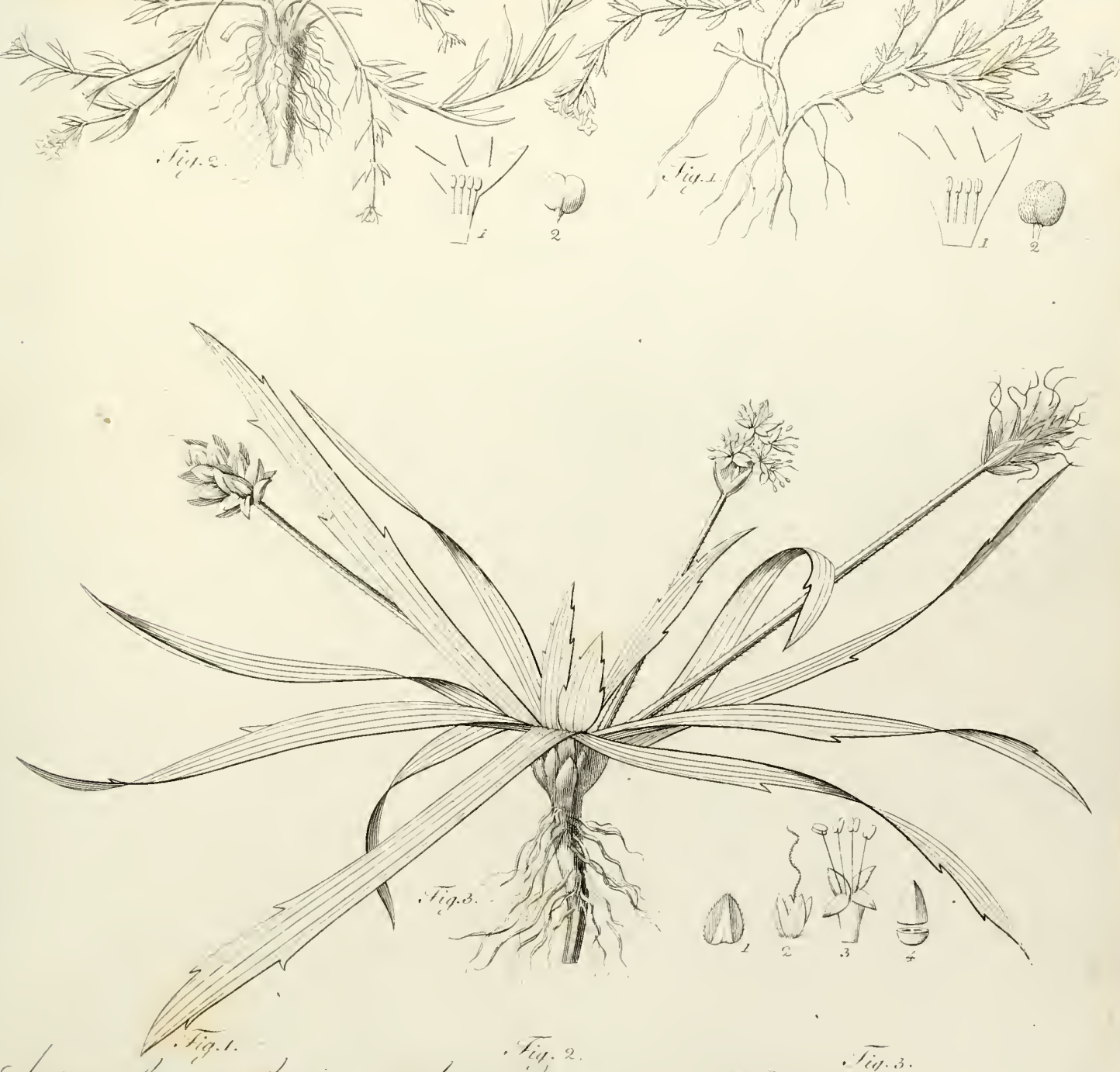

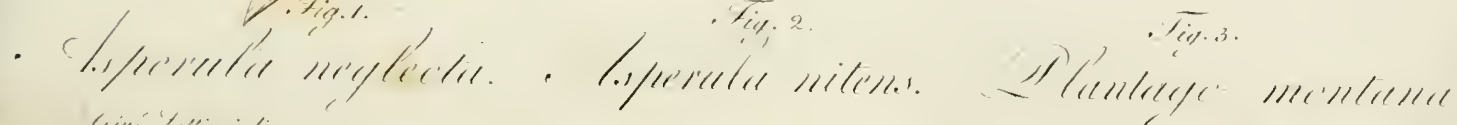

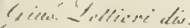


ข. พIr:

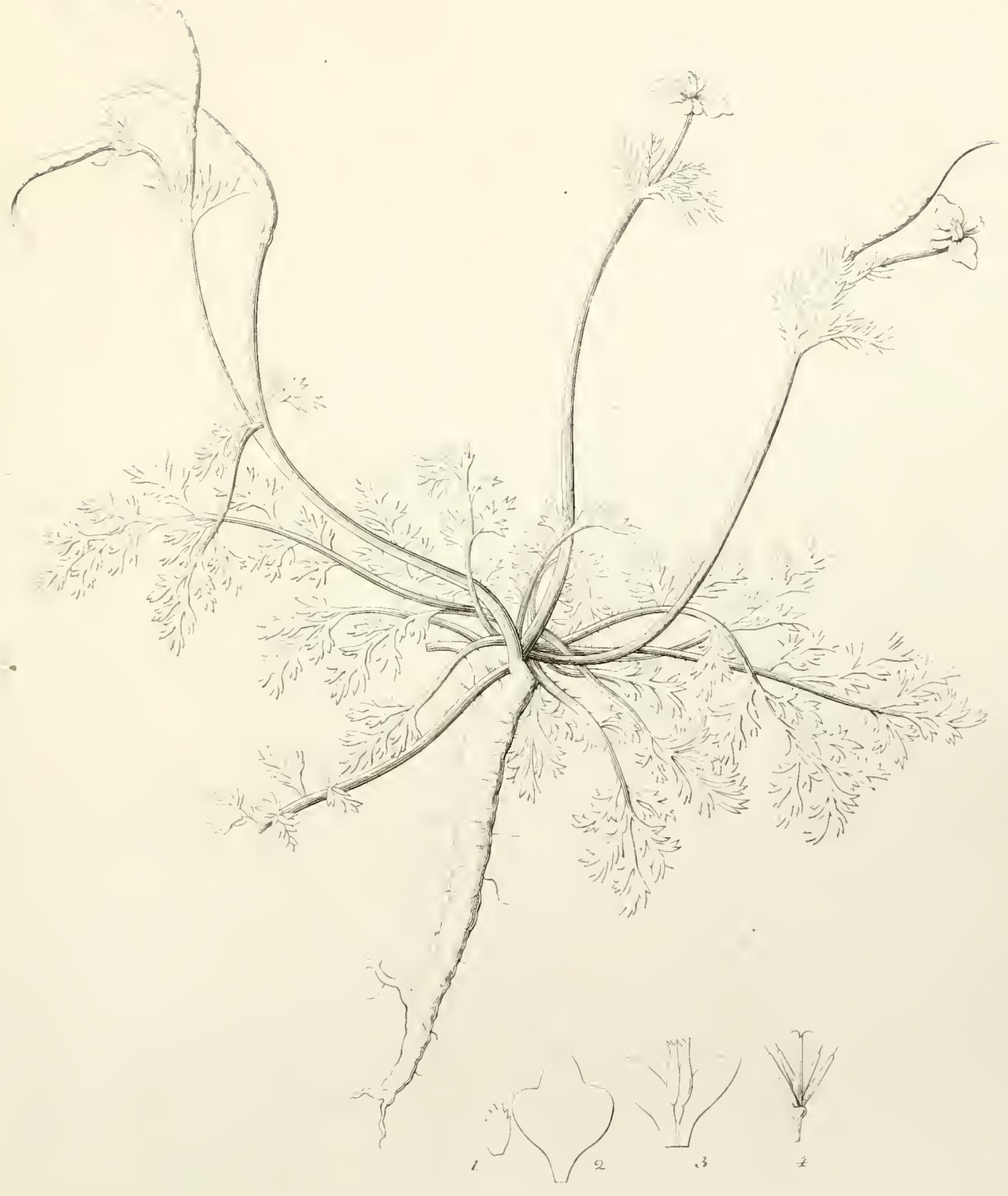

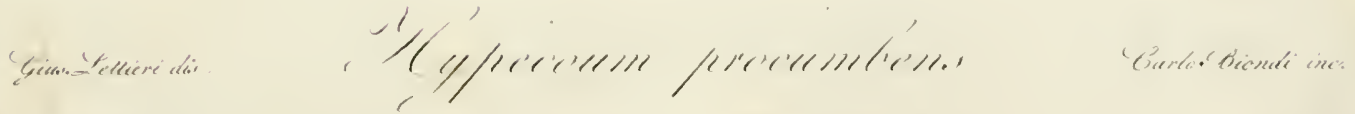




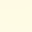




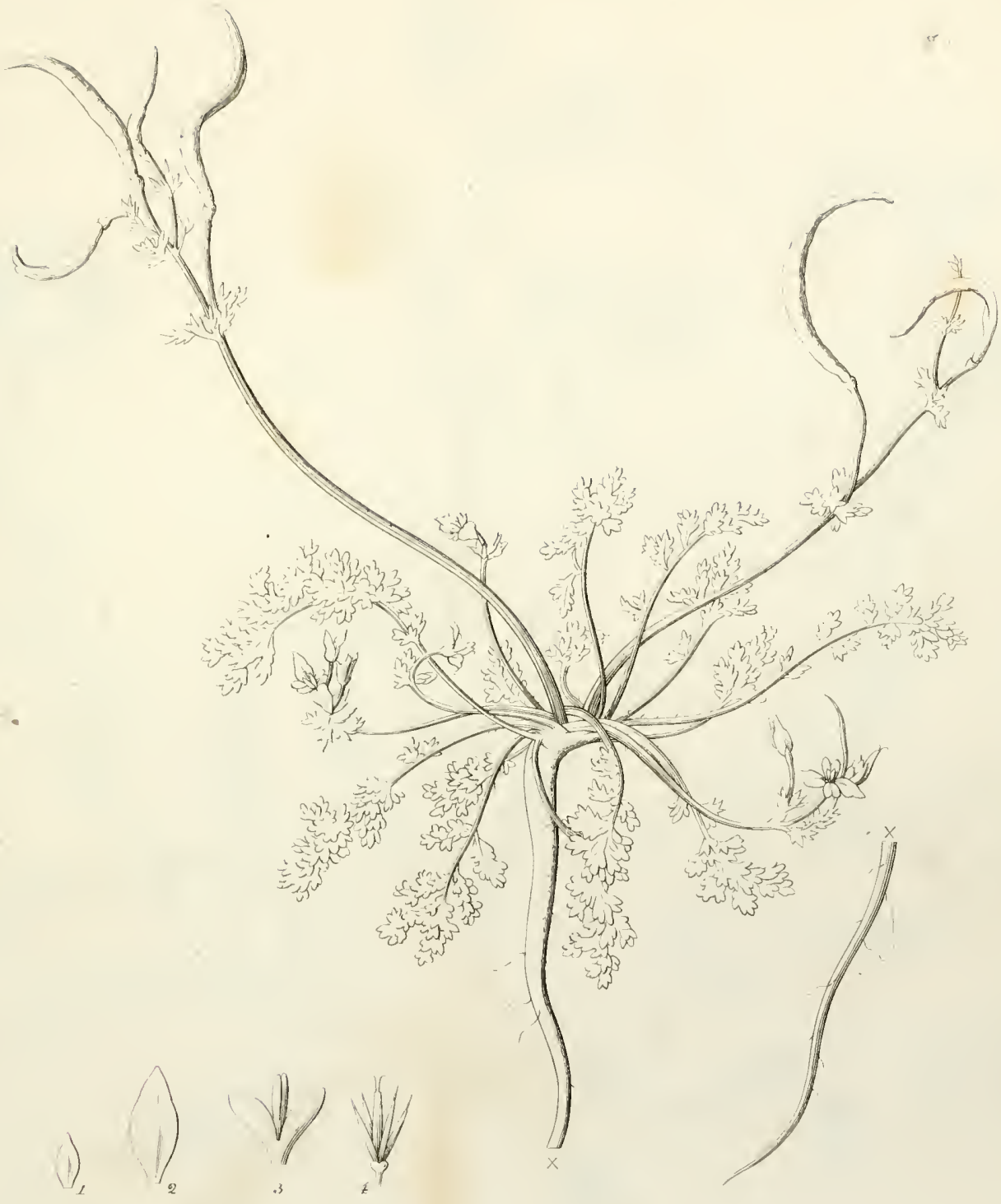

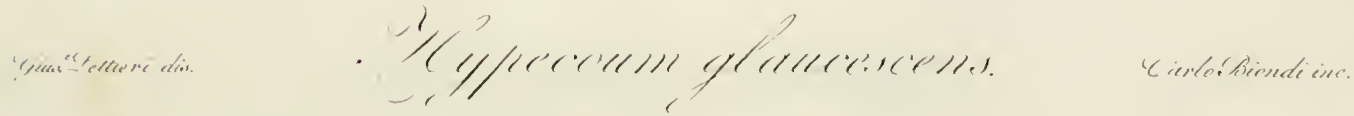





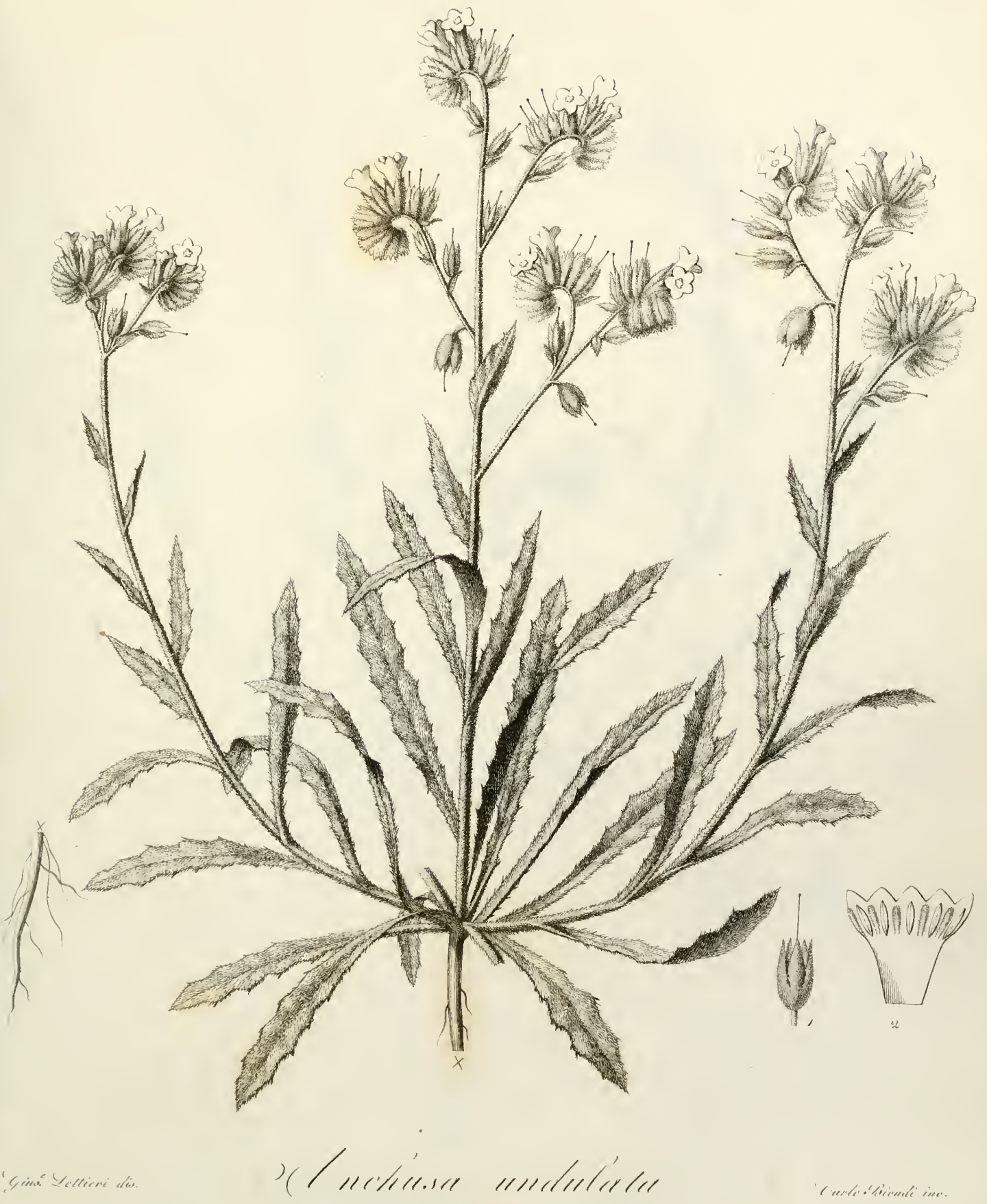





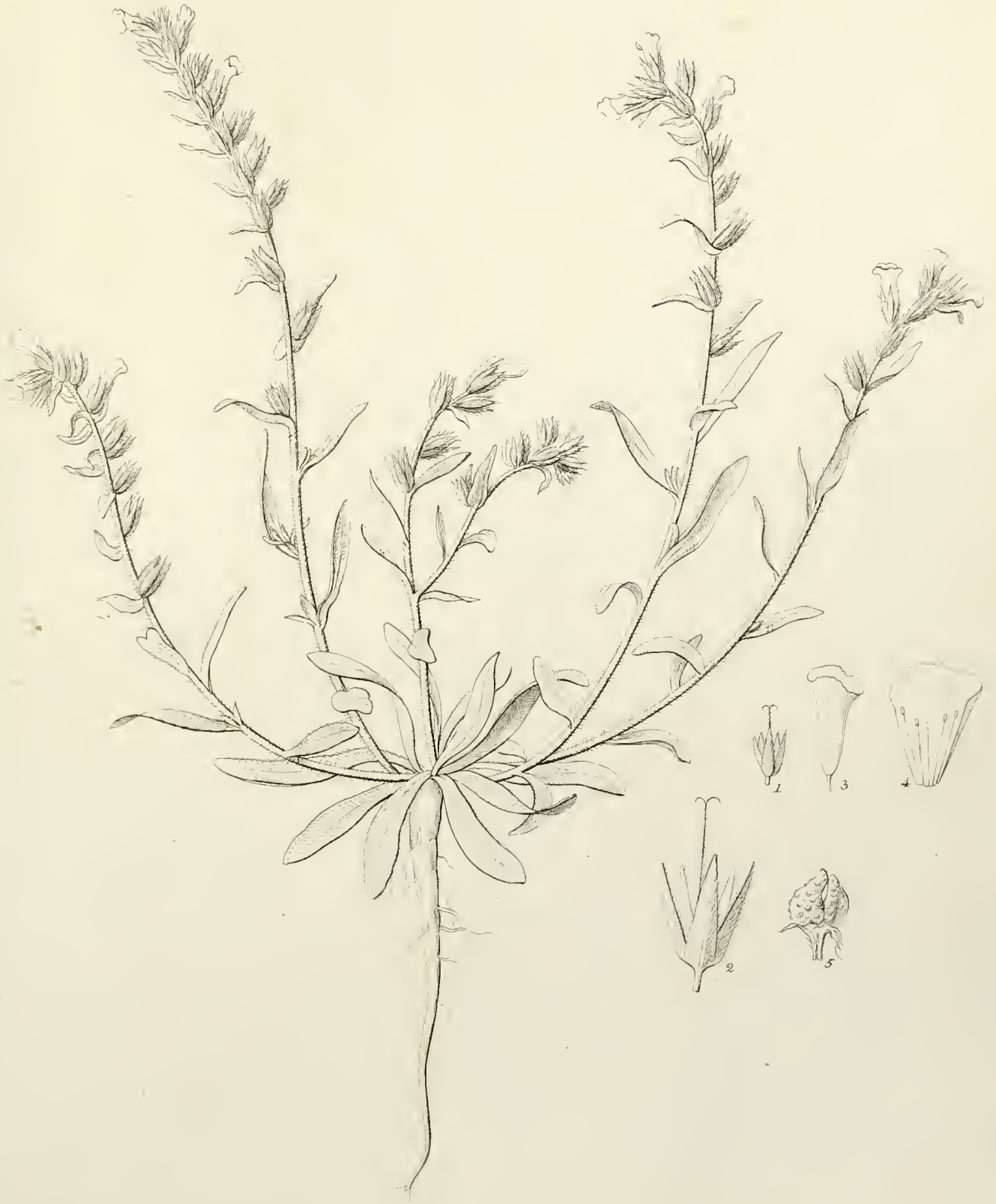

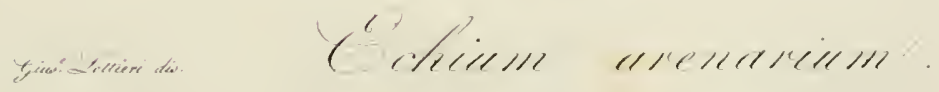






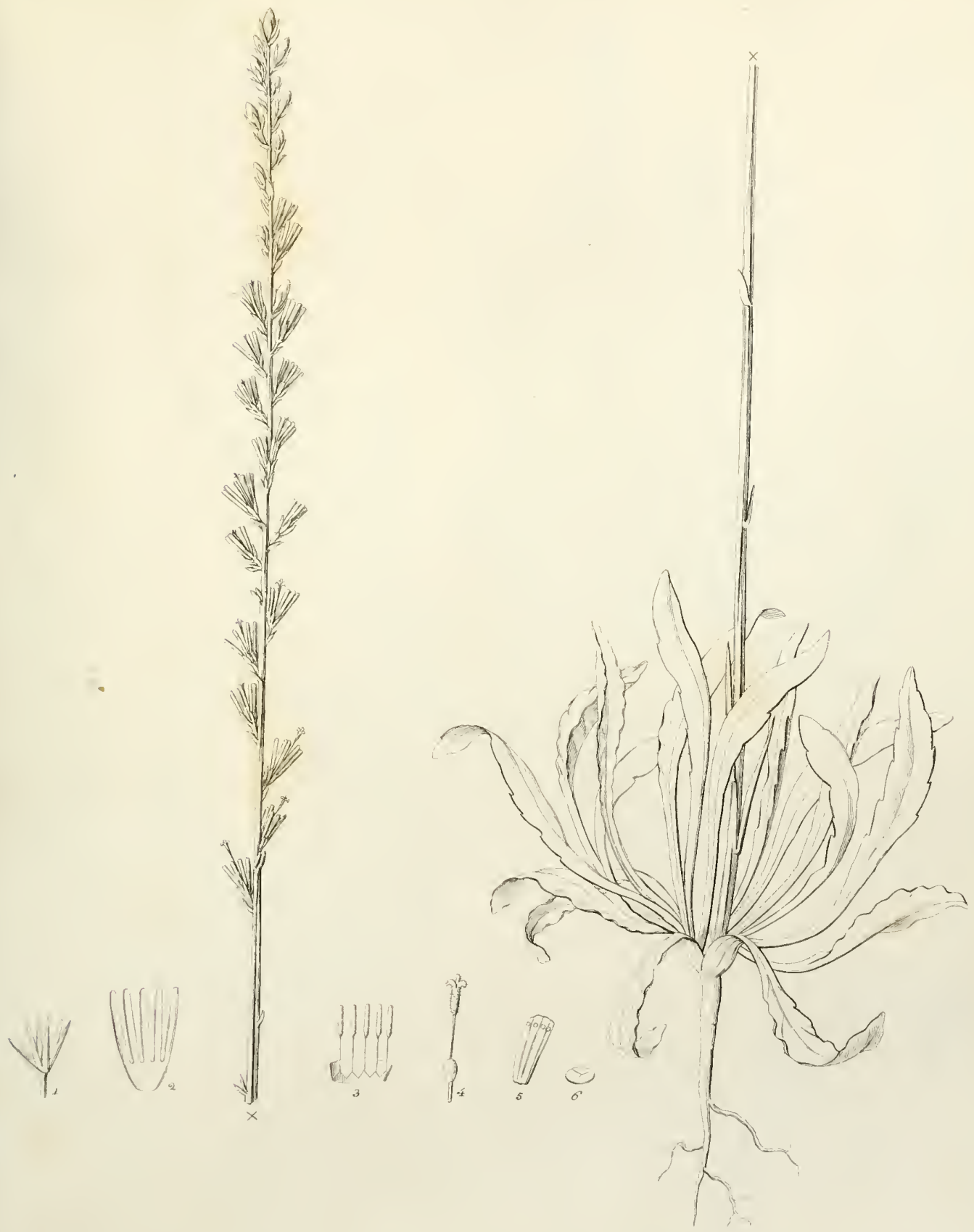

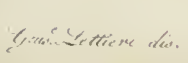

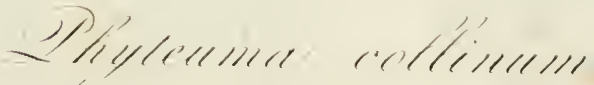





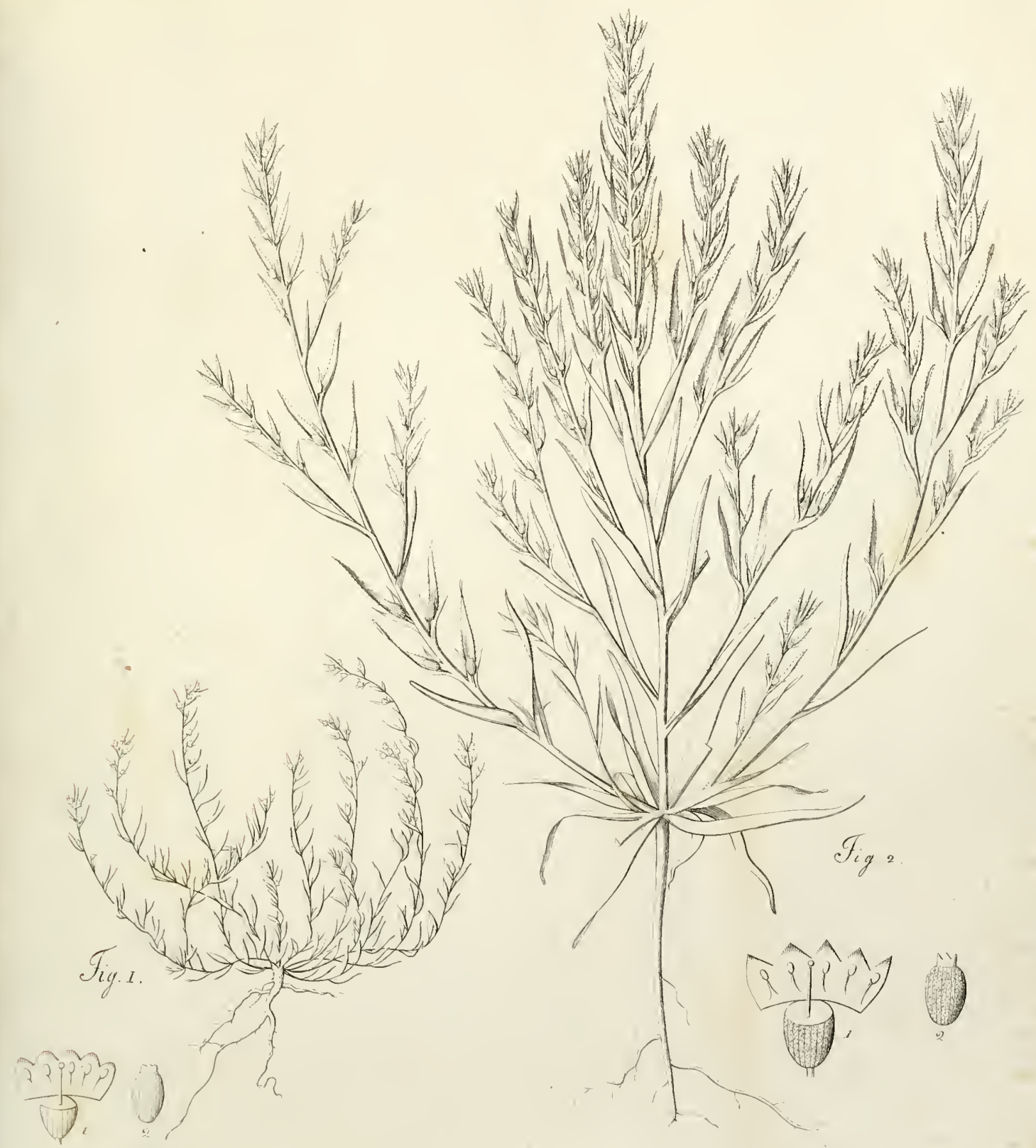

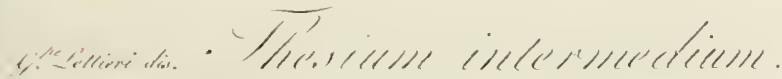

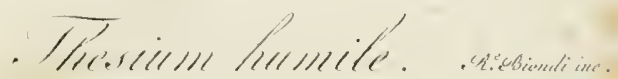




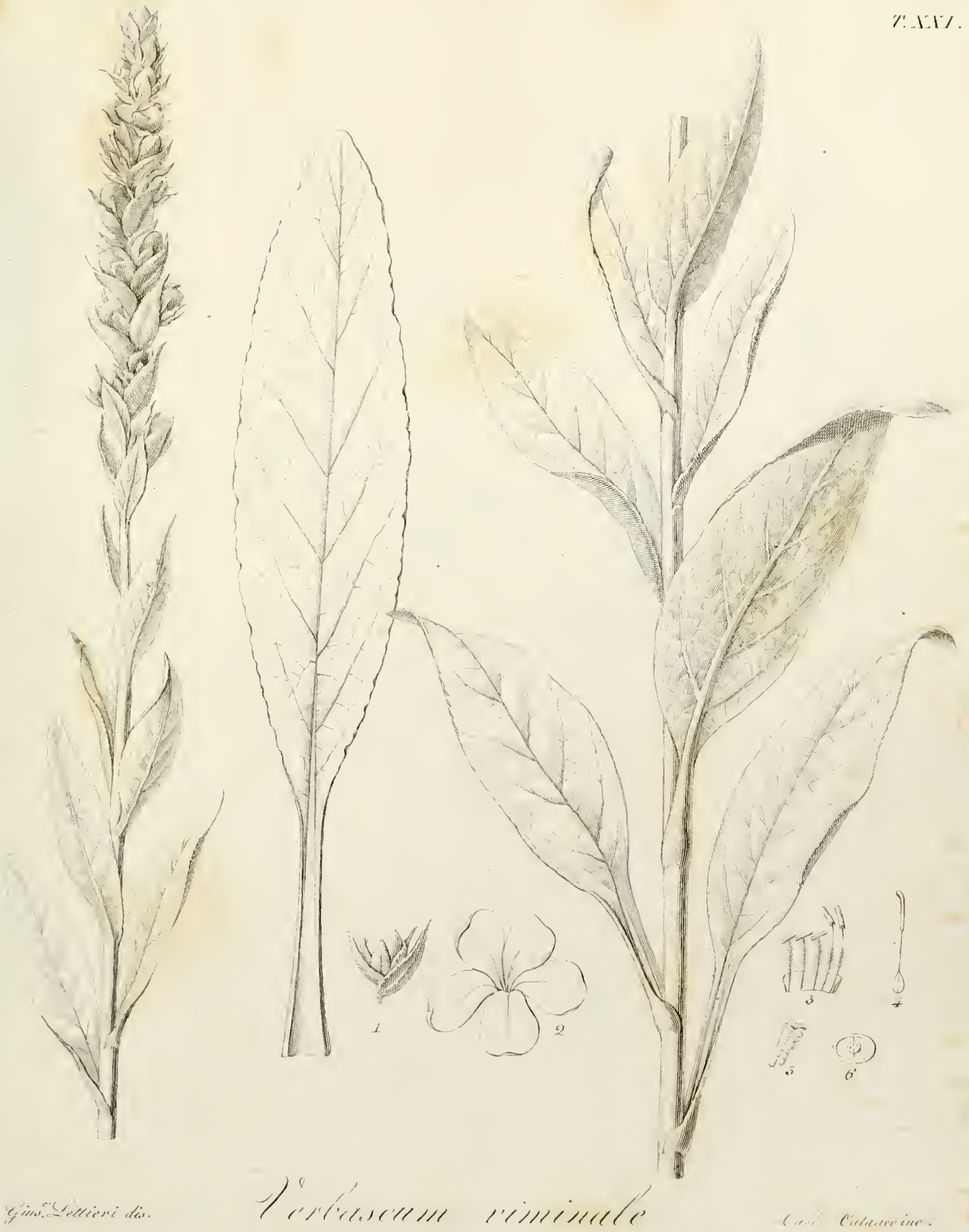




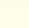




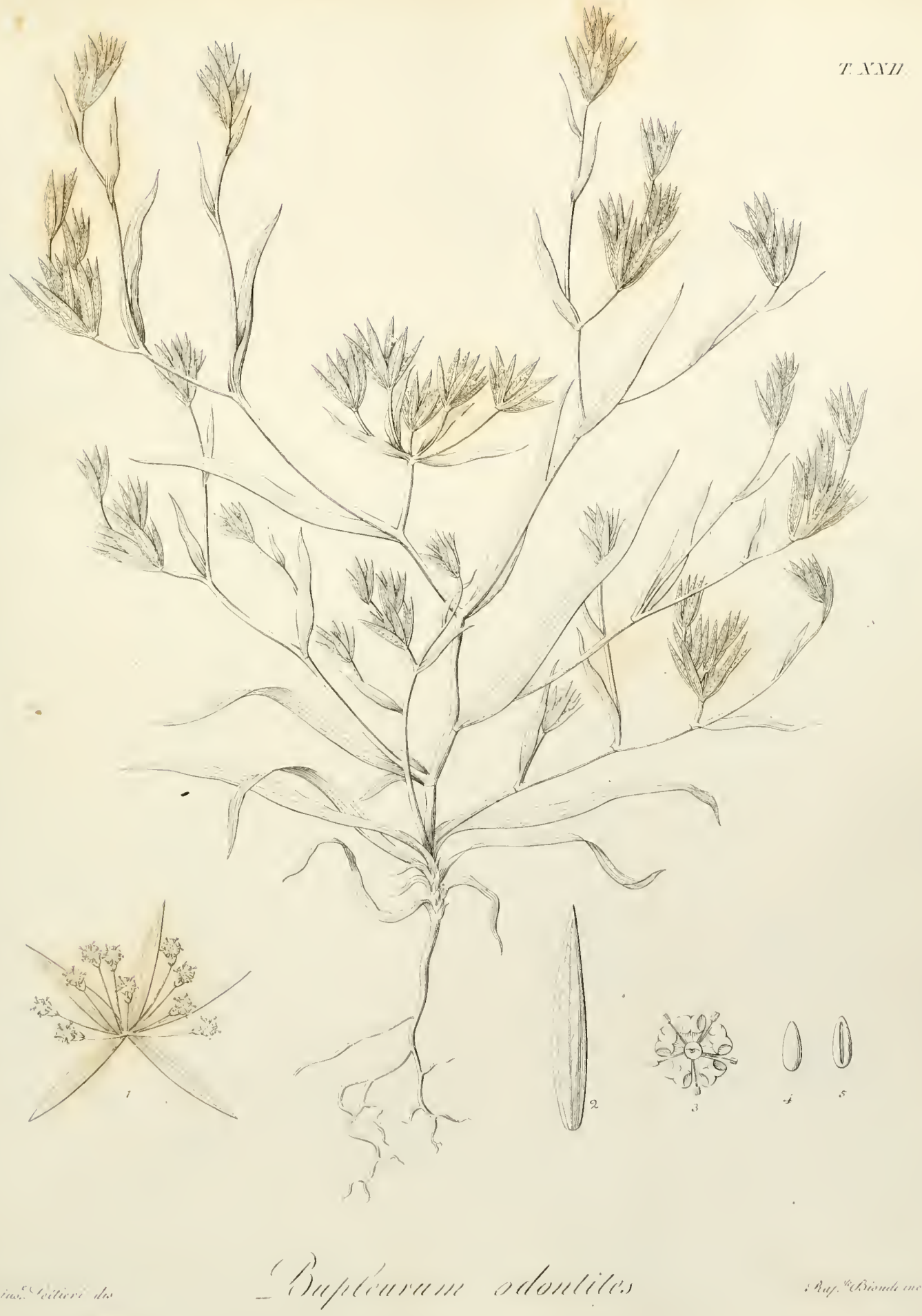




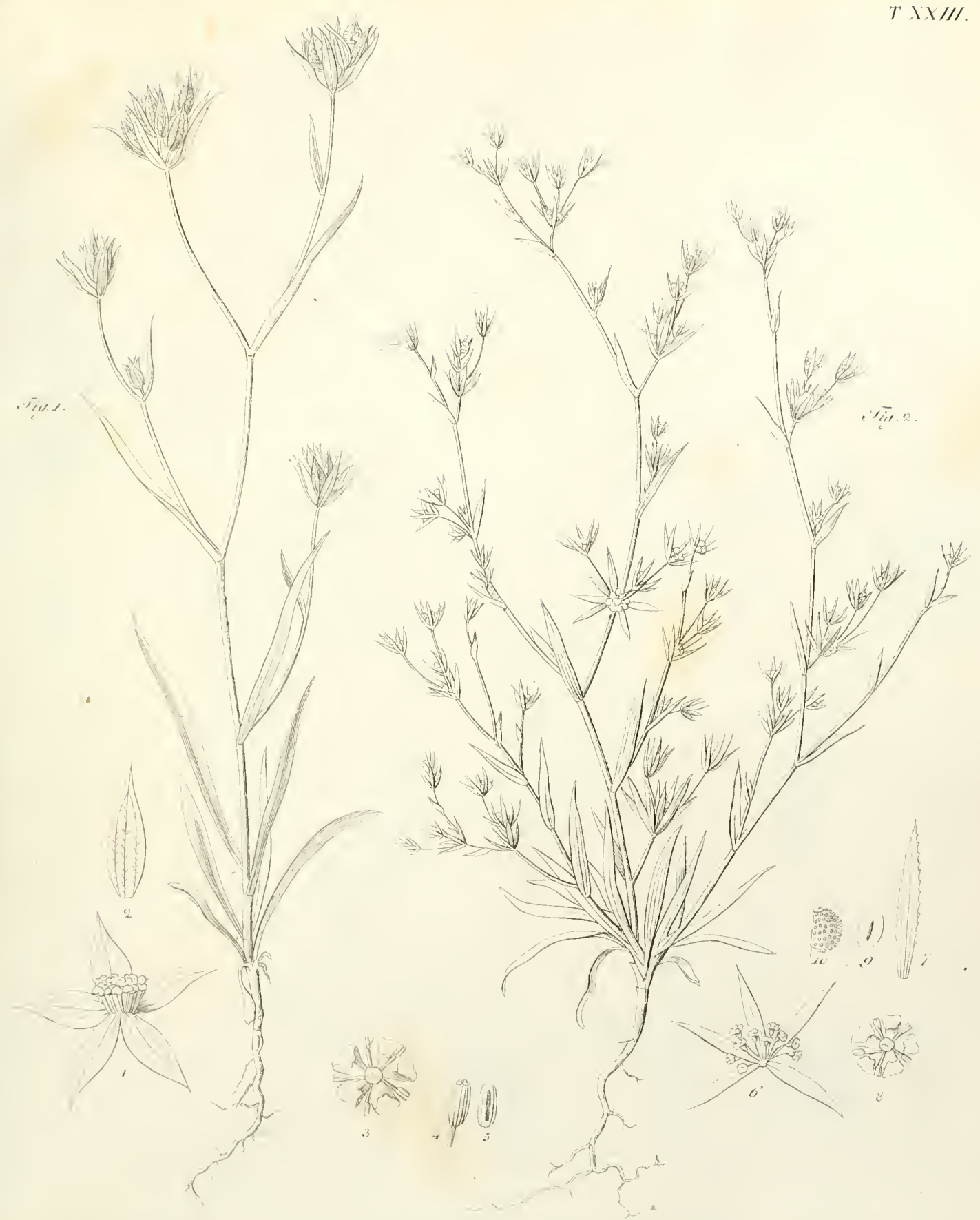

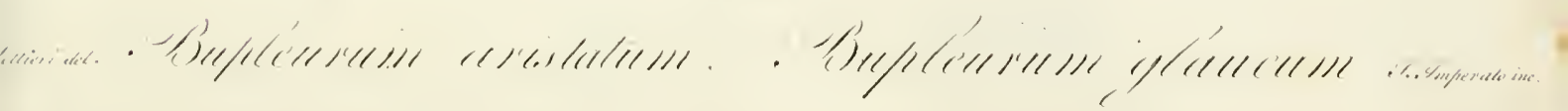





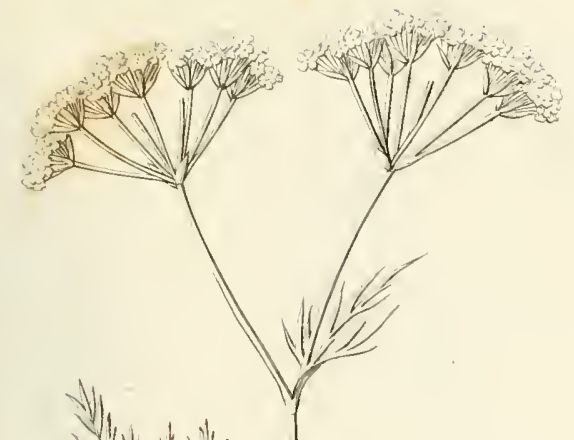





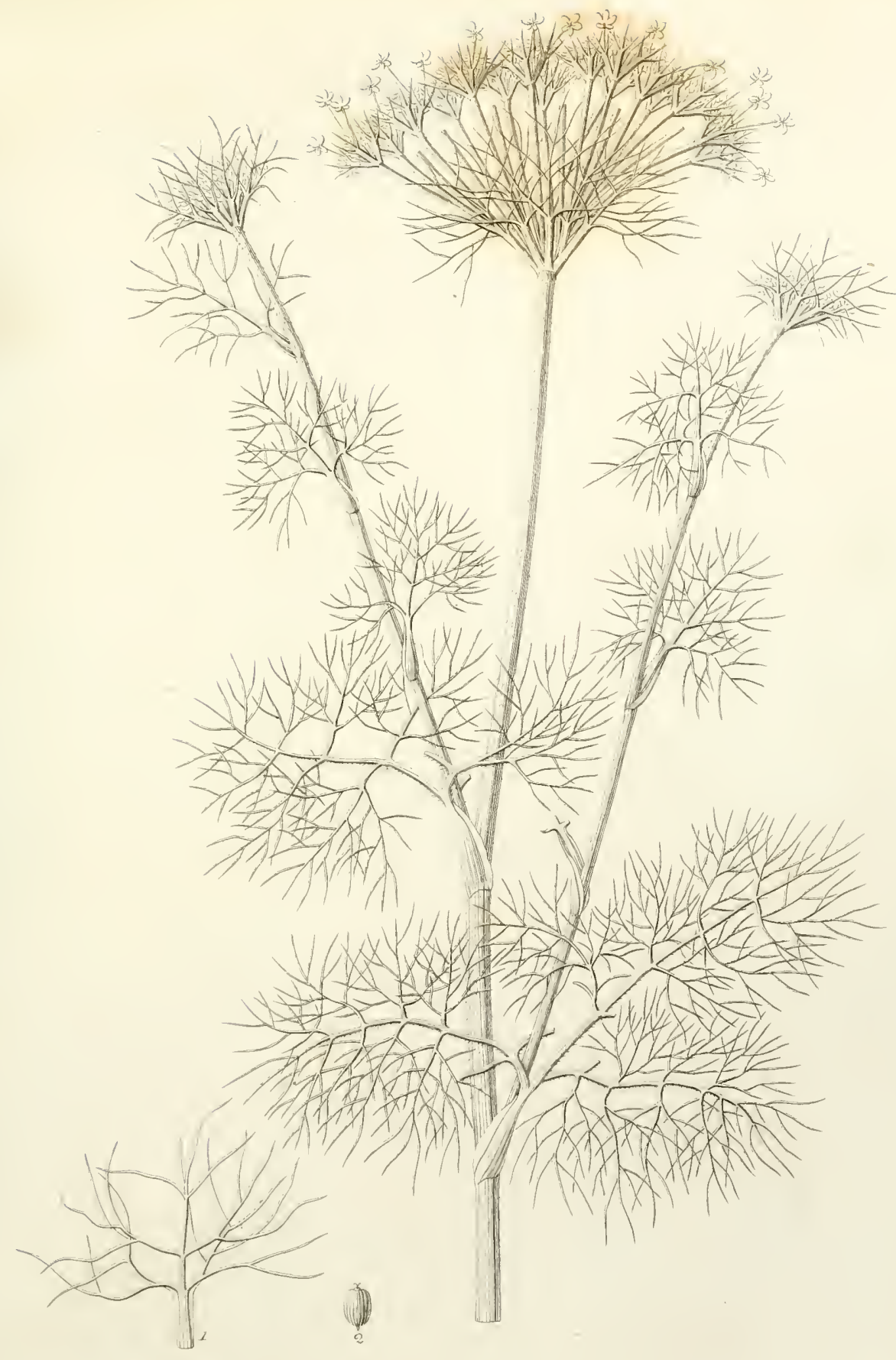





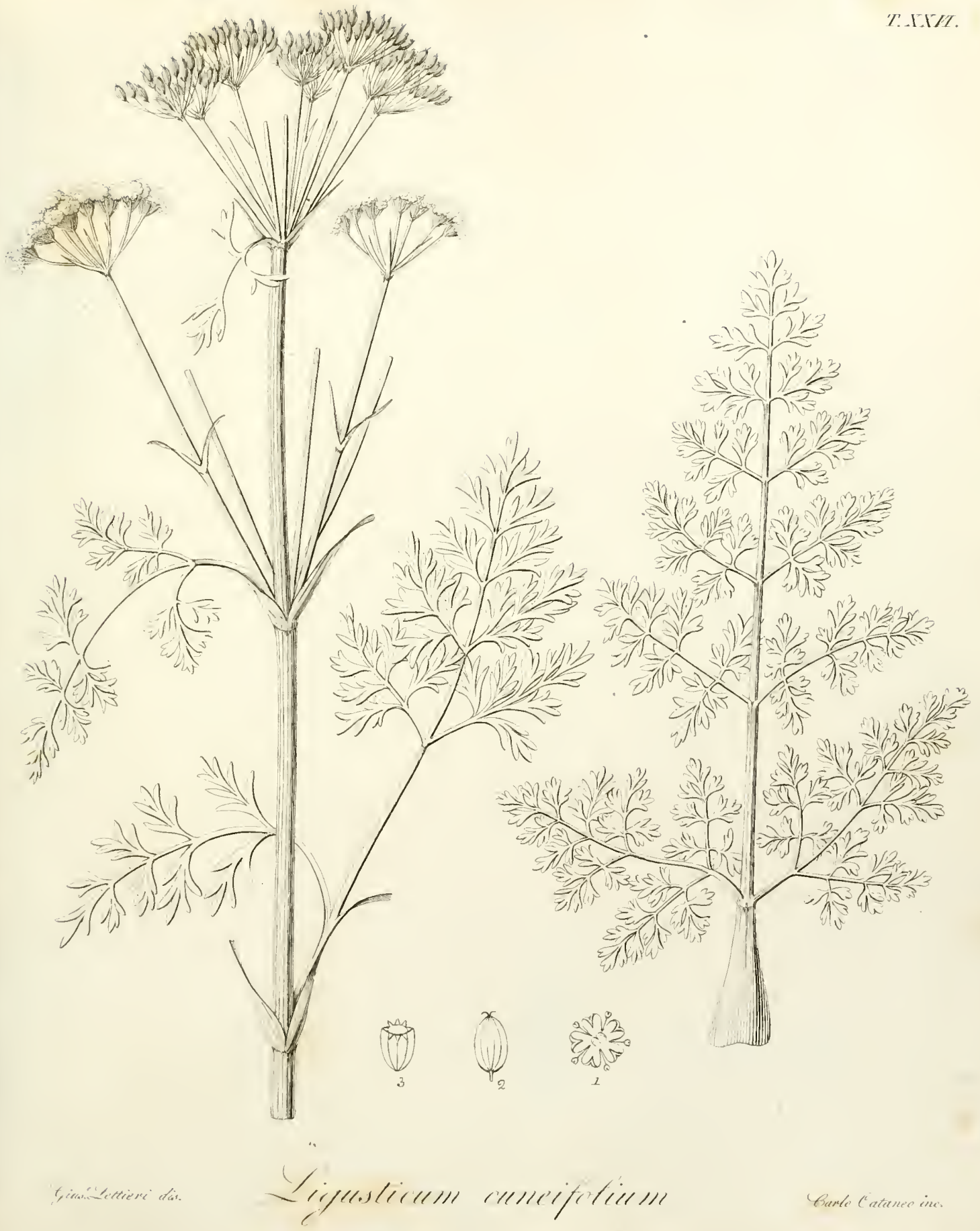





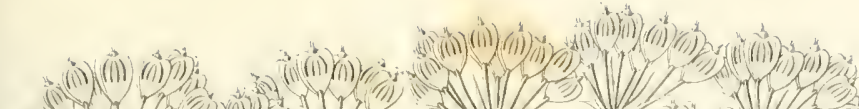
[5. $\pi$
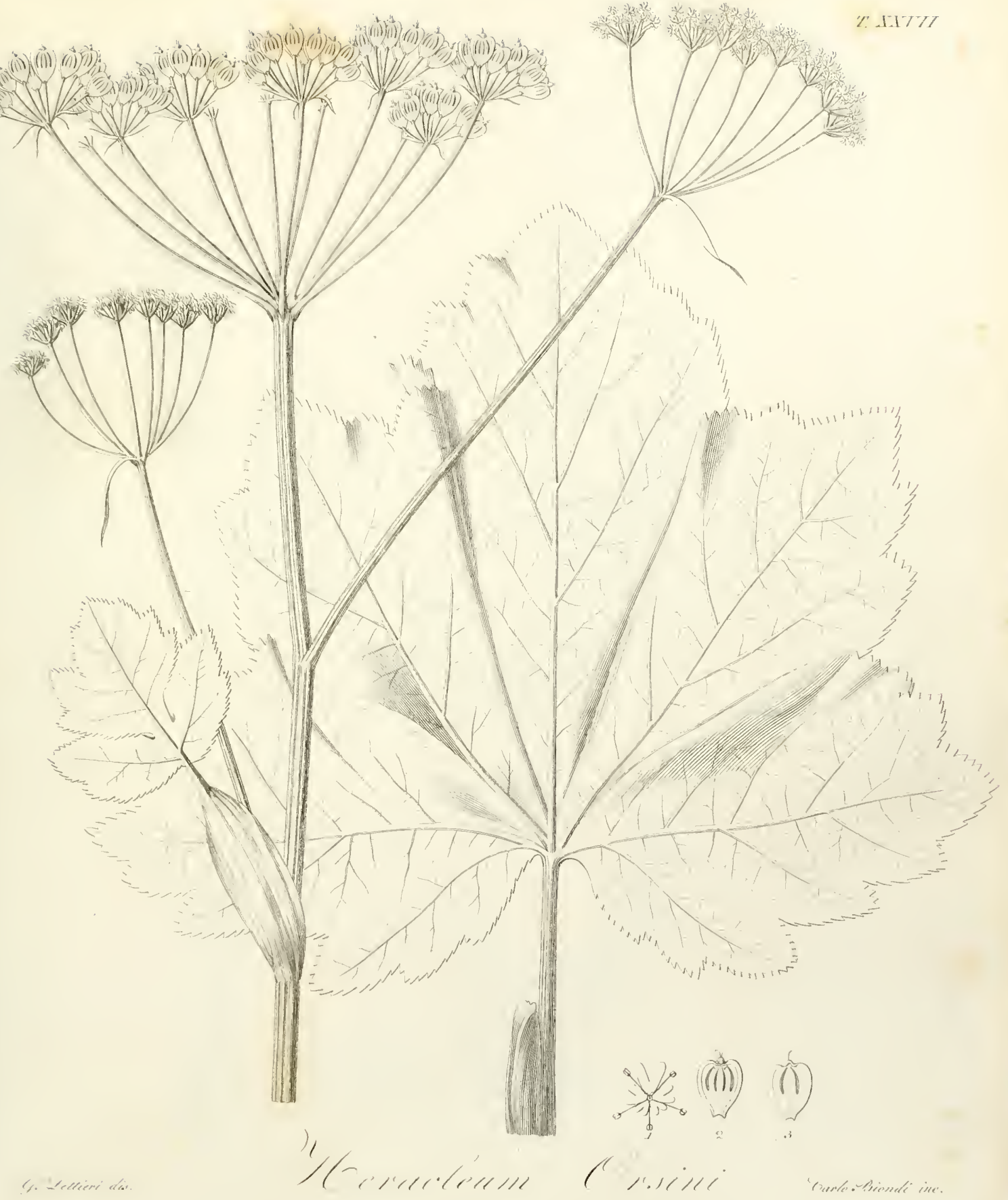
放

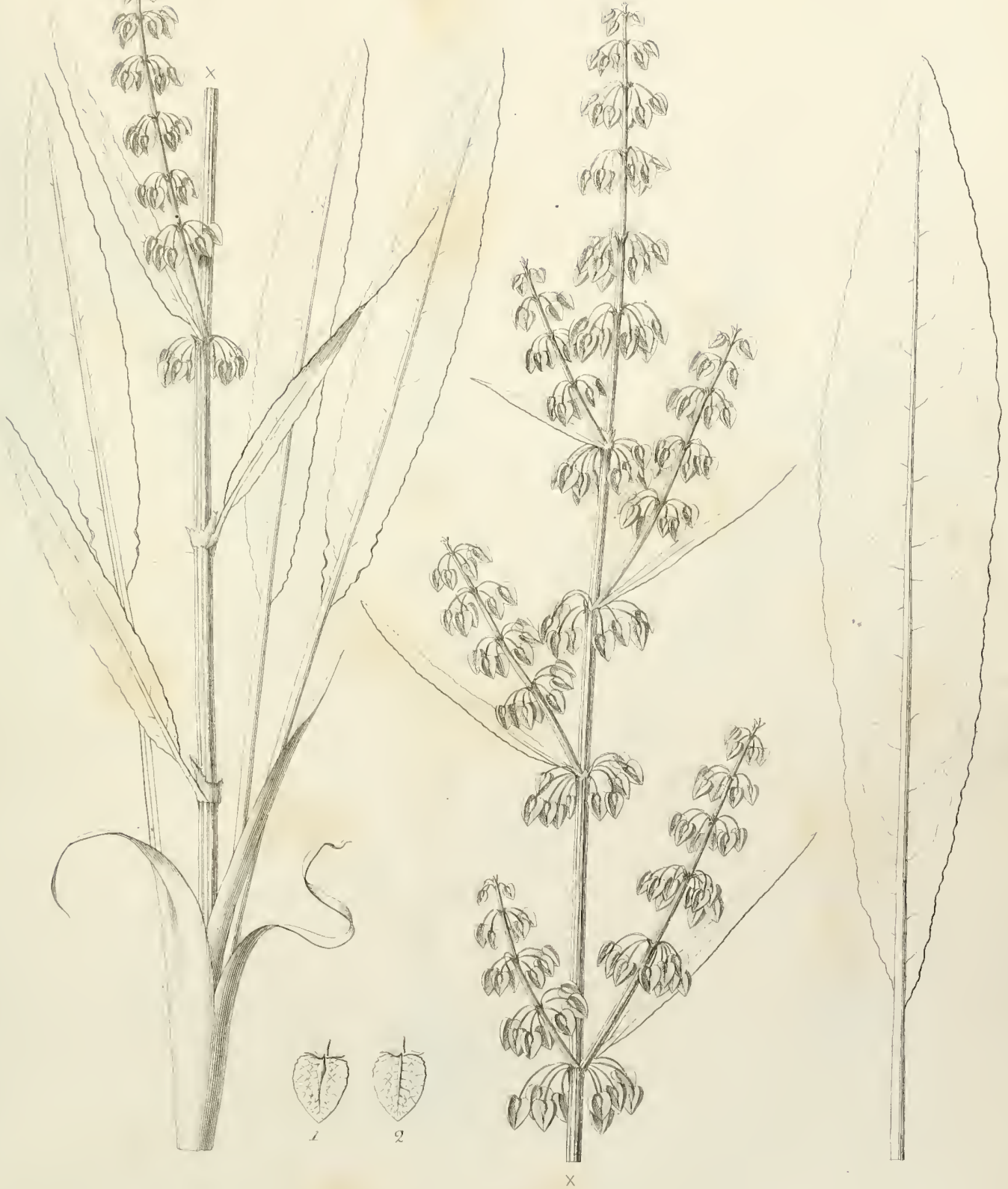


Y.LYXY.

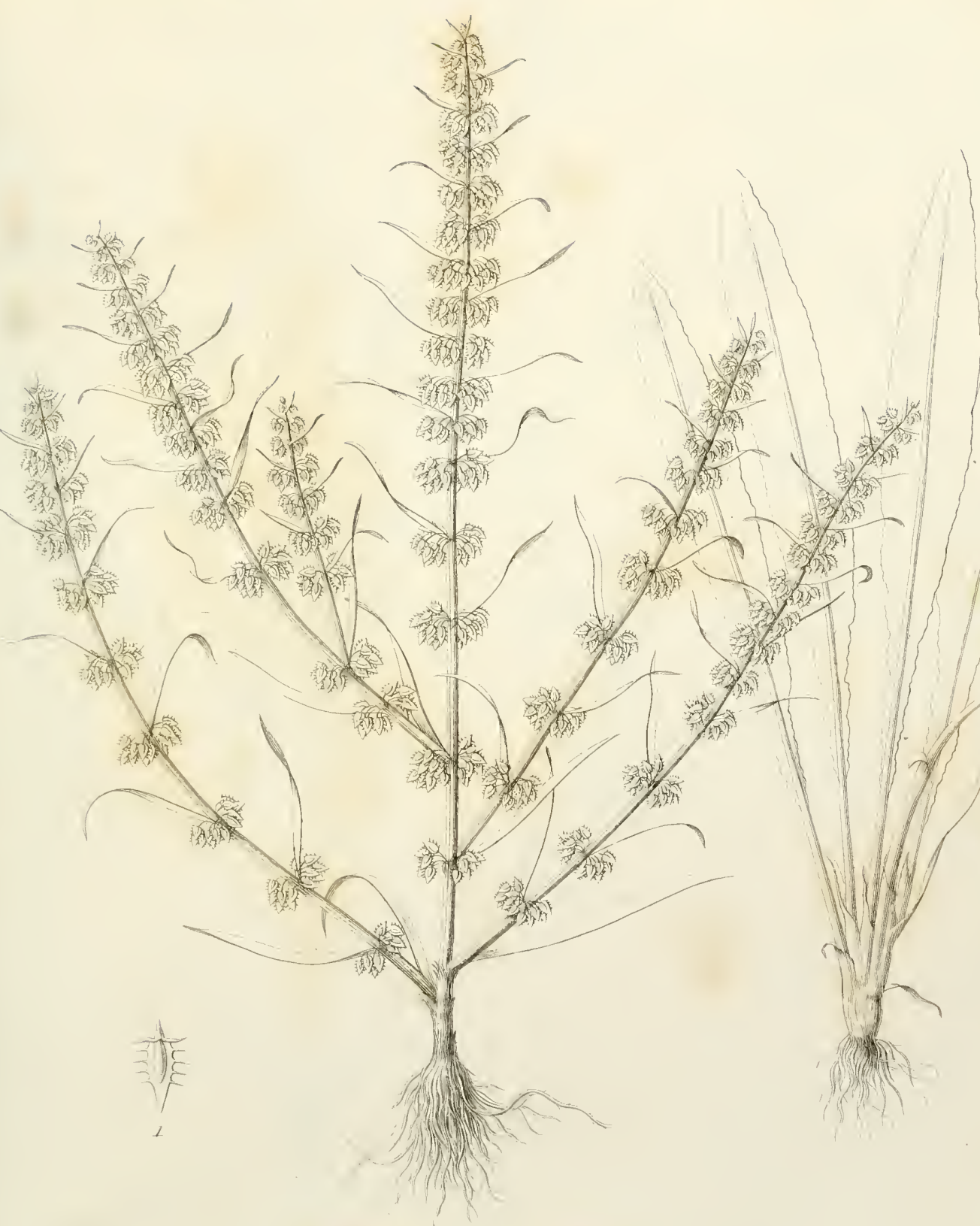

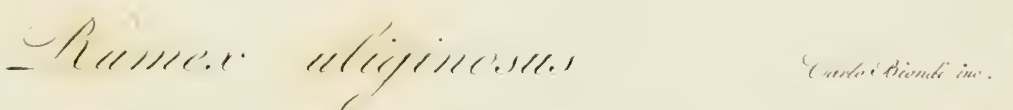




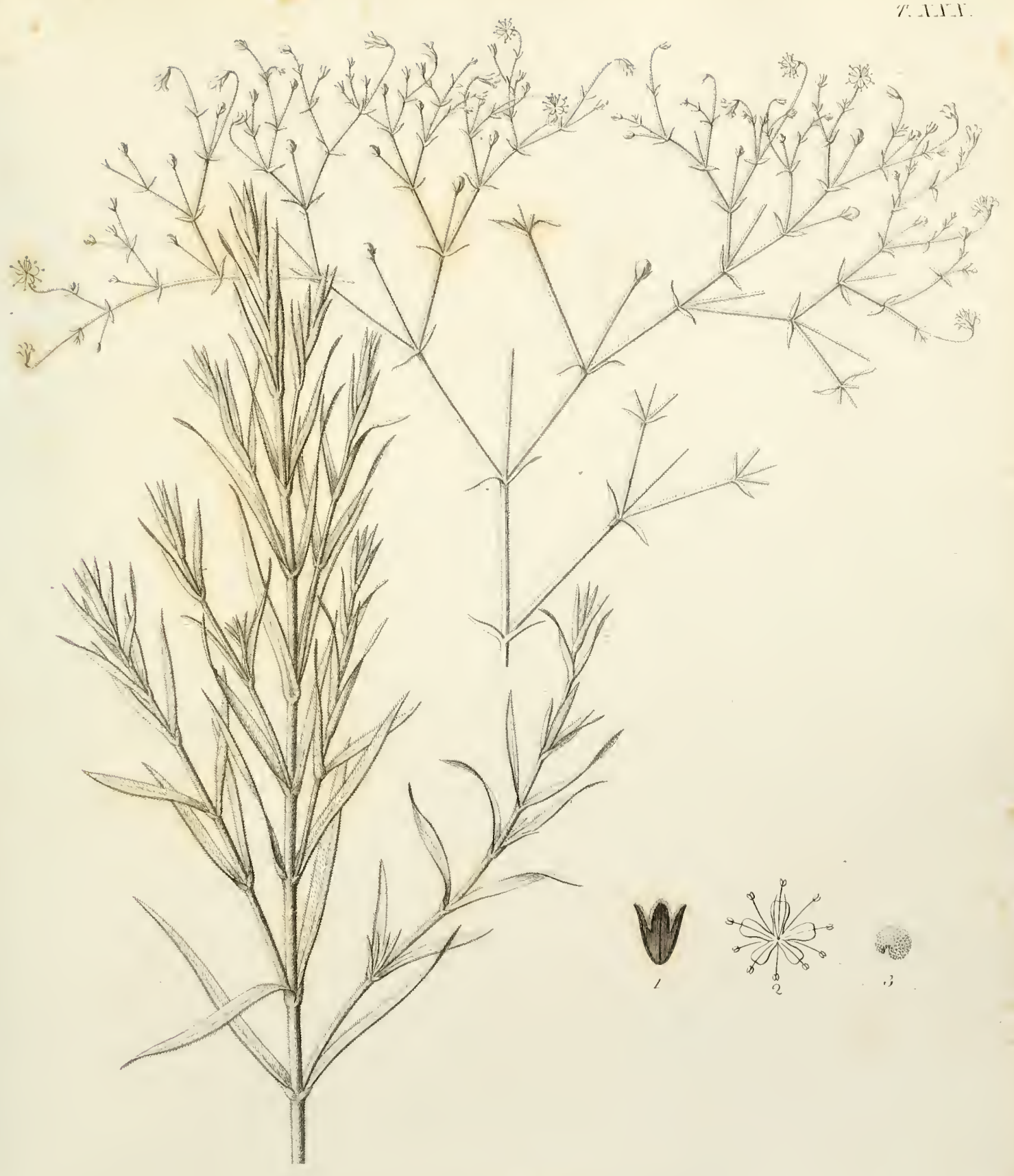

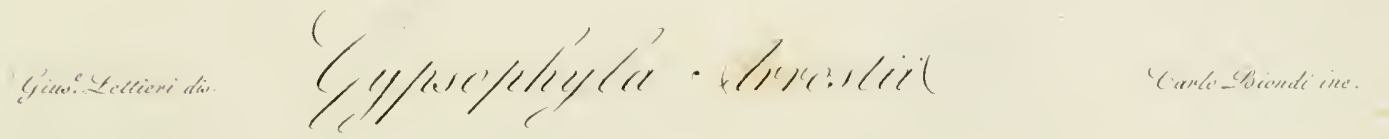



\% I.YT

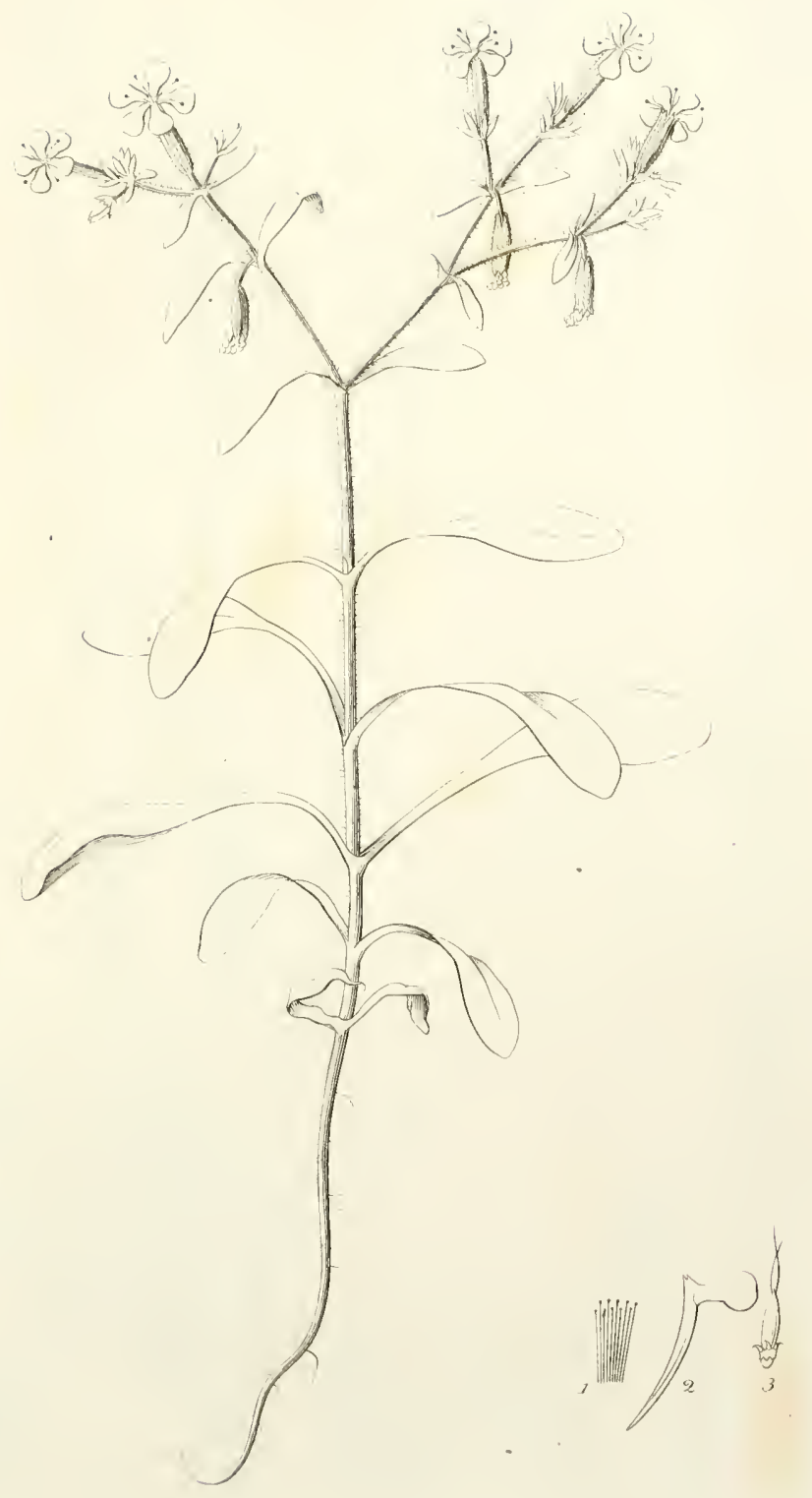

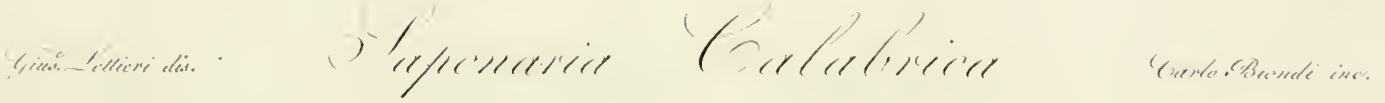




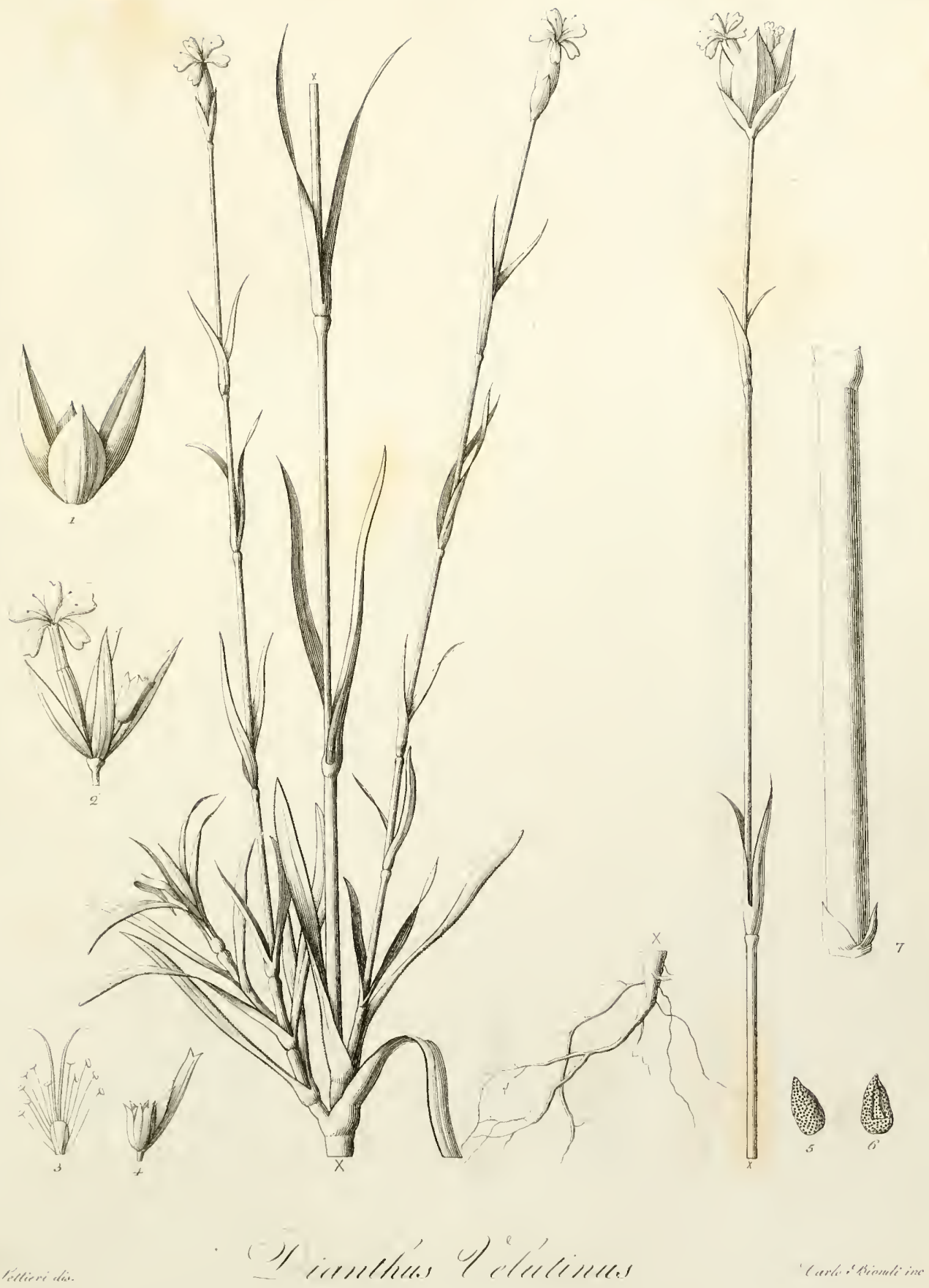


\%:XXY/I.

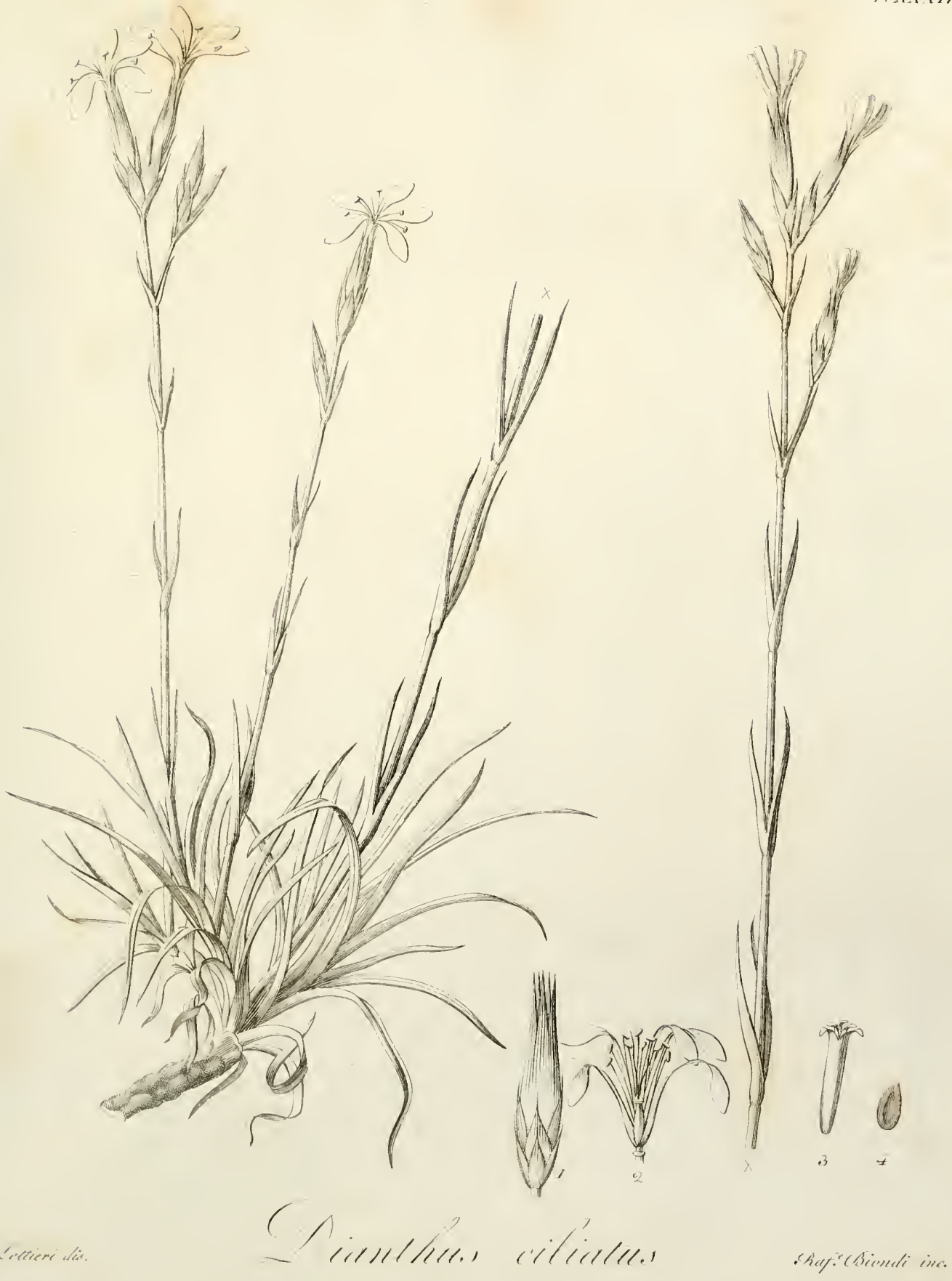


. 


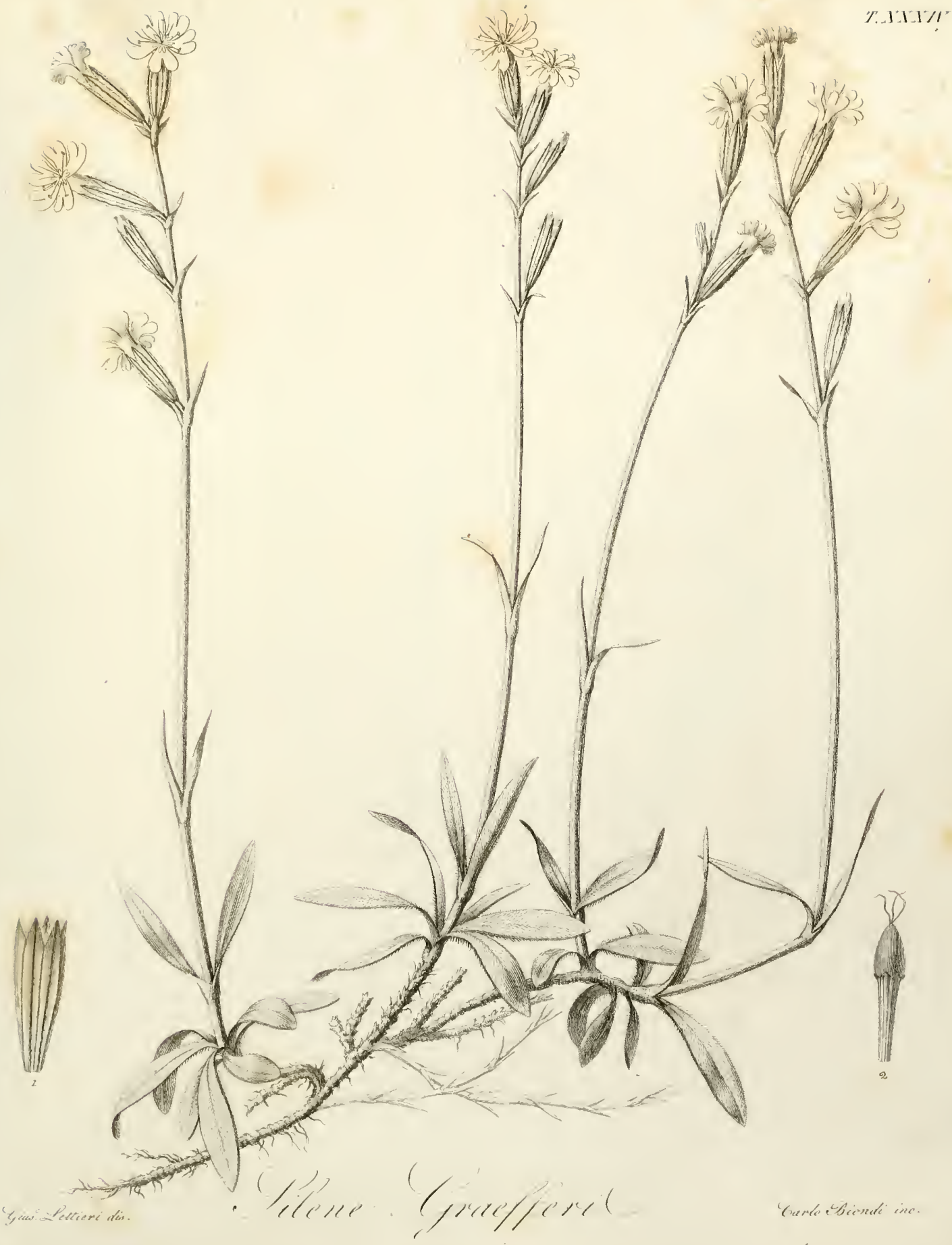




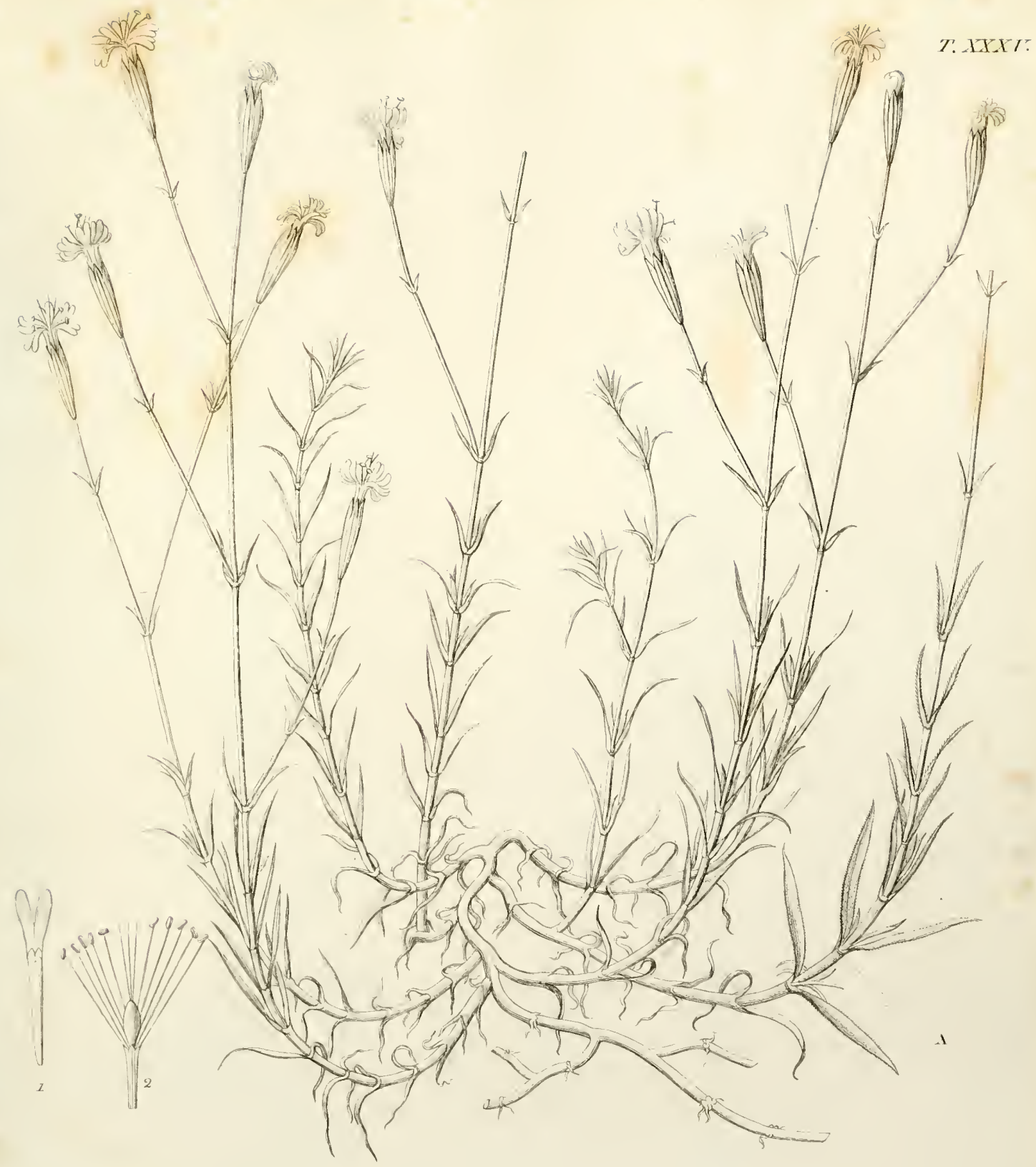

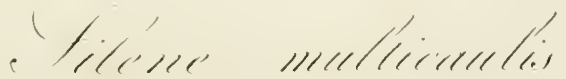





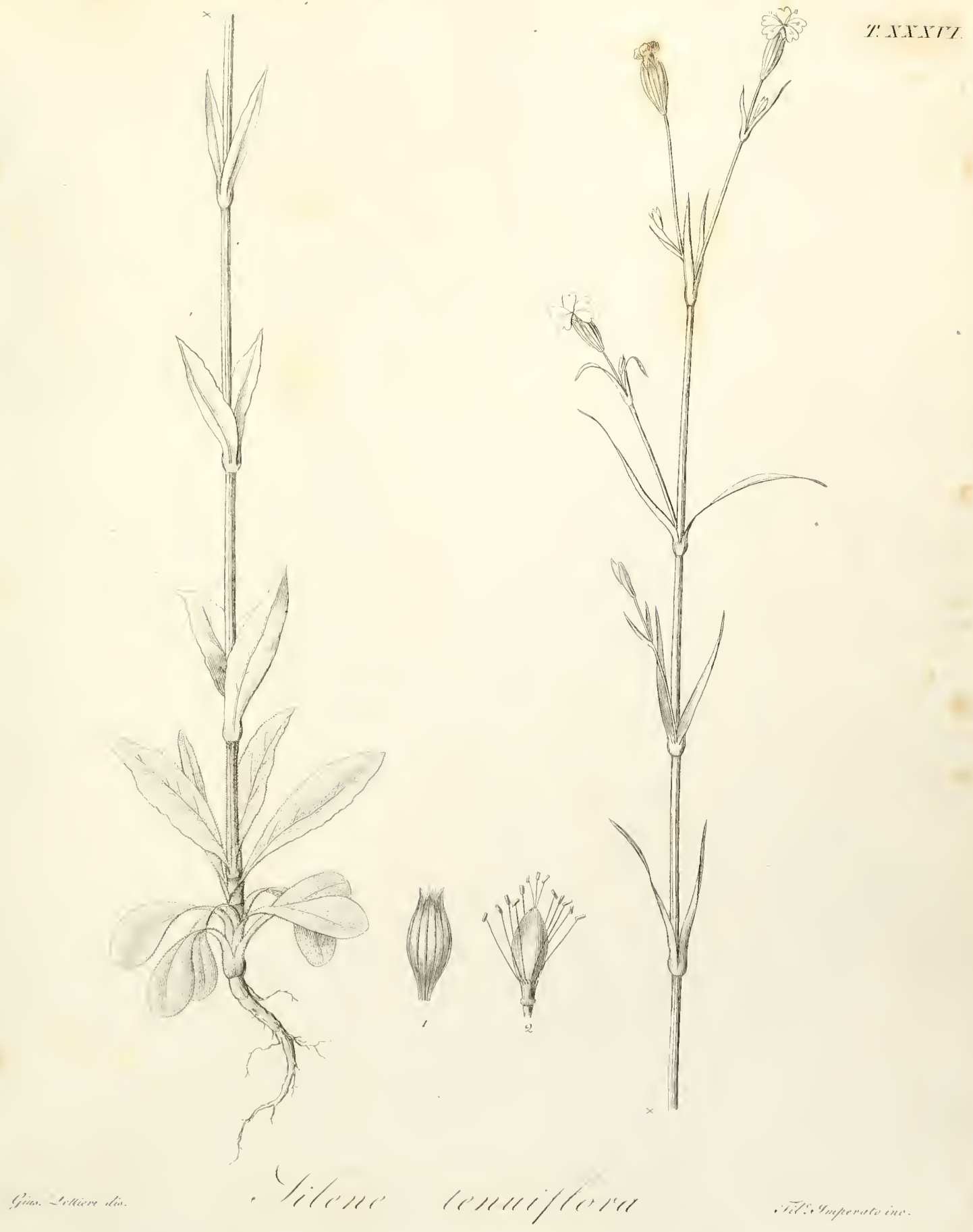




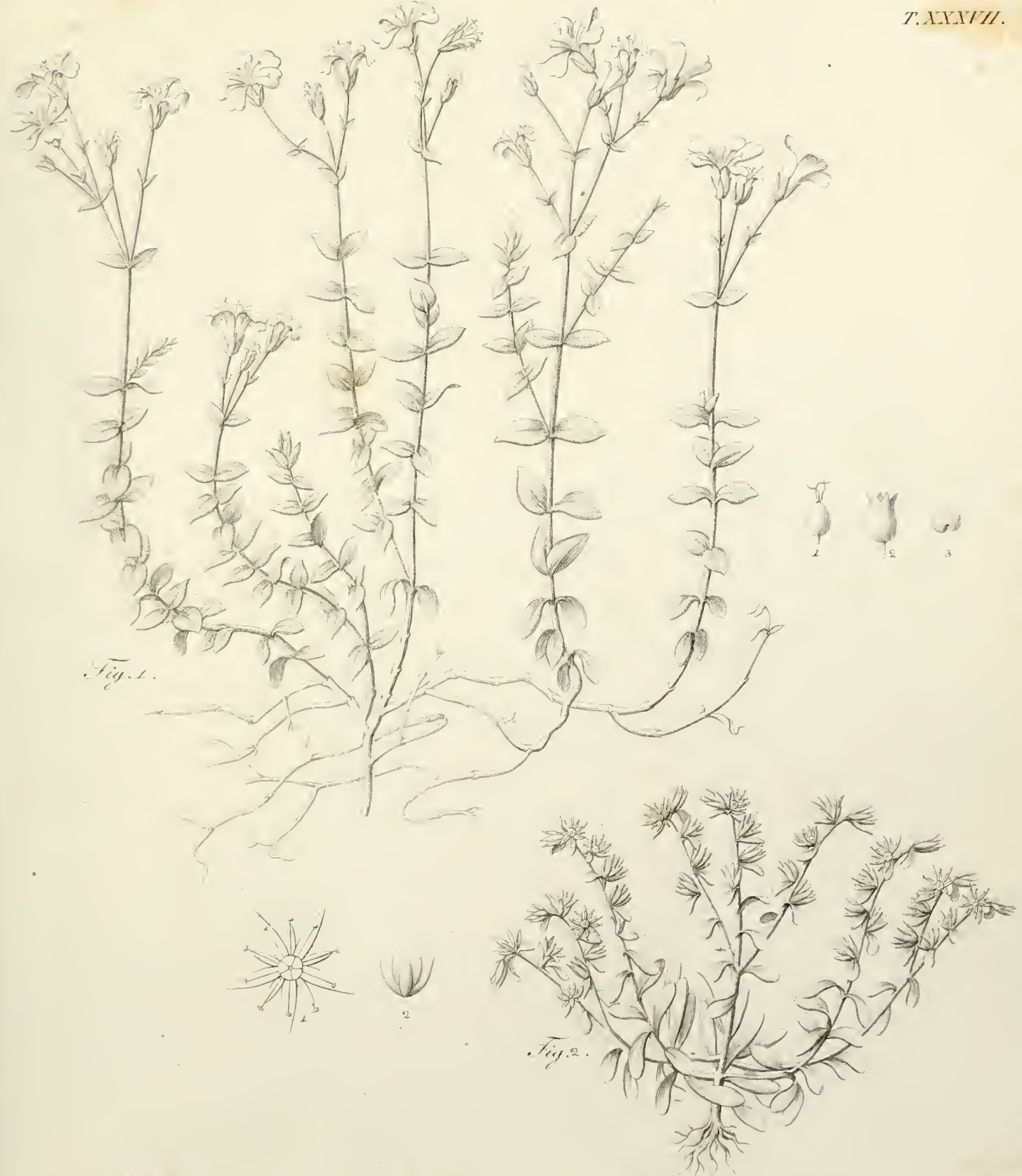

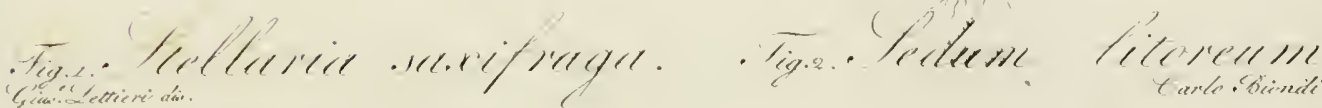




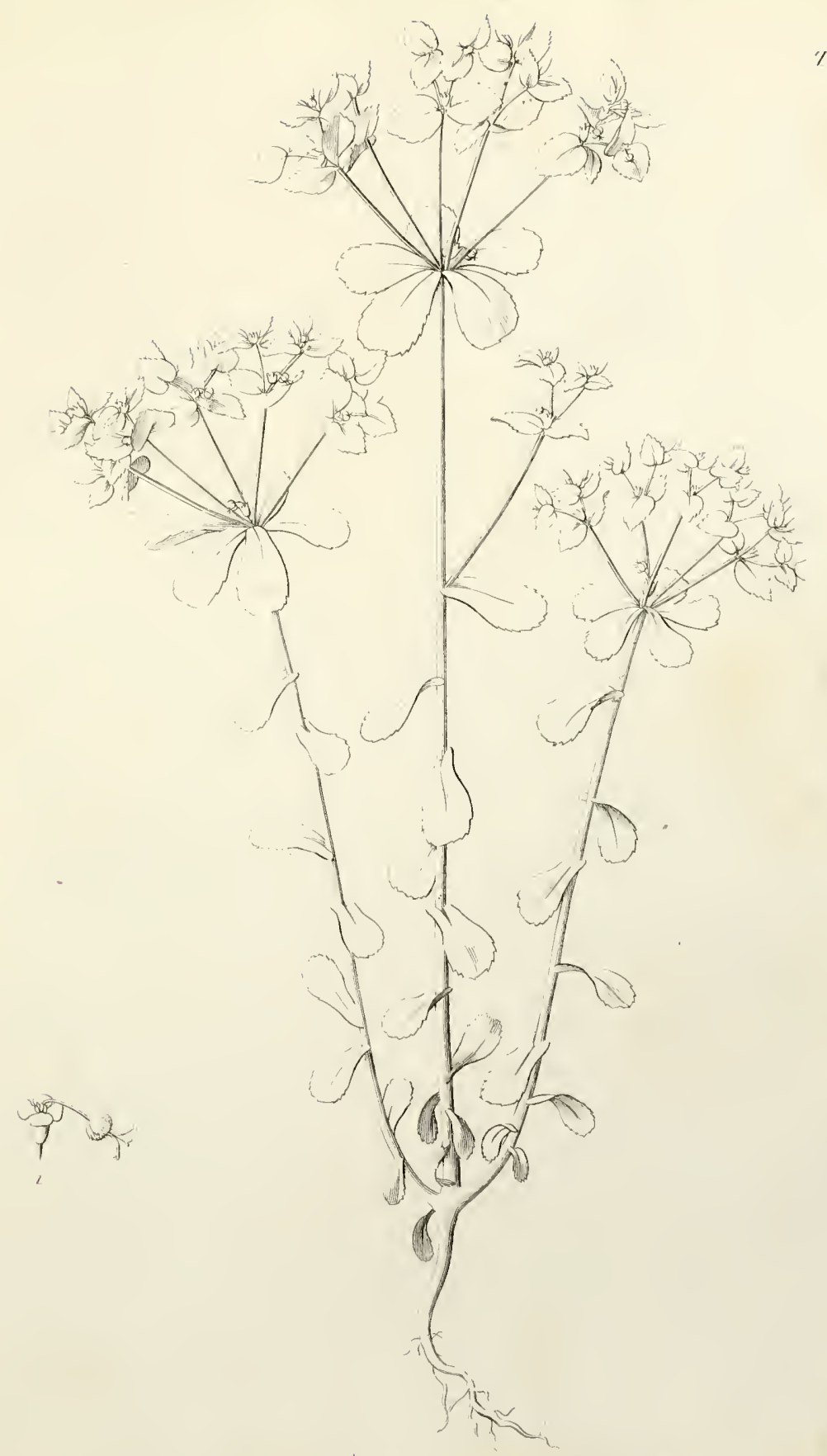

". IXX/III 


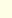



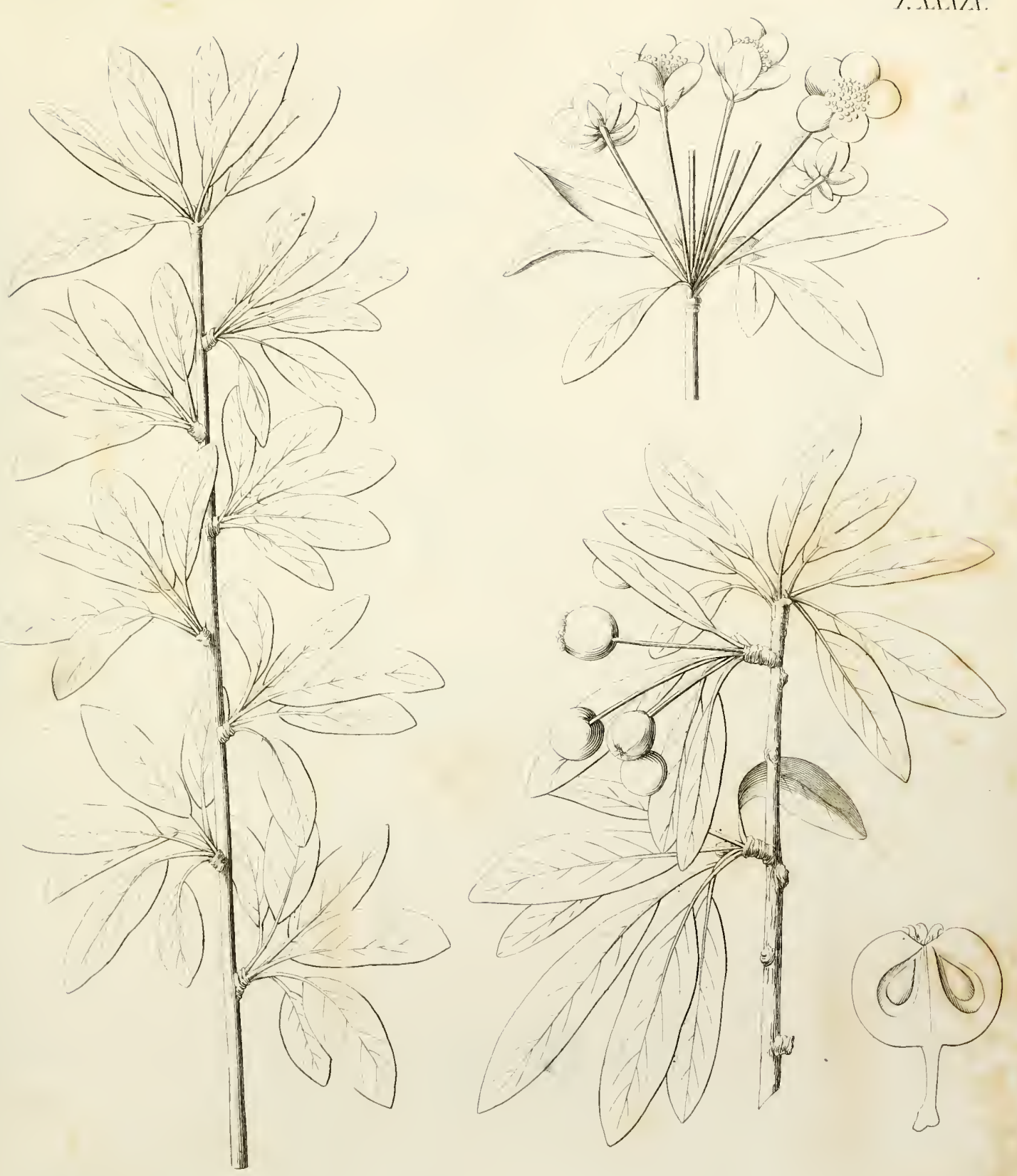

Yimontertiers dis

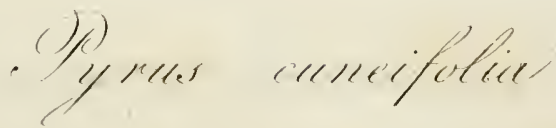

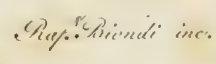



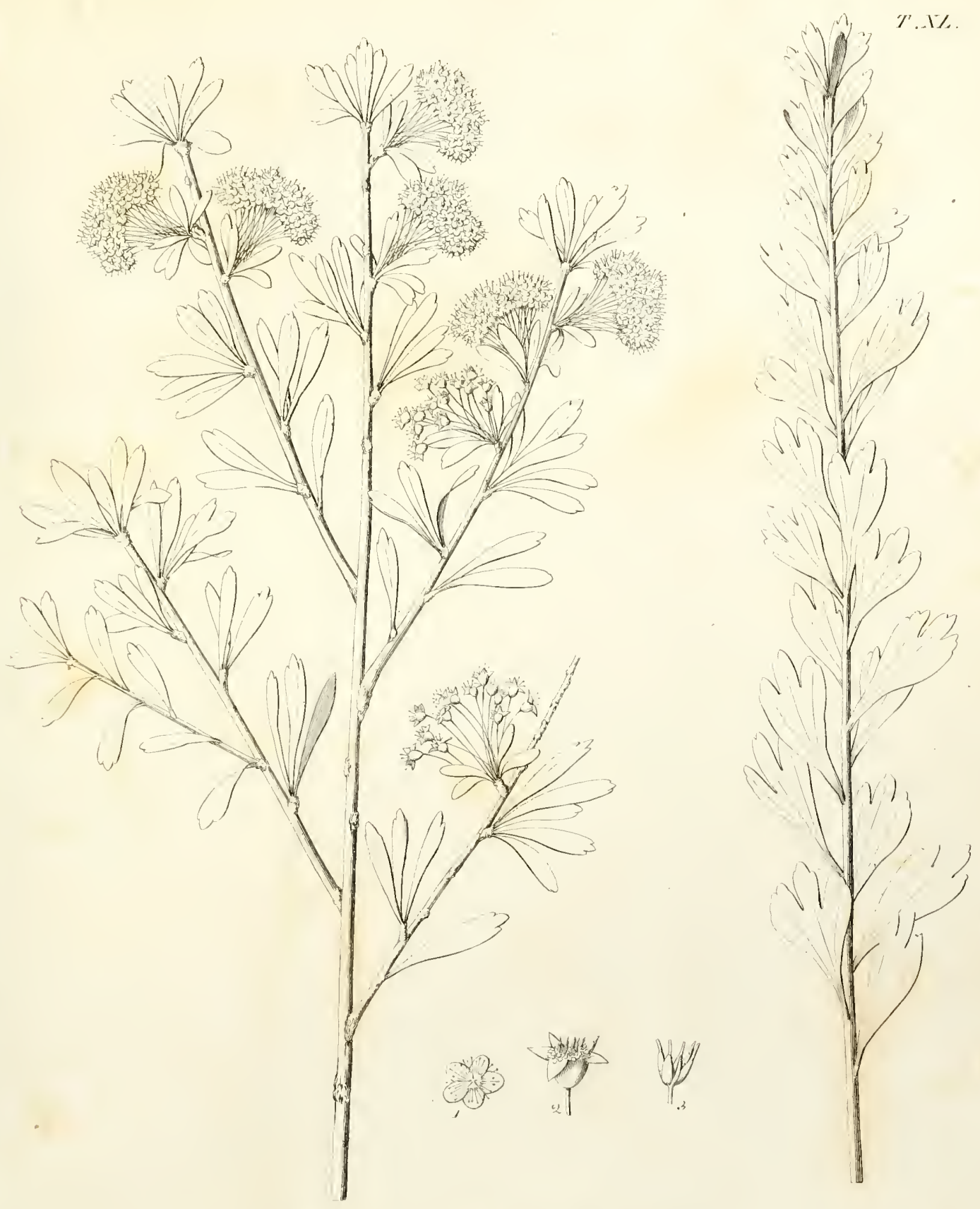

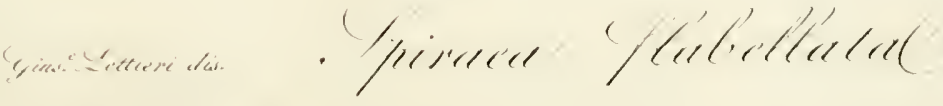

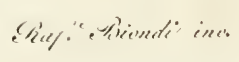




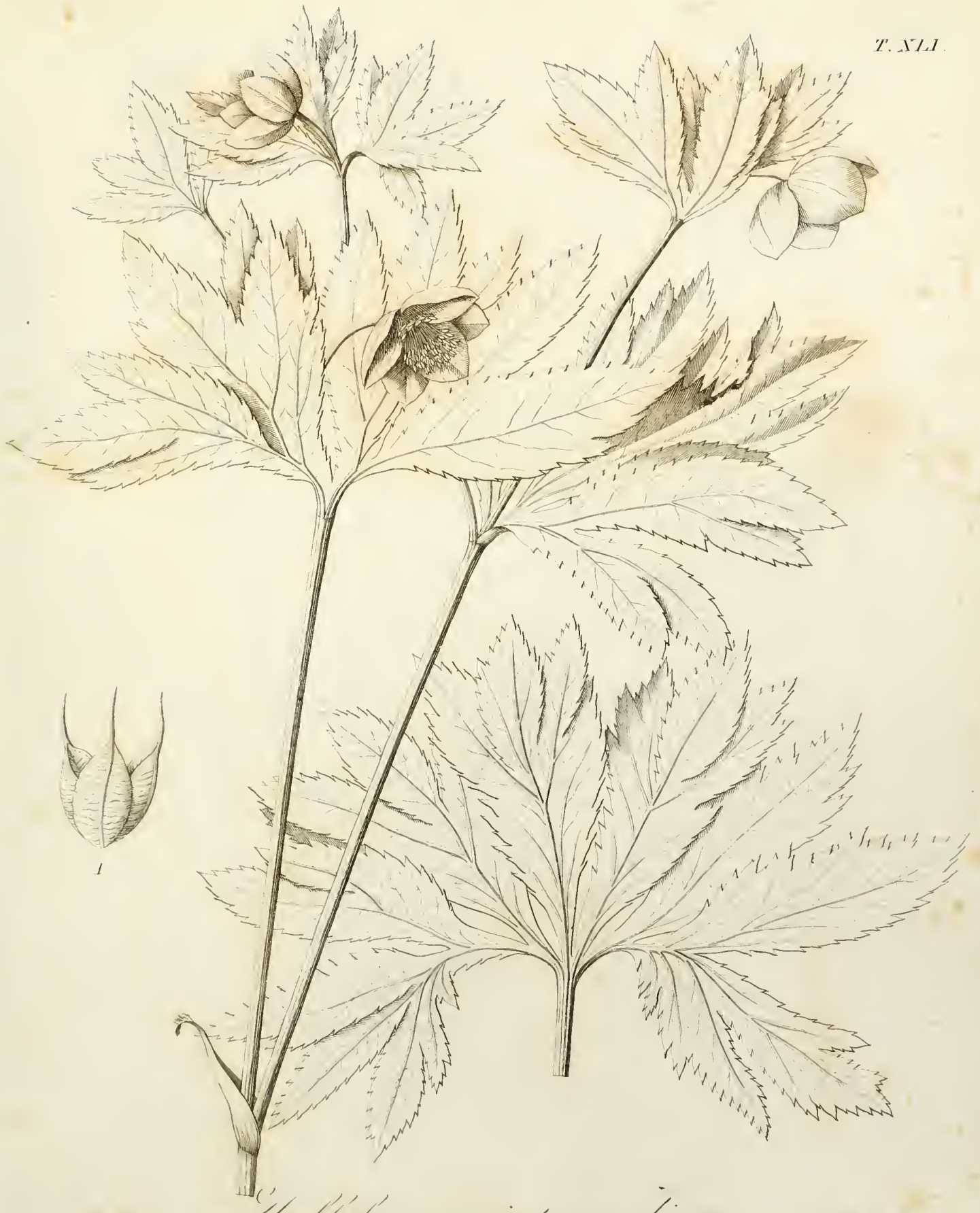

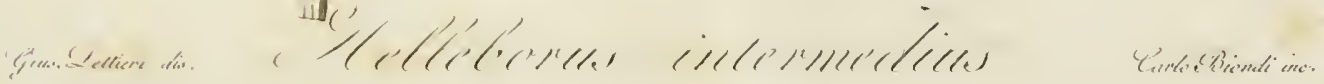


. 


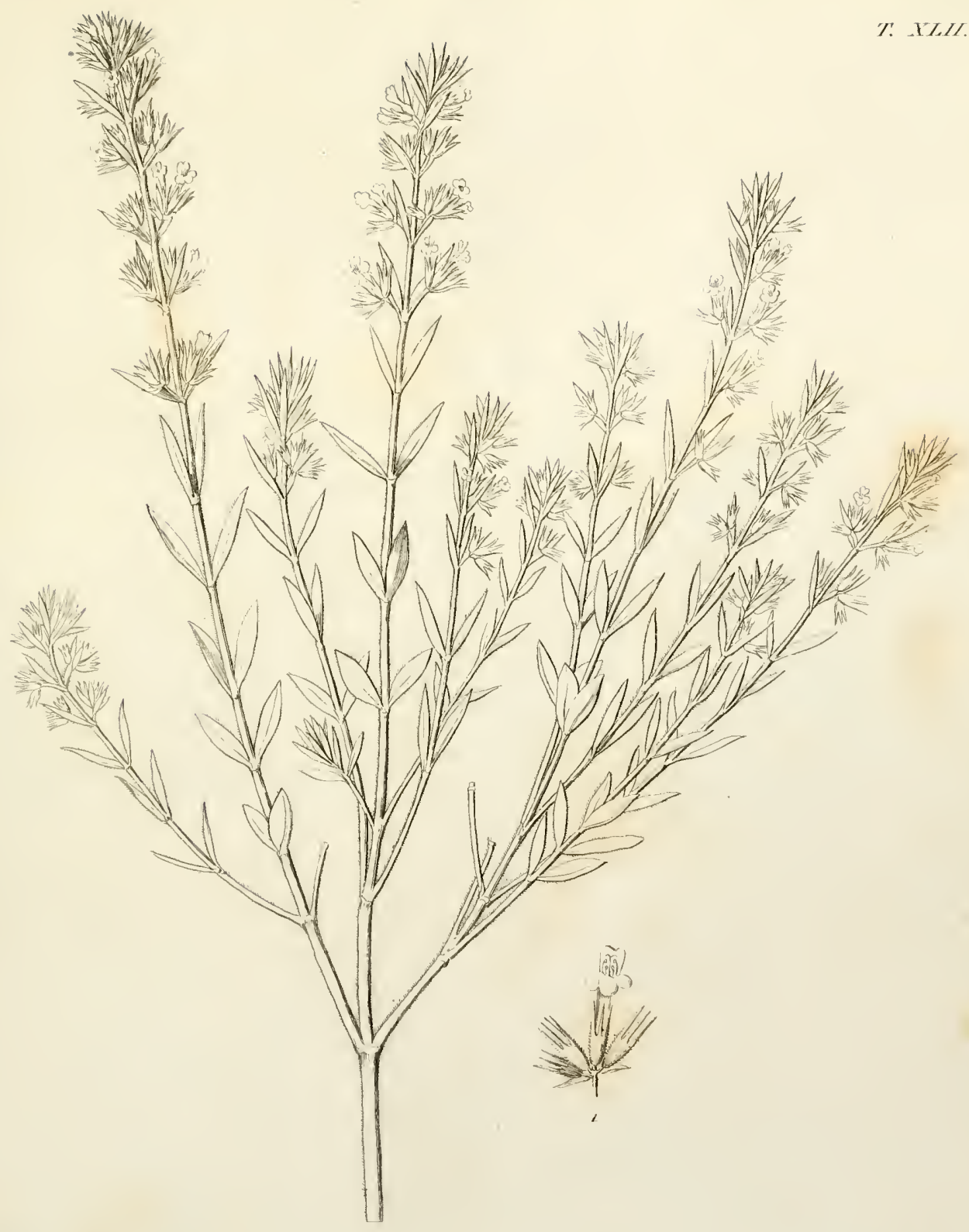

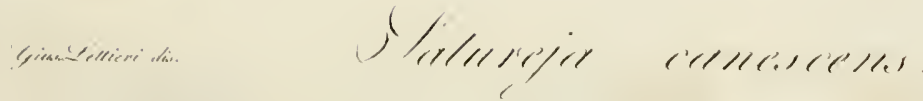


. 


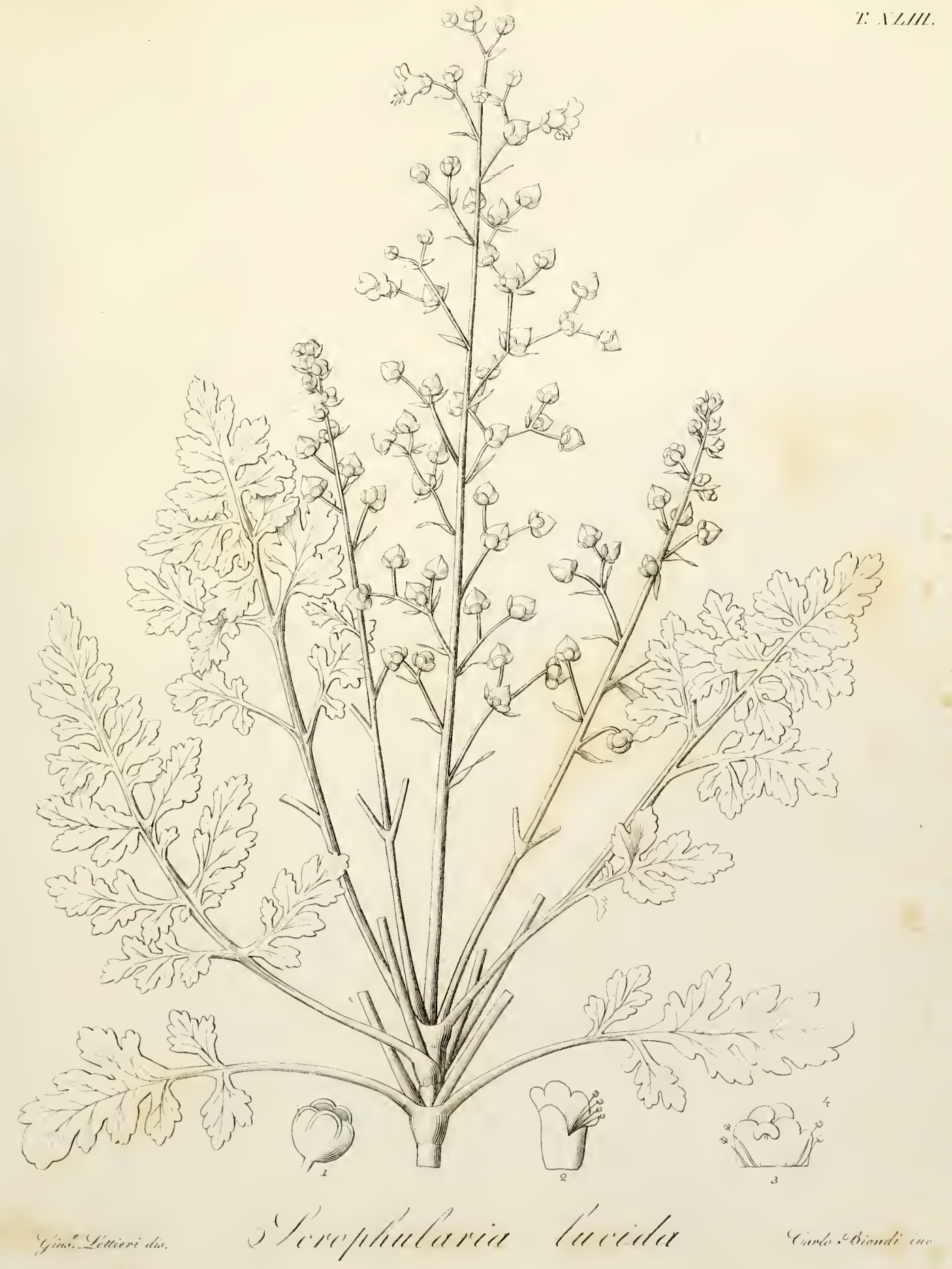




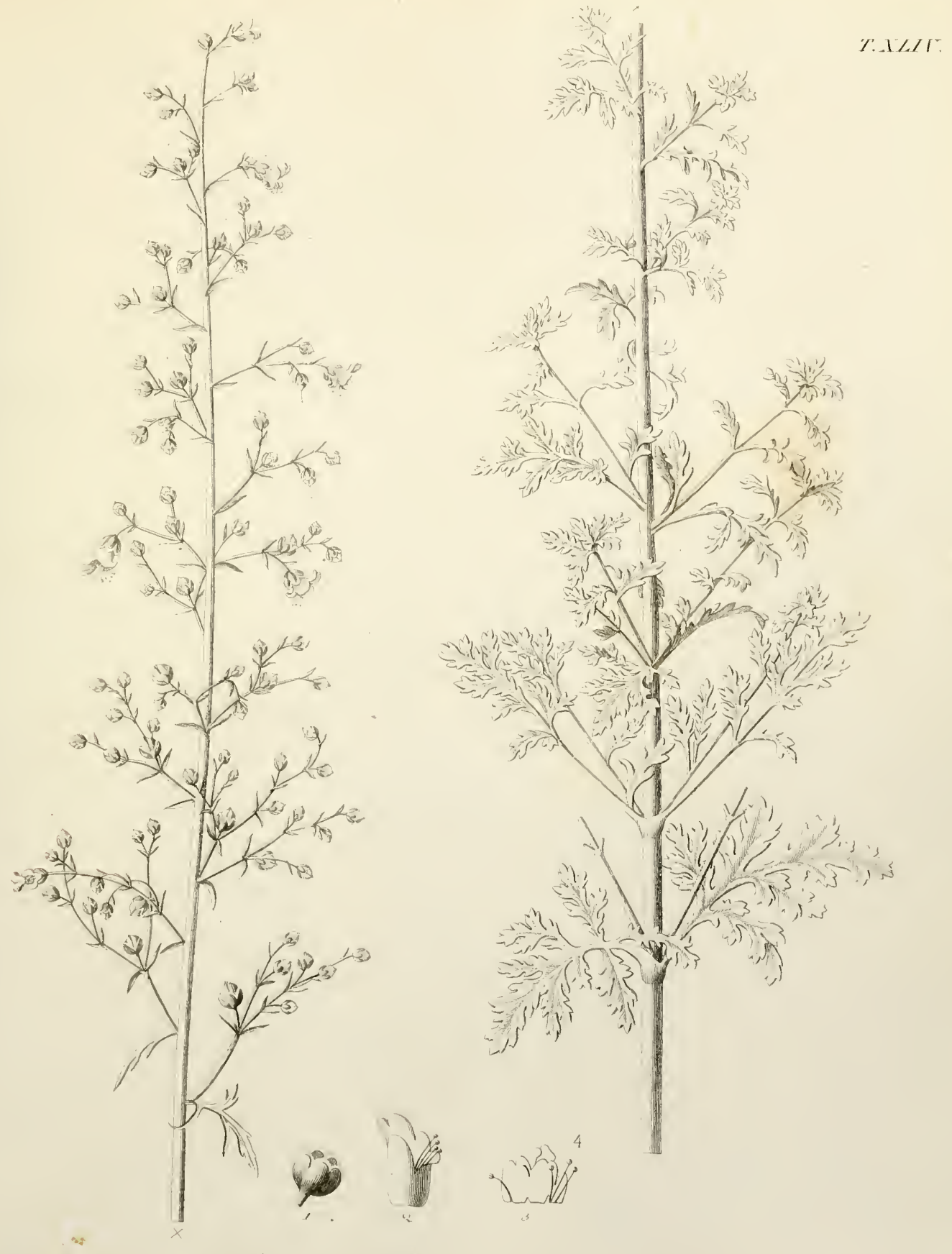

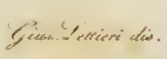

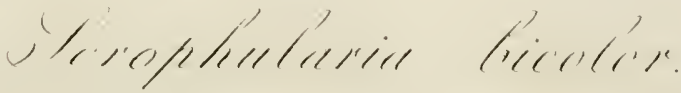

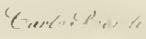





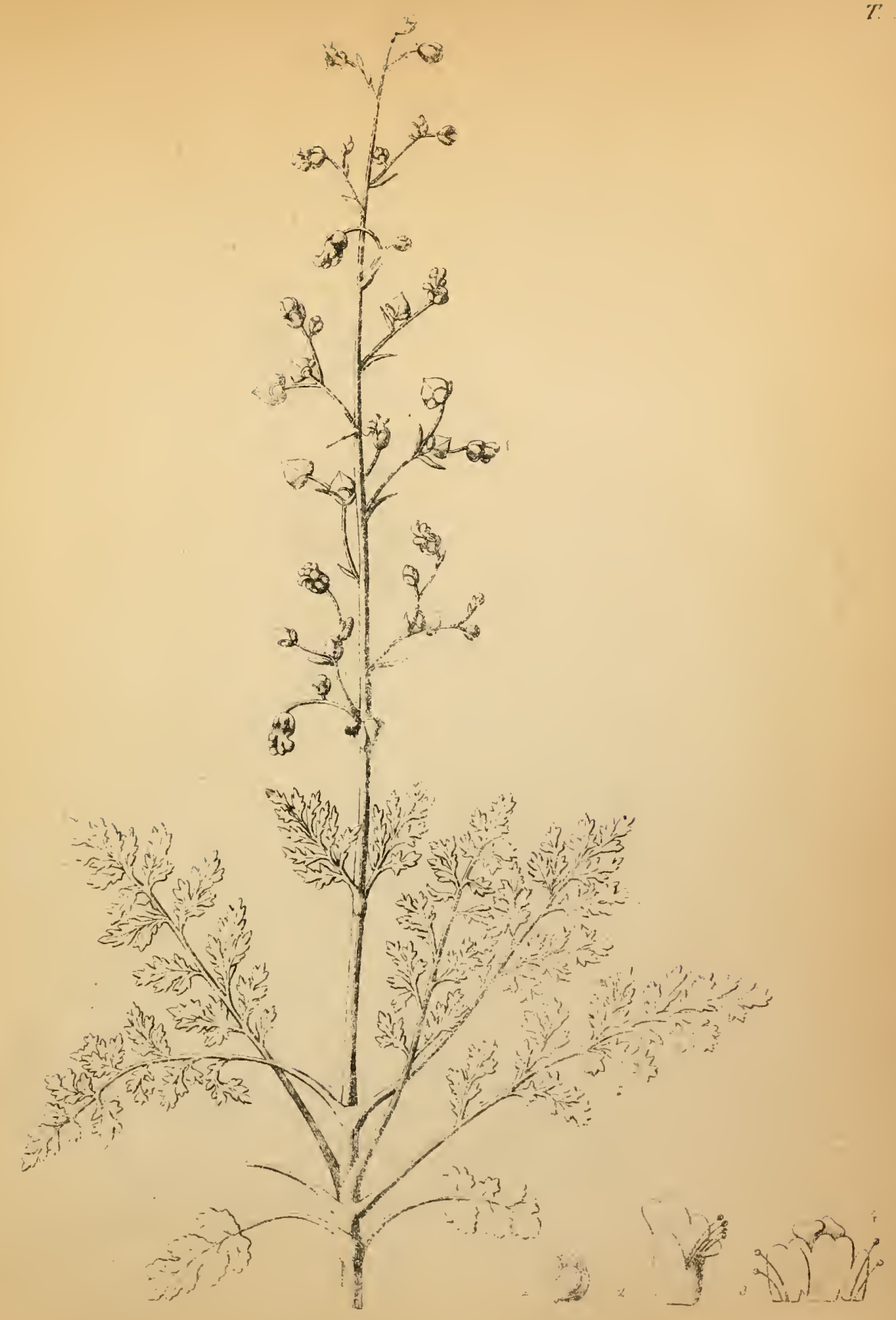

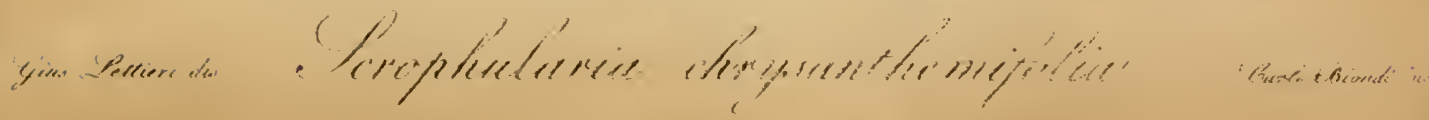





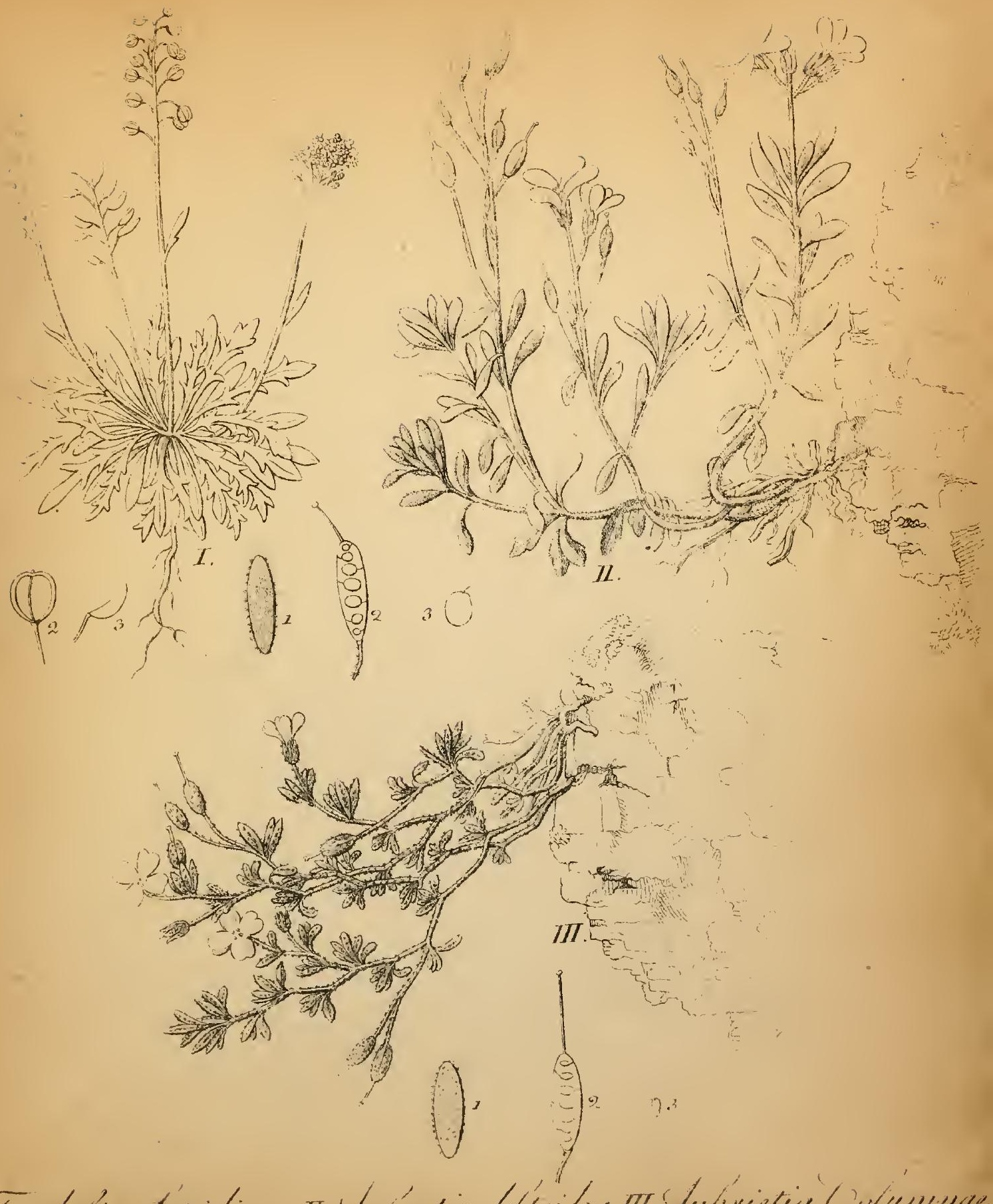

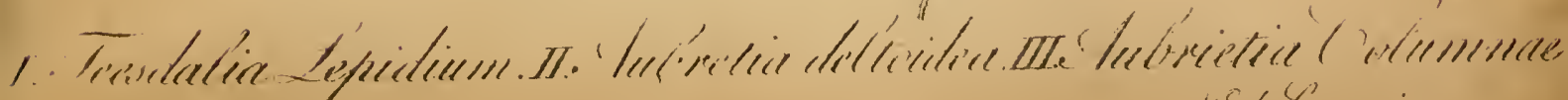

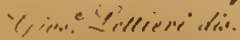



\%: . $13.1 \%$

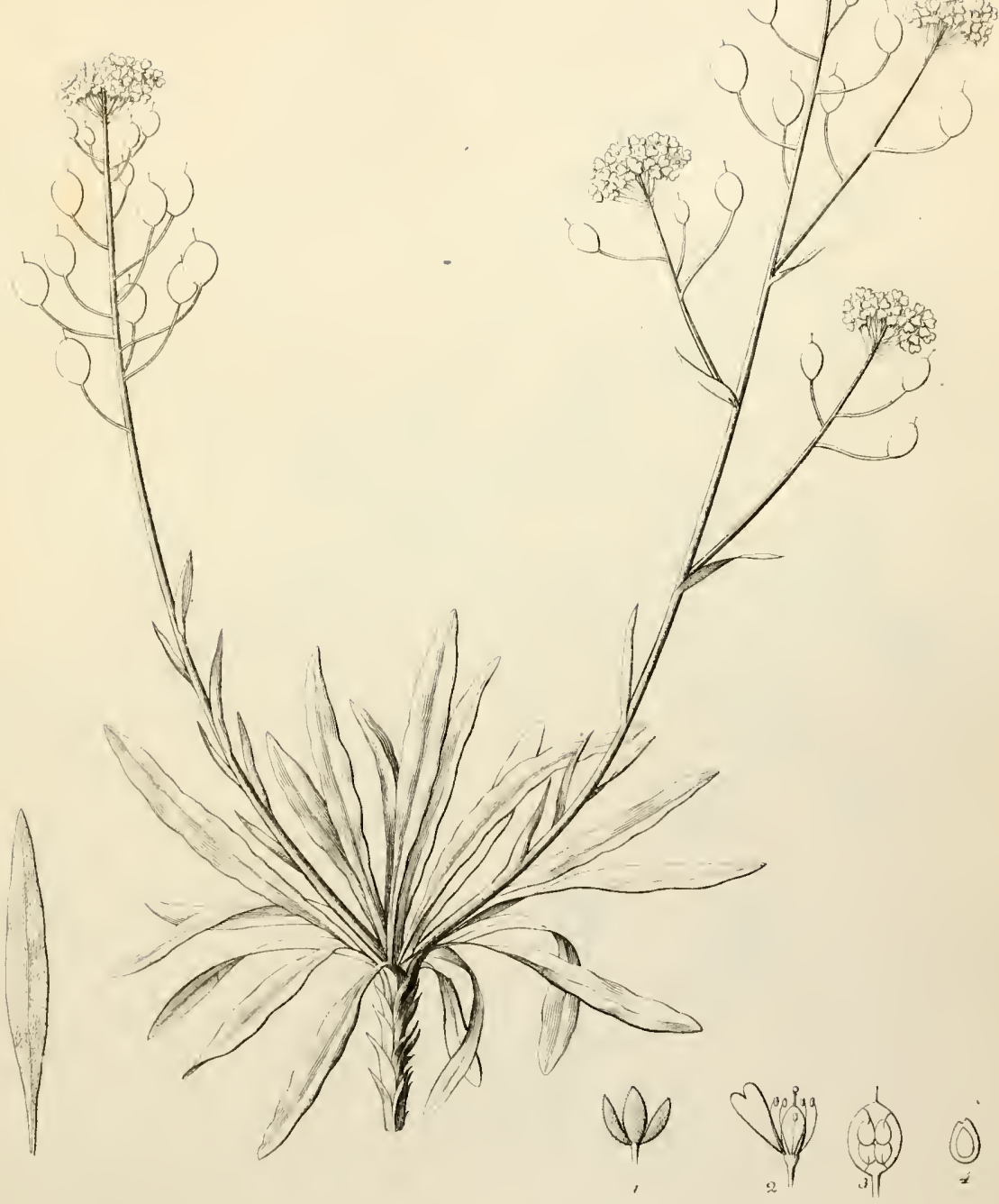

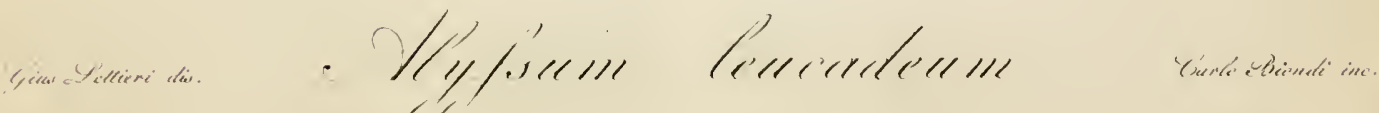


7. IJIJ

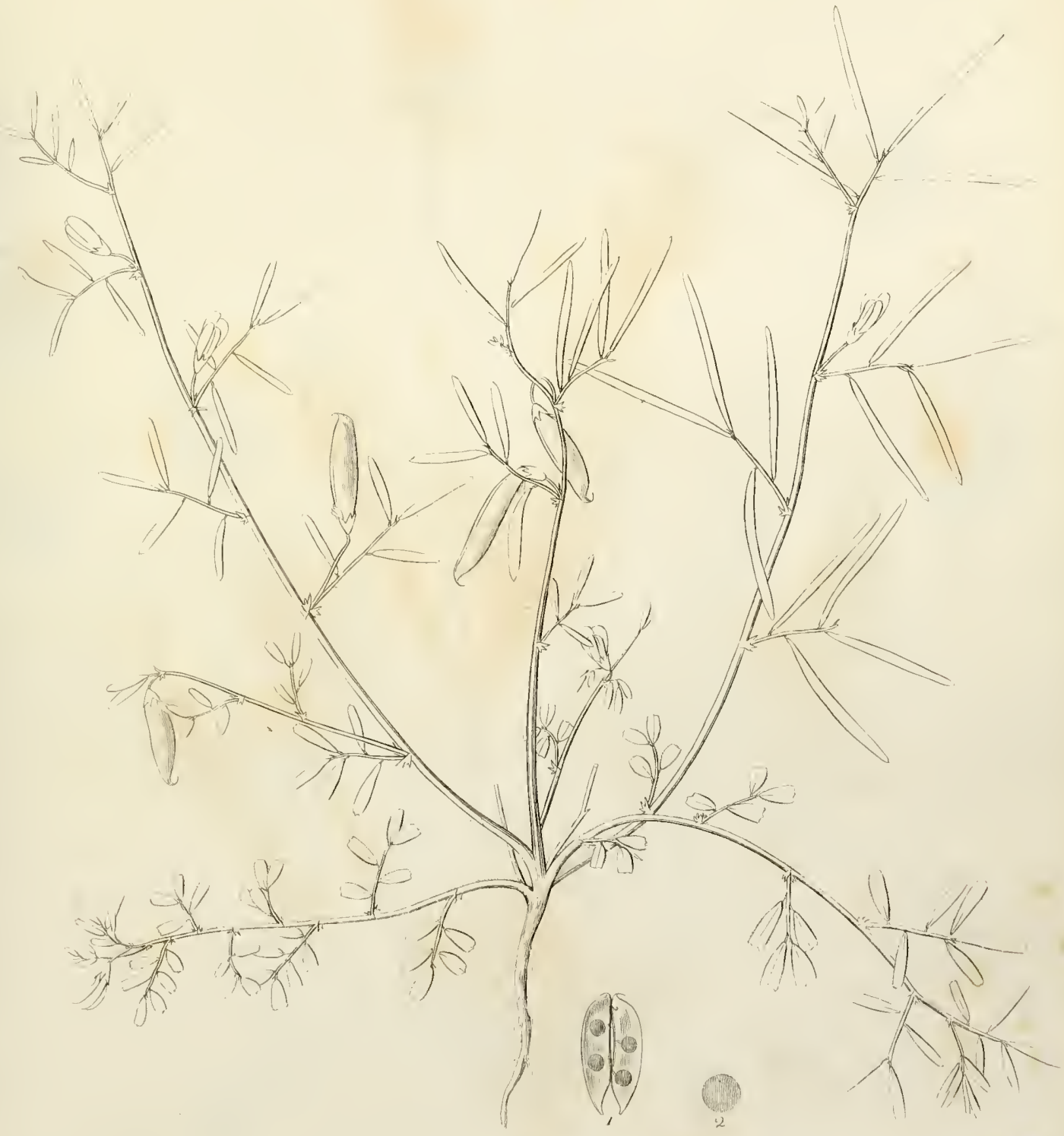

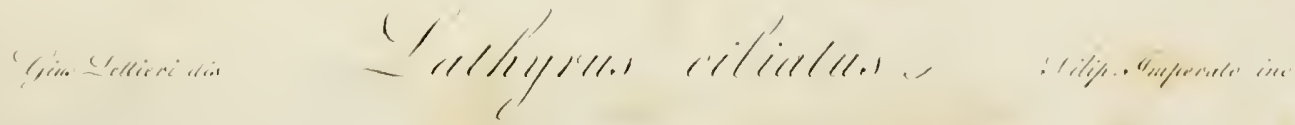





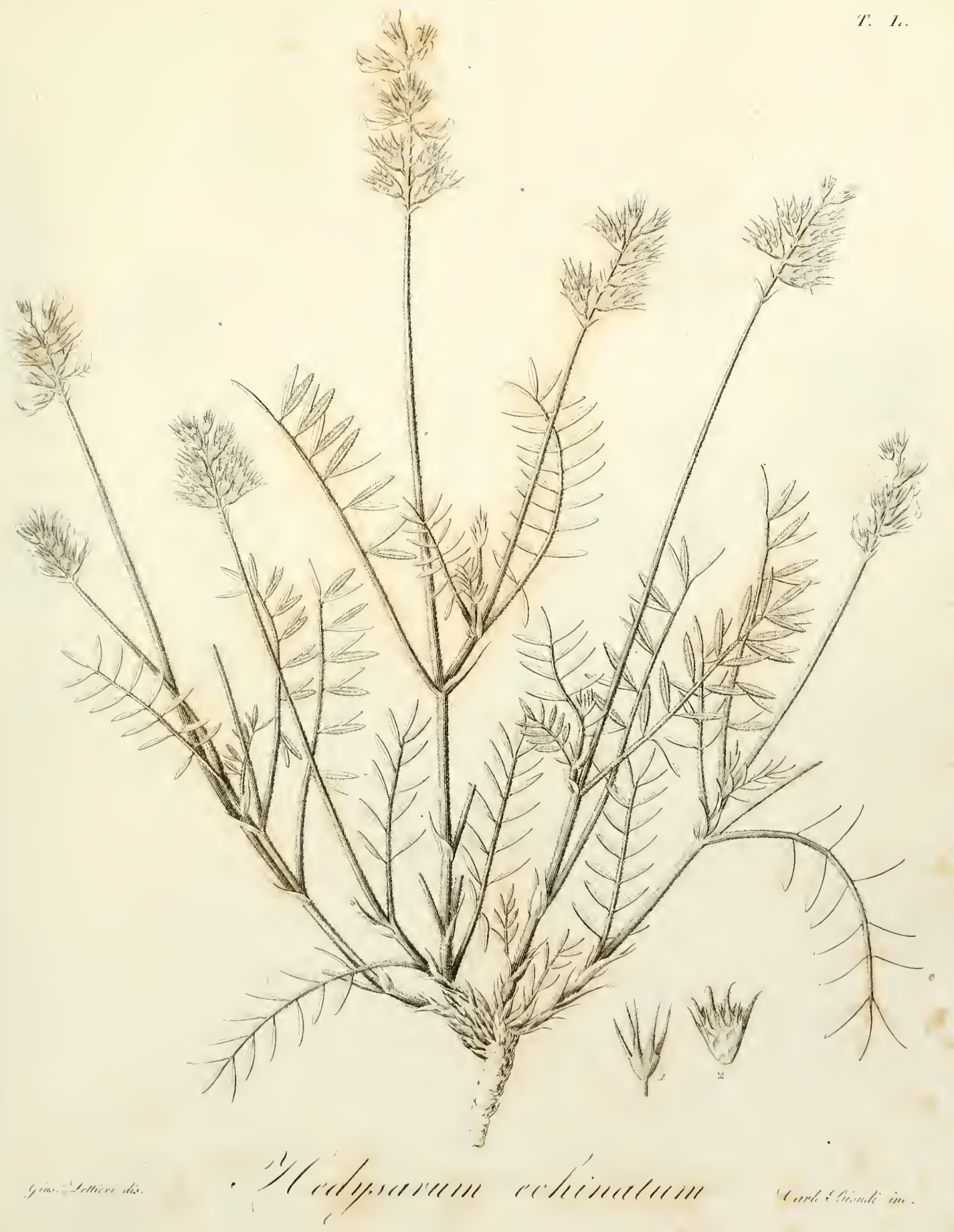





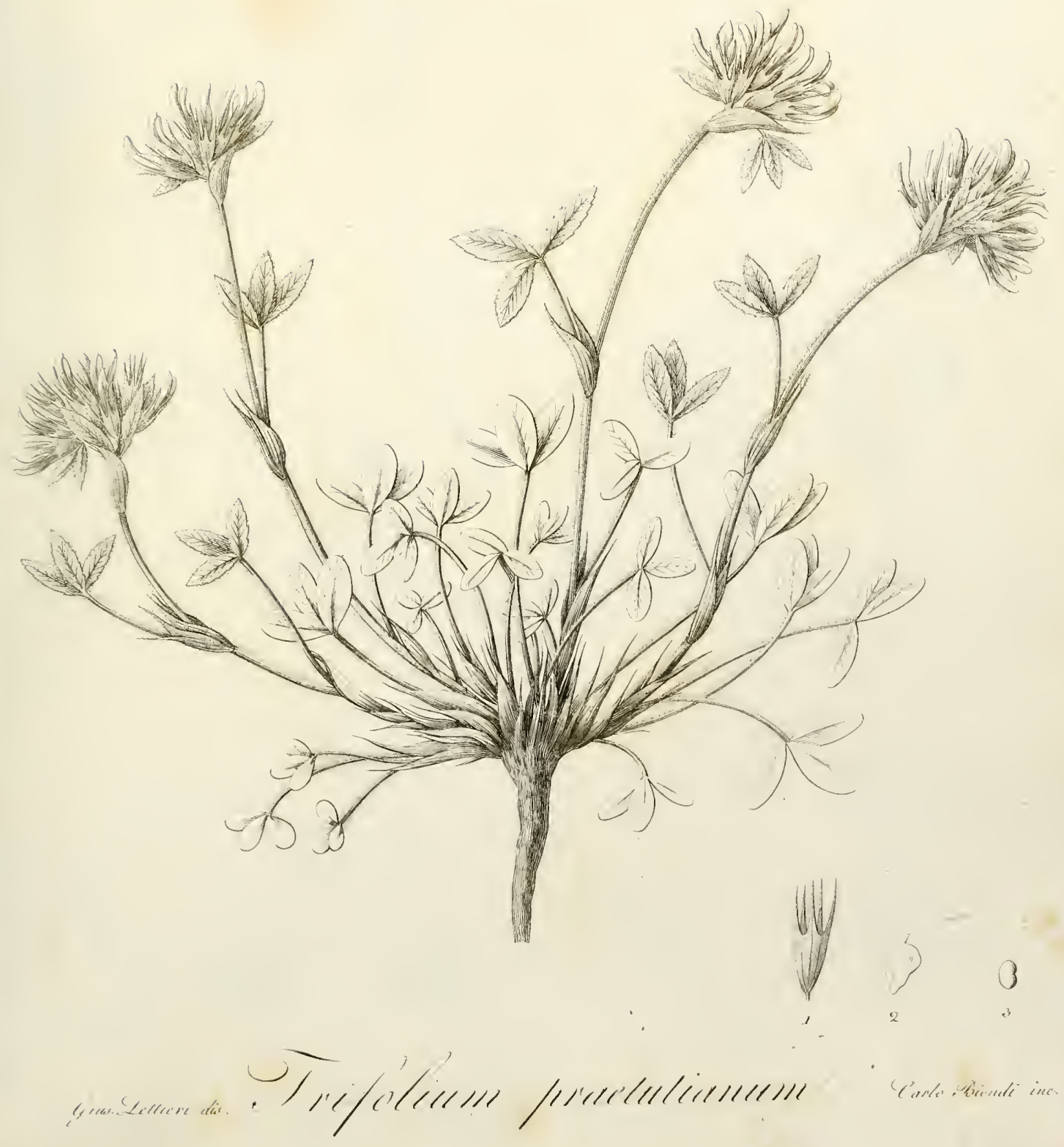


I. I.11.

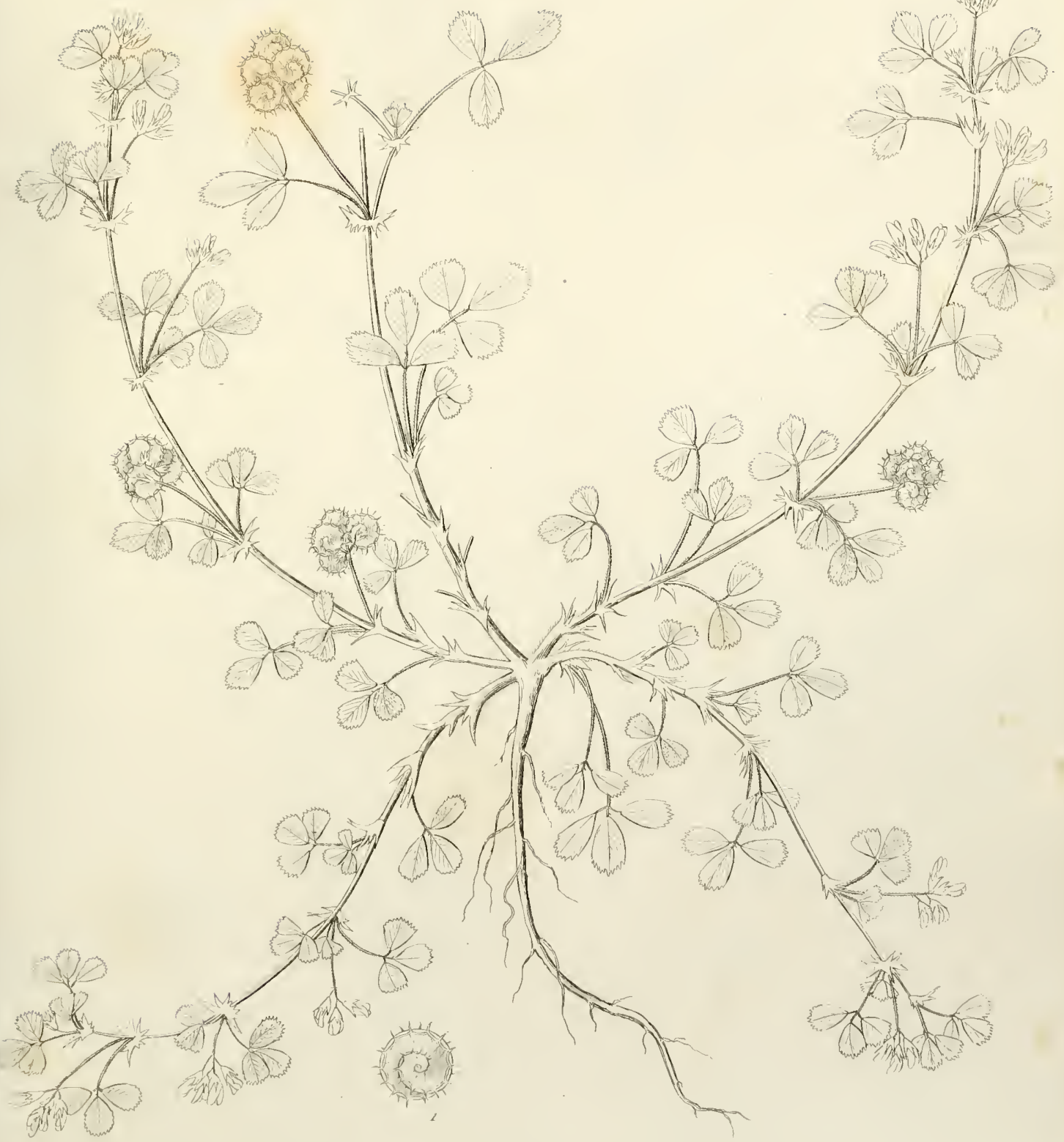

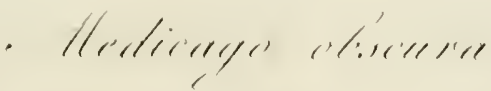




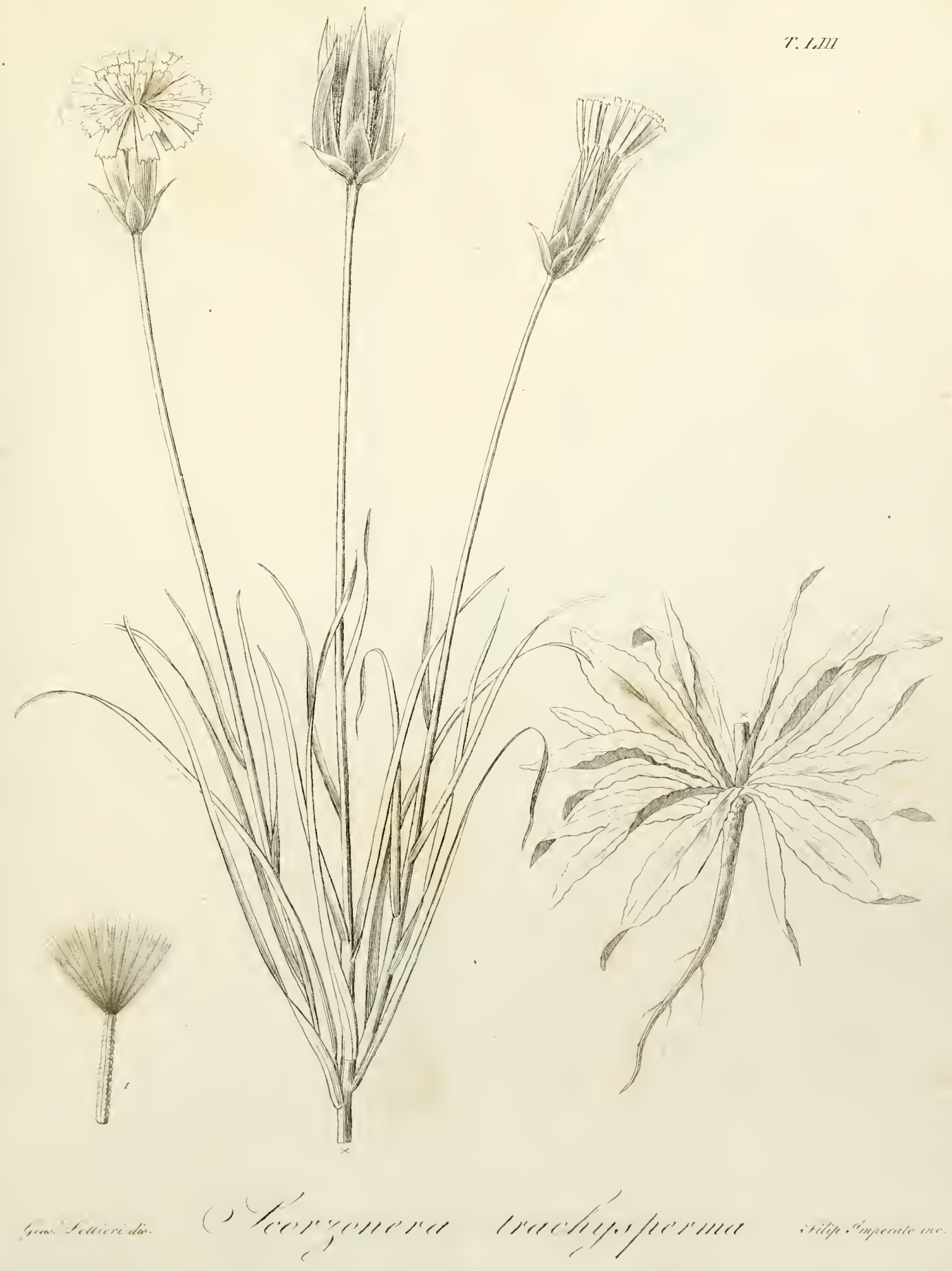


-

. 
\%. 1.,

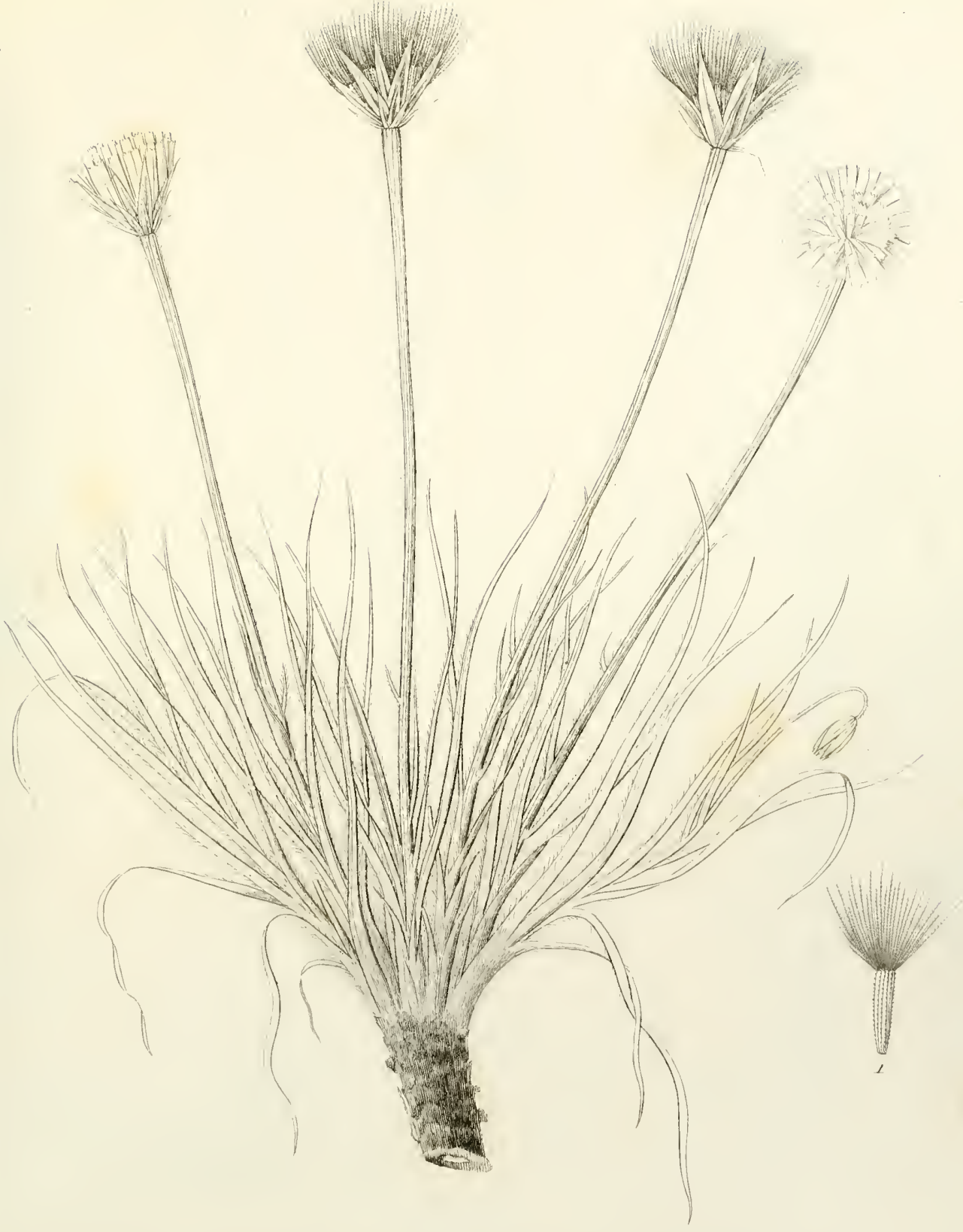

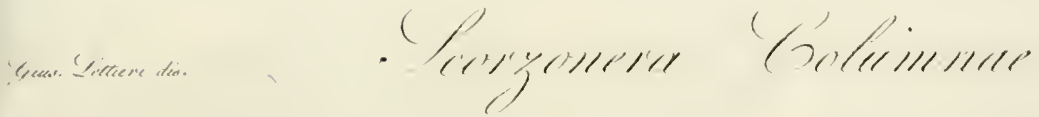

- Tivilise Timperate inc 


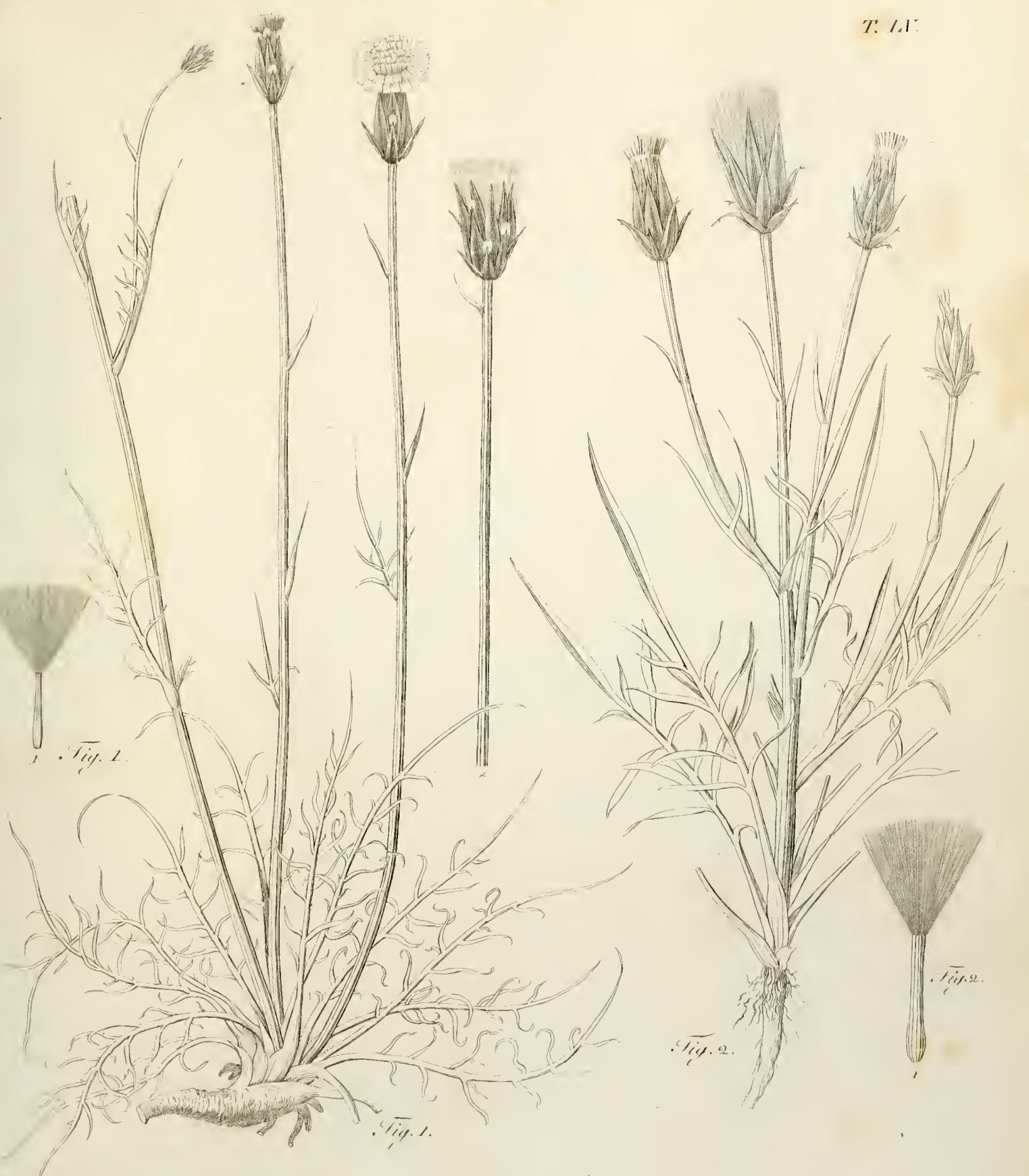

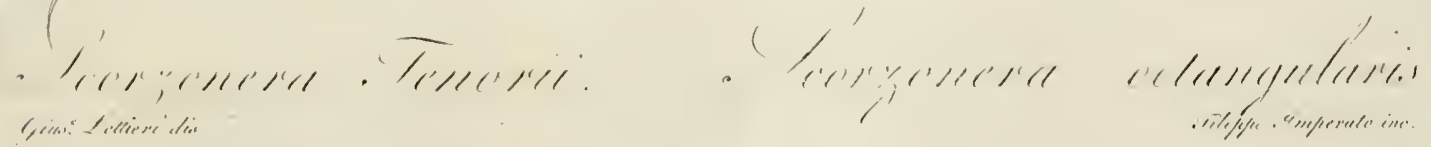


- 


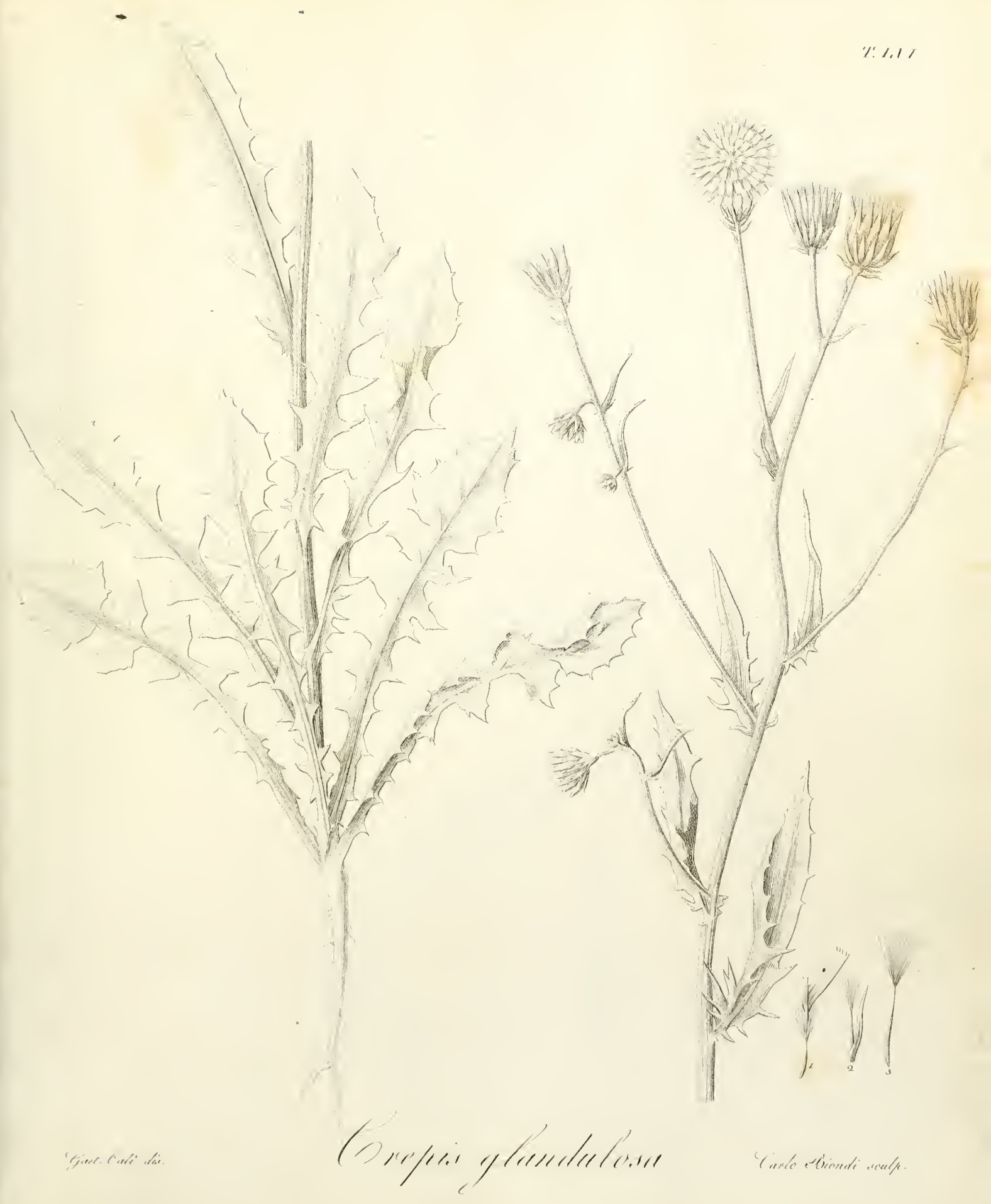




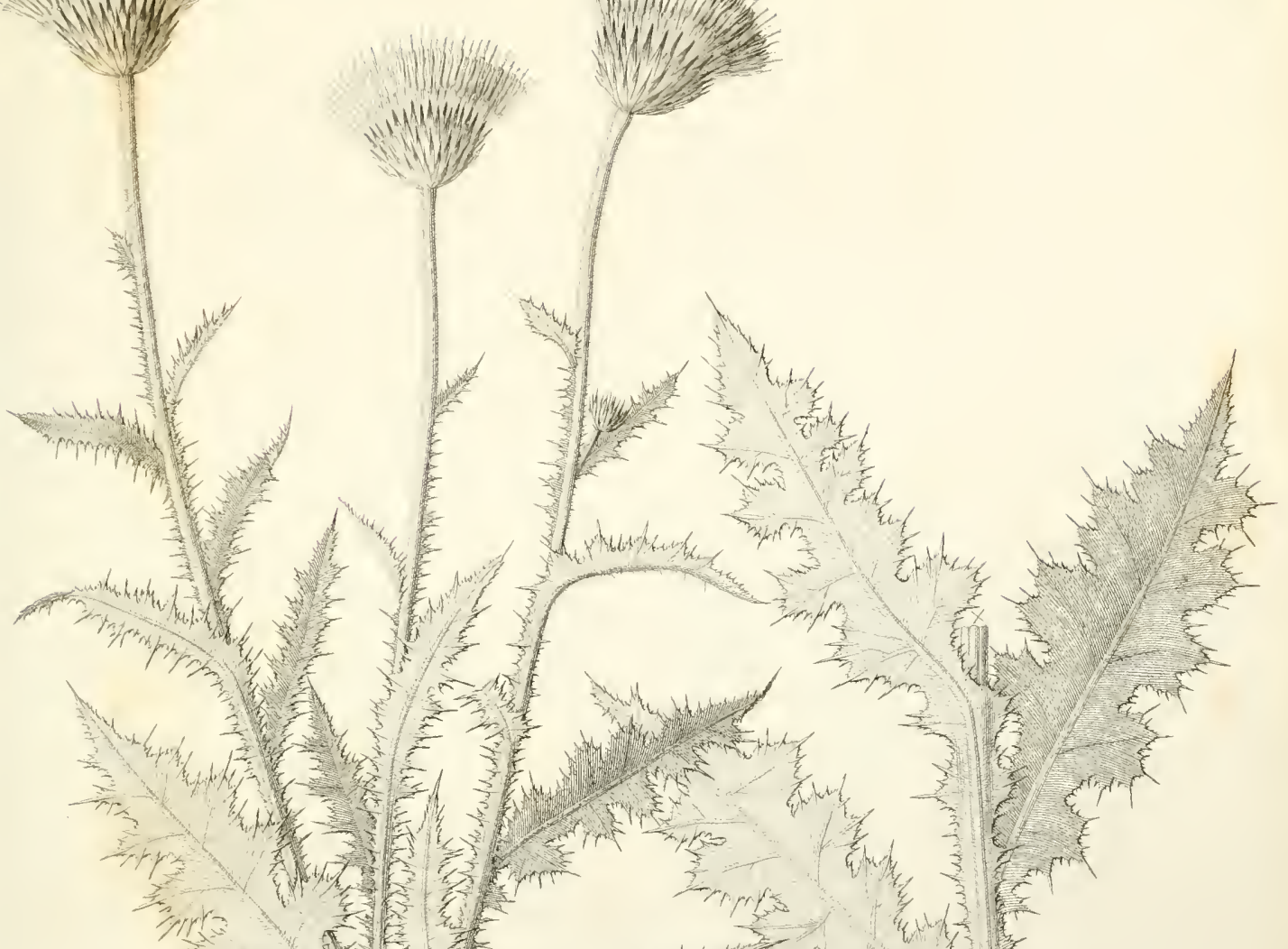

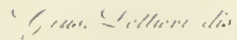
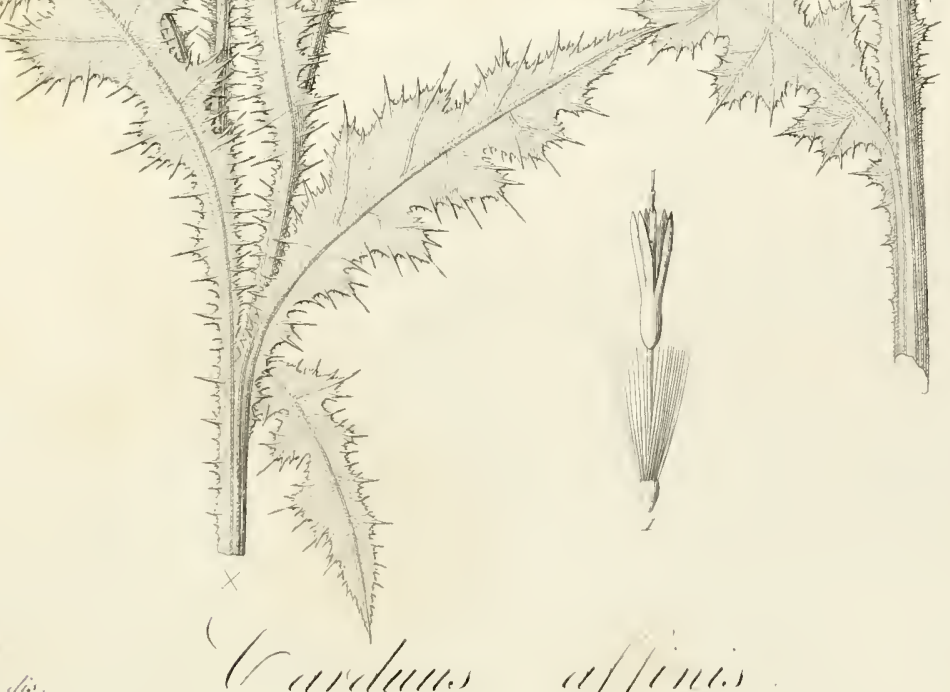


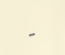




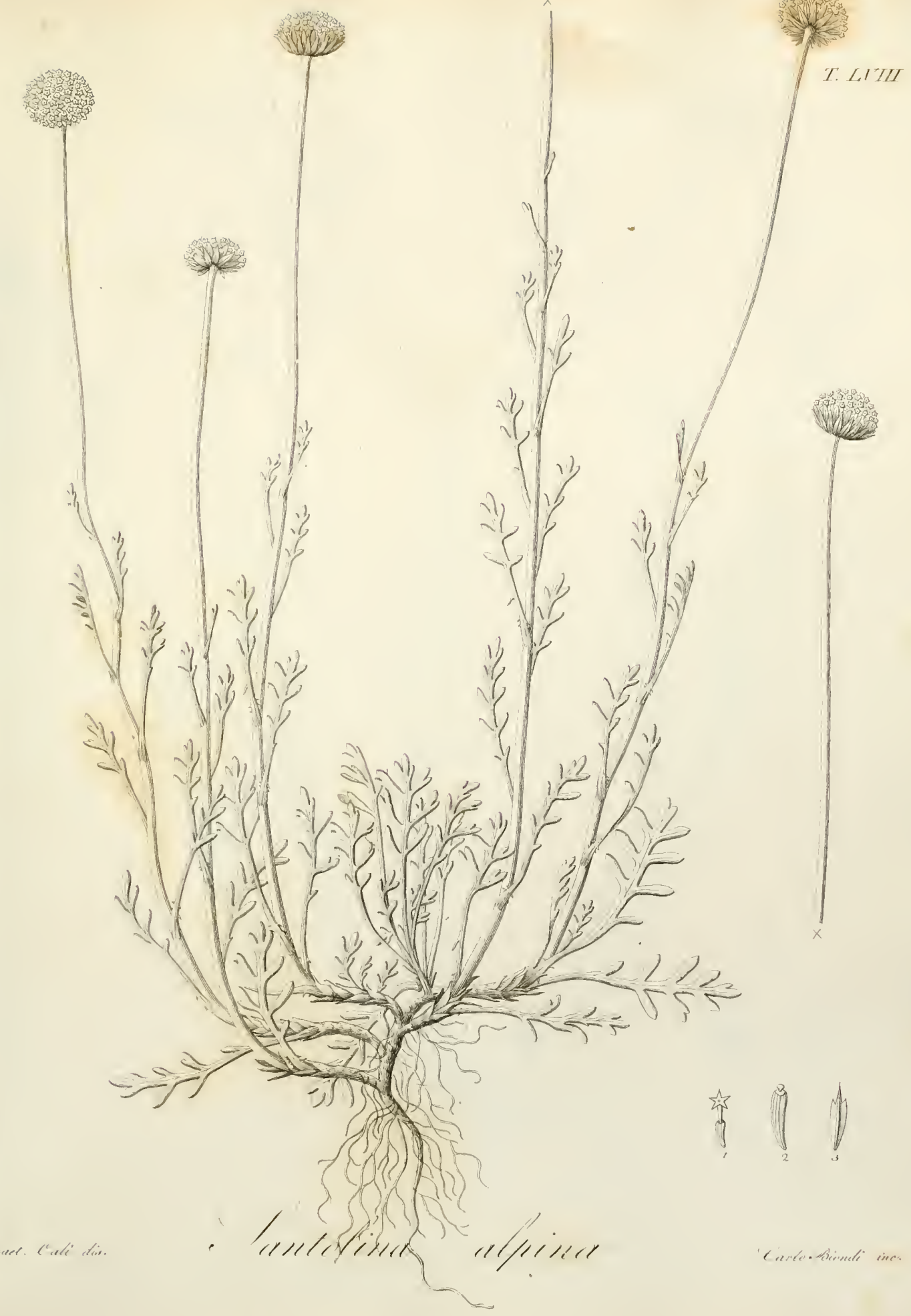




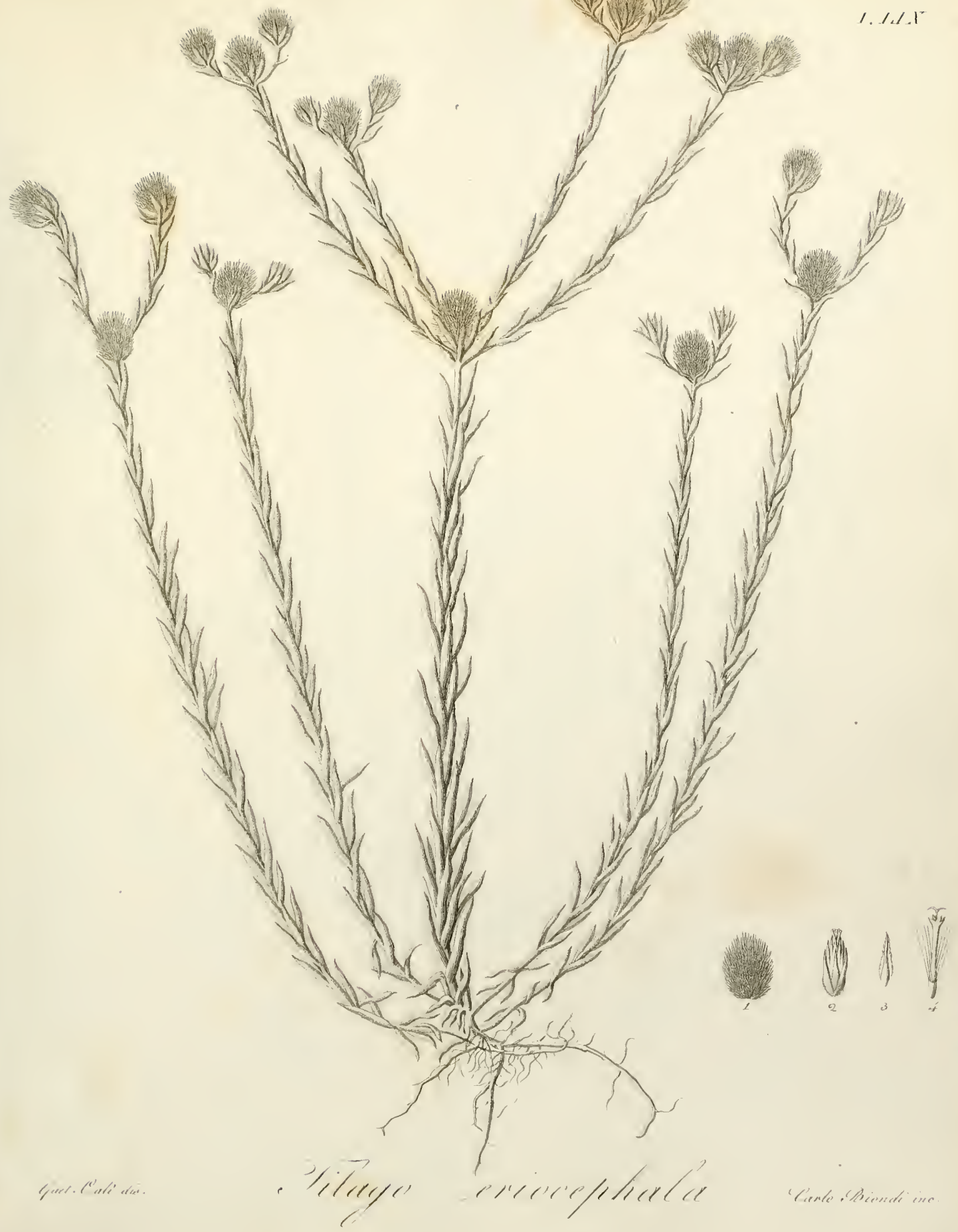




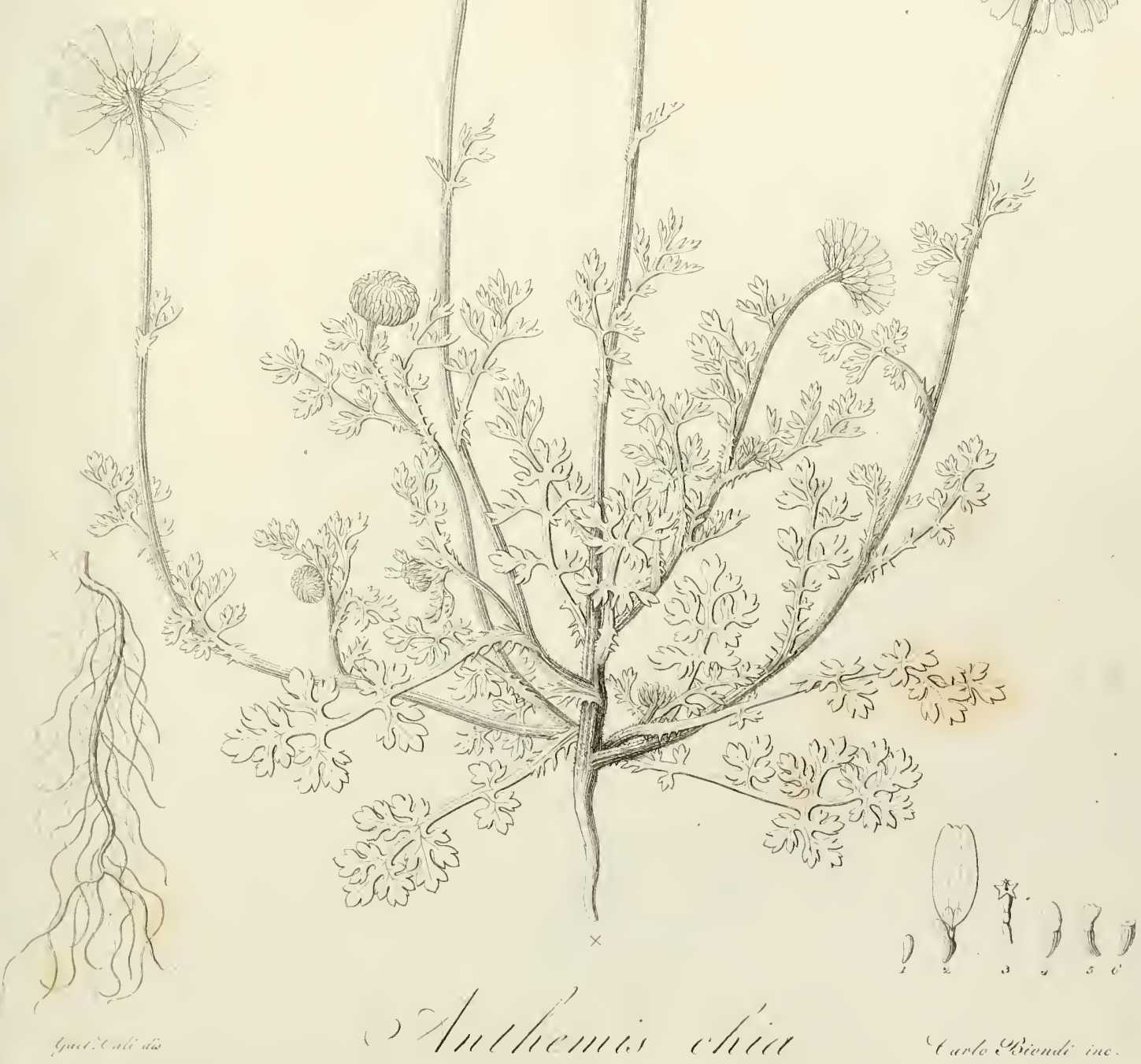


0 



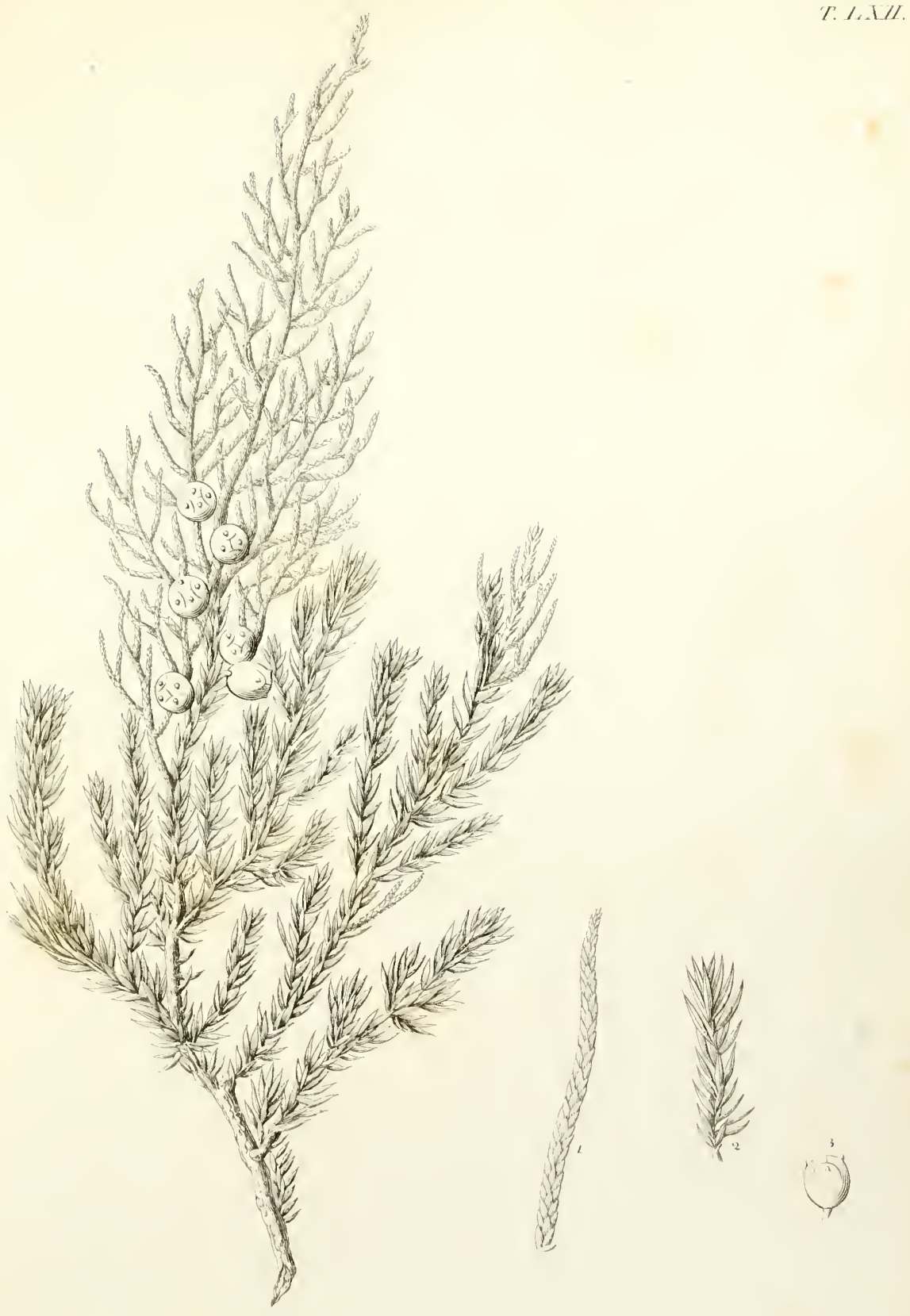


7: $/ 1.1 / 1 / 1$

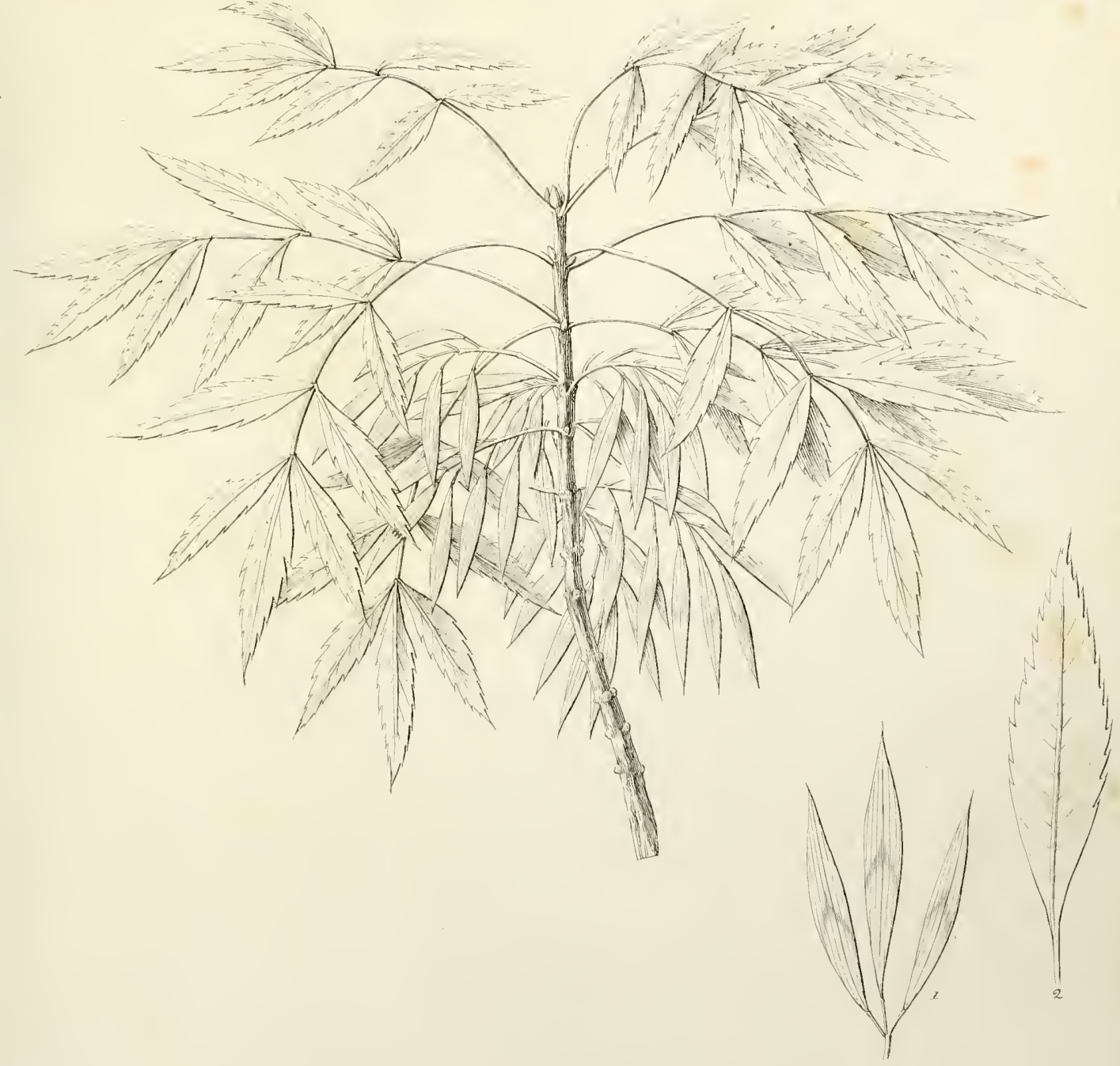

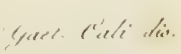

Pereriveles merlerles

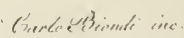




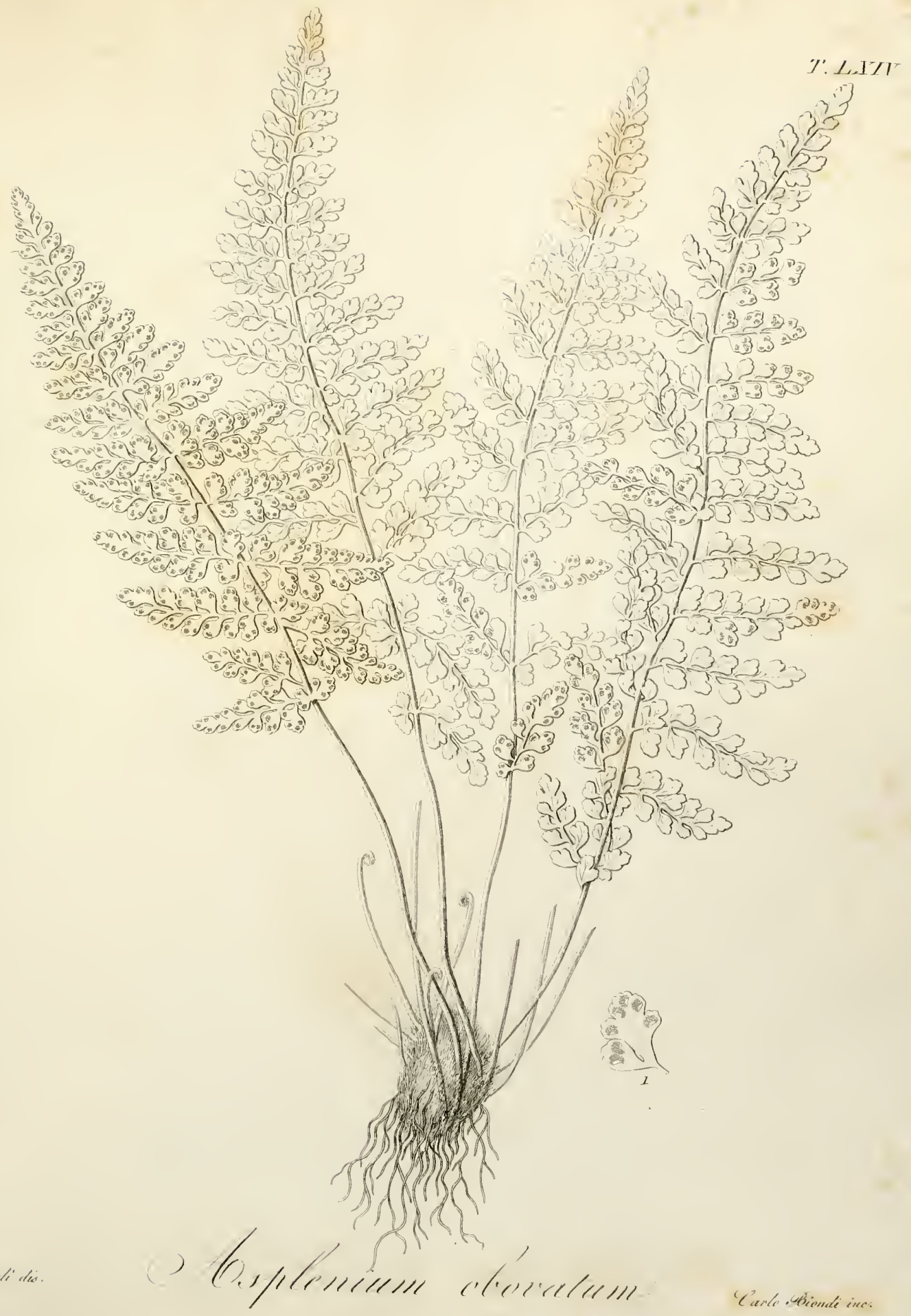



T. 1.17

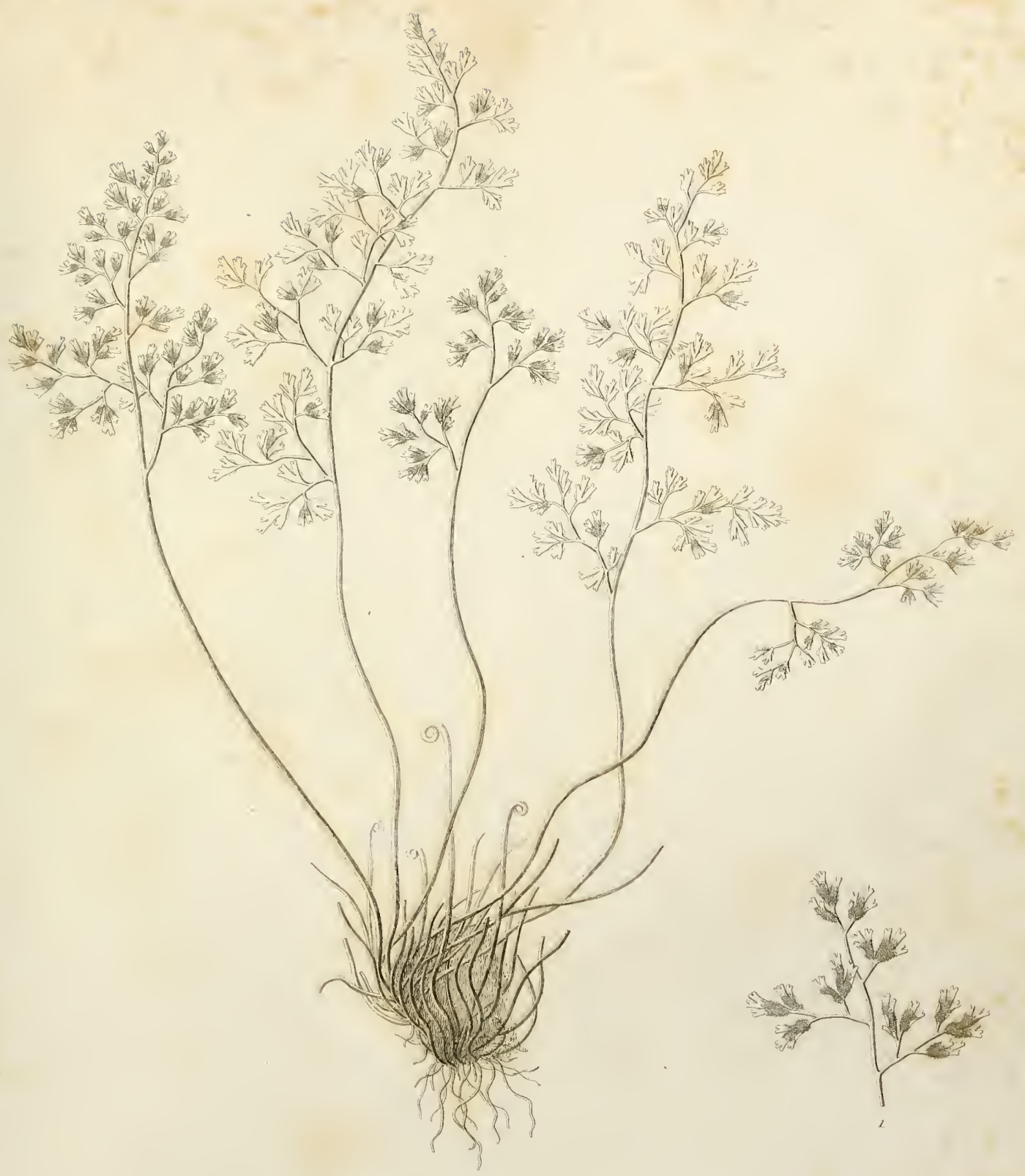

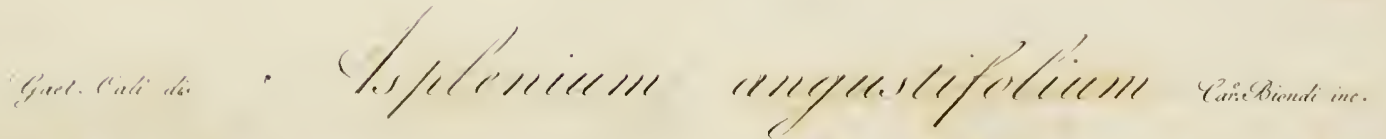





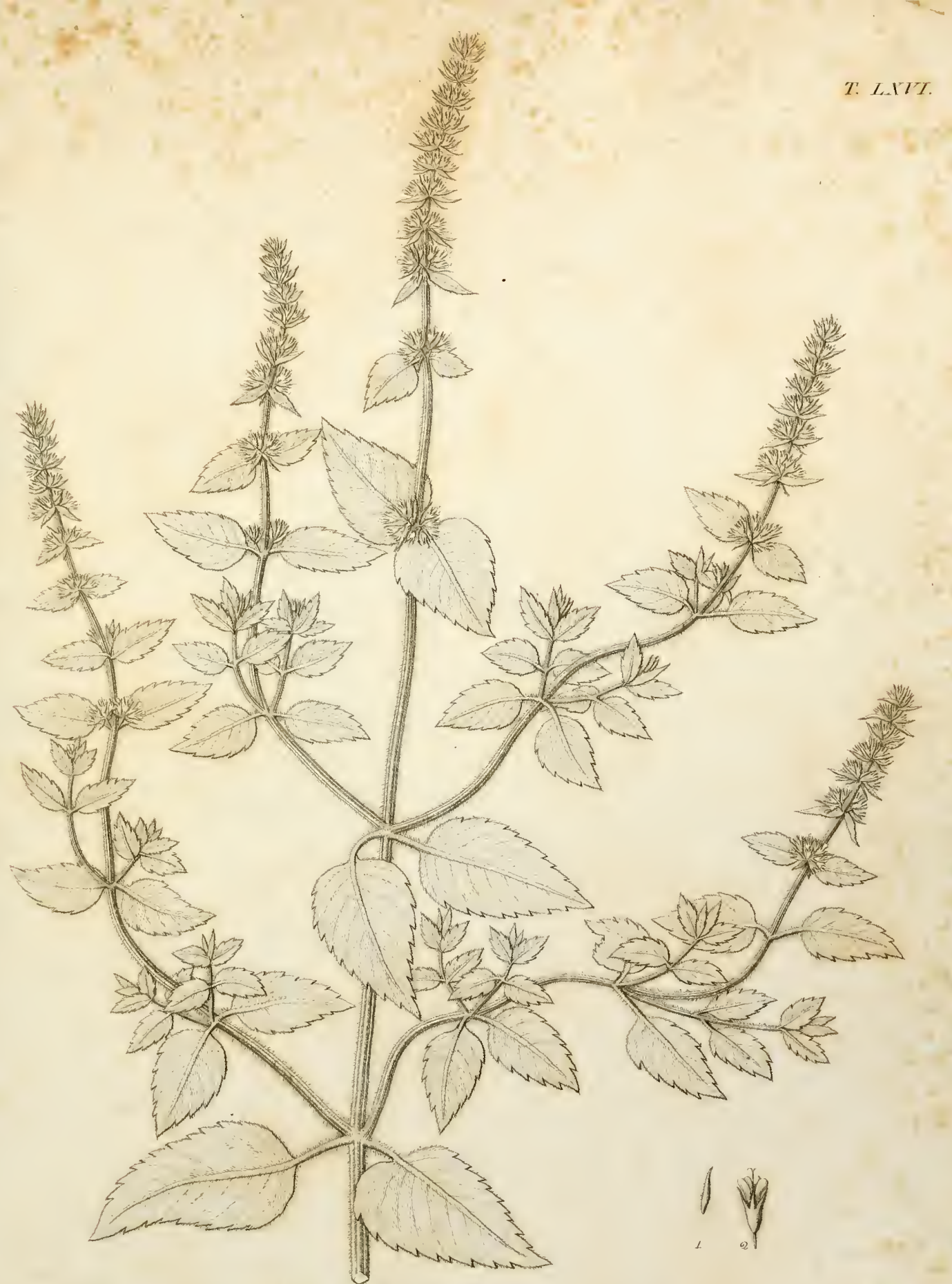




.

- 

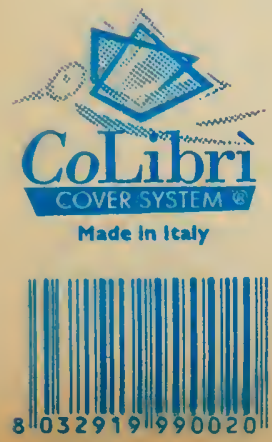

1.

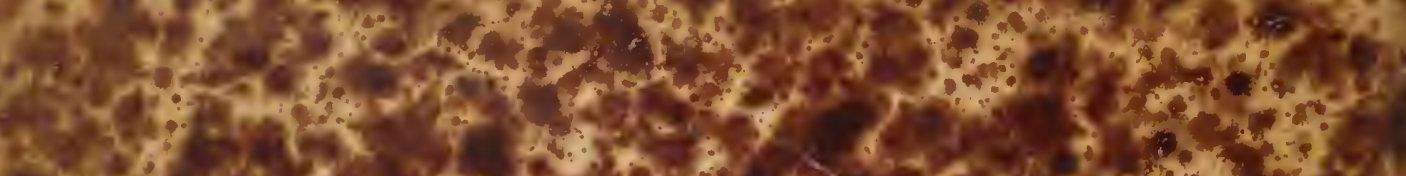
(2)

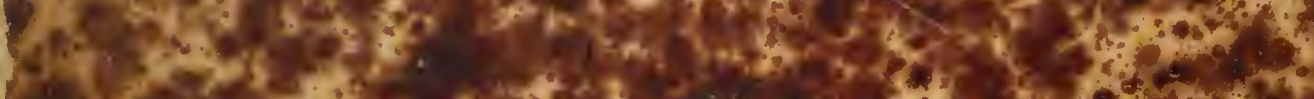

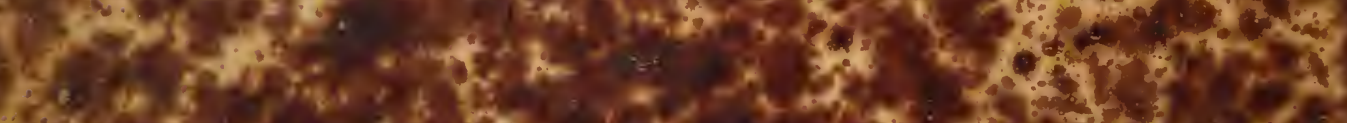

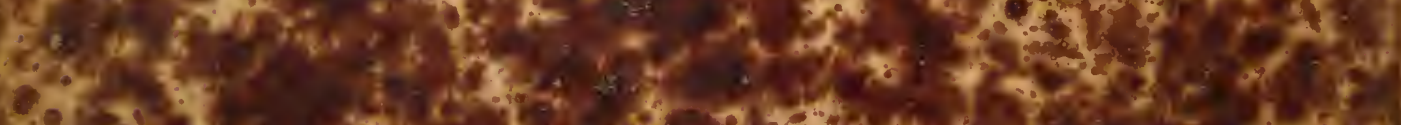

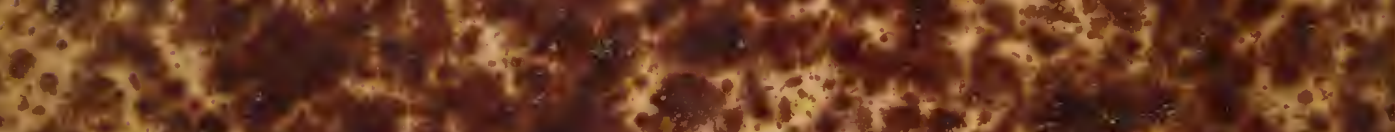

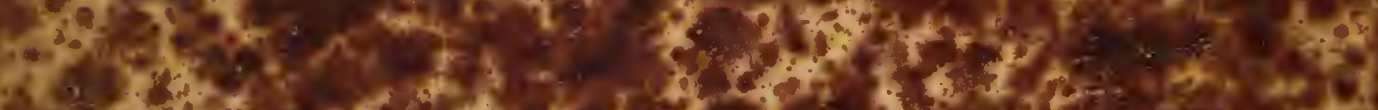
2.

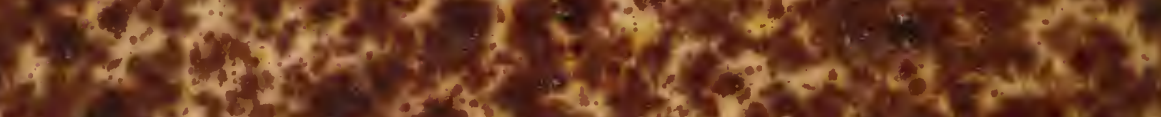

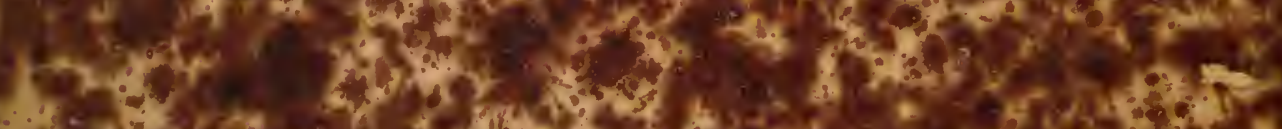

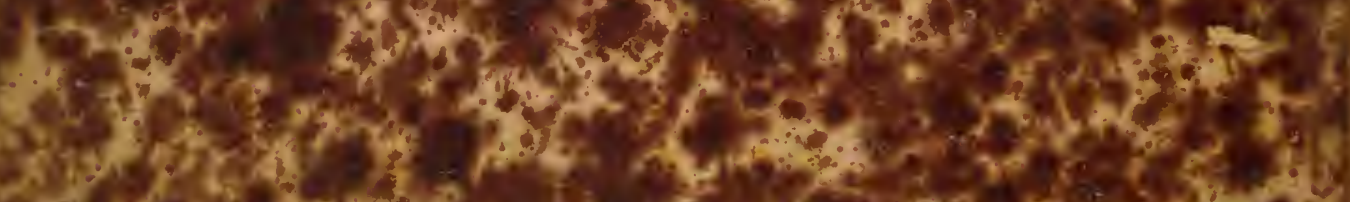

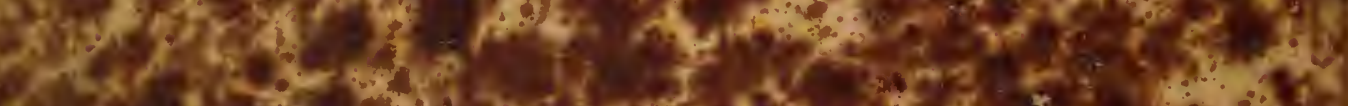

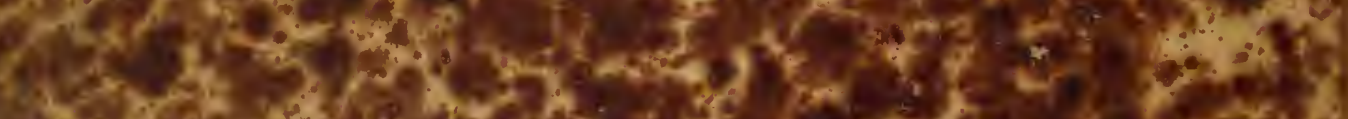

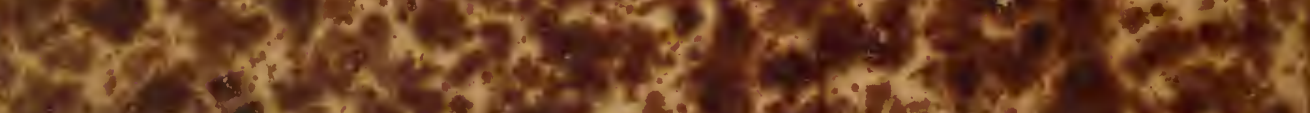

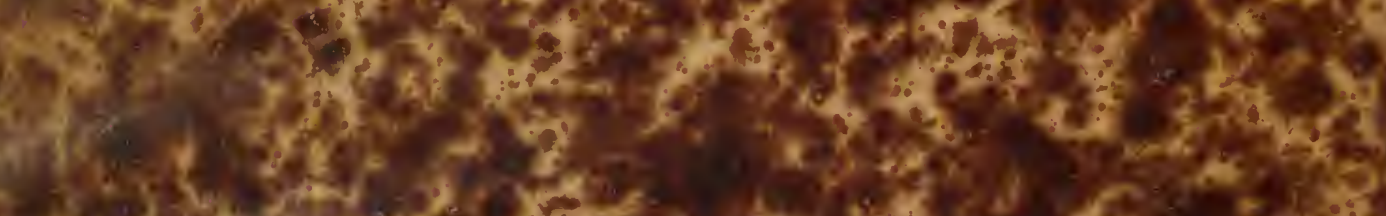

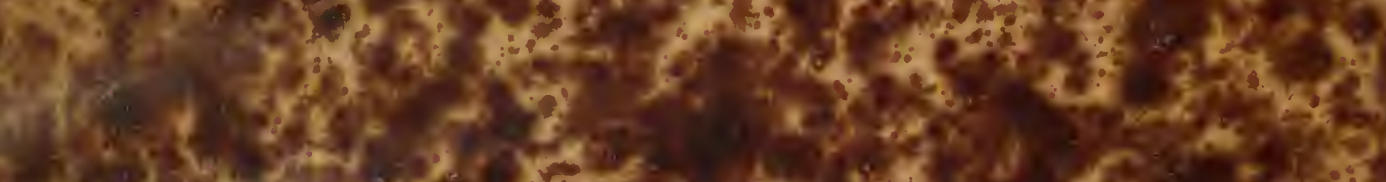

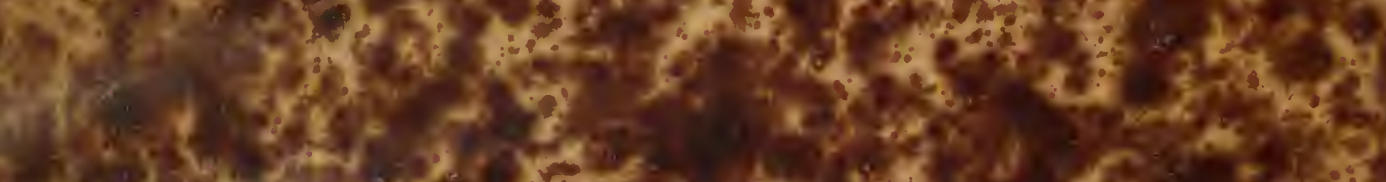

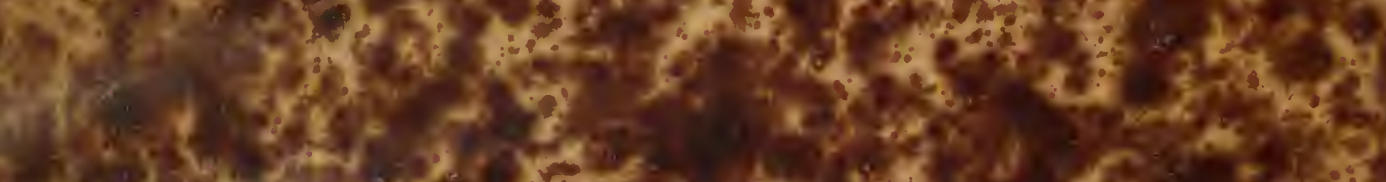
4
4

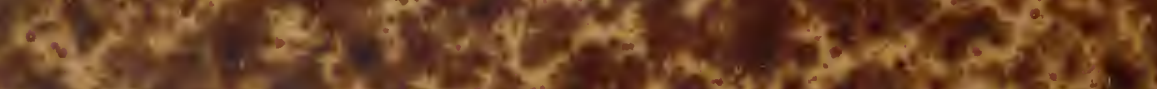

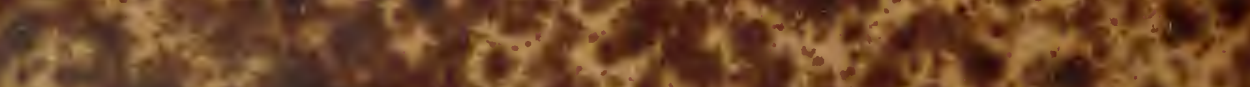

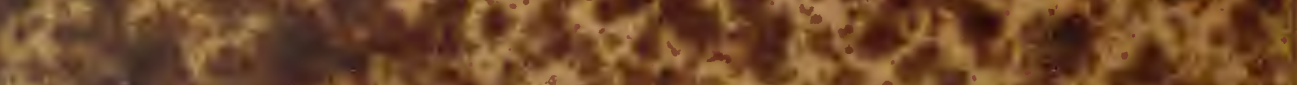

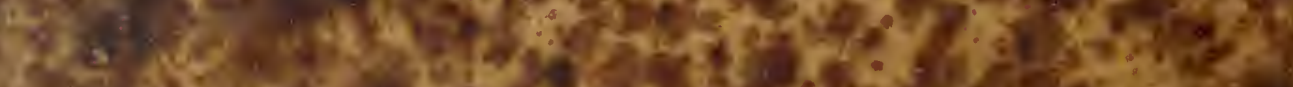

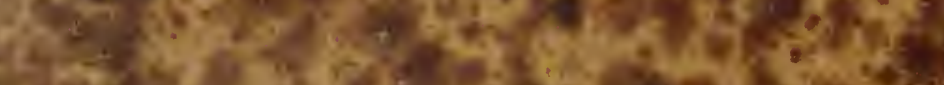

